\title{
LA RAMA MADURA UN MODELO DE PRODUCCIÓN DE YERBA MATE UTILIZADO EN LA PIPORÉ
}

“LA YERBA TIENE SECRETO, ESTÁ EN EL CORTE ...” TAREFERO

Roque Gallardo

Trabajo de Tesis para ser presentado como

requisito parcial para optar al Título de

MAGISTER EN PROCESOS LOCALES DE INNOVACION Y DESARROLLO RURAL (PLIDER)

UNIVERSIDAD NACIONAL DE LA PLATA

FACULTAD DE CIENCIAS AGRARIAS Y FORESTALES

DEPARTAMENTO DE DESARROLLO RURAL

CARRERA DE MAESTRIA

La Plata, Argentina

Julio 2020 
Magister Scientiae en Procesos Locales

de Innovación y Desarrollo Rural

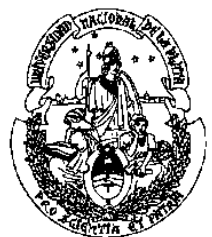

LA RAMA MADURA UN MODELO DE PRODUCCIÓN DE YERBA MATE UTILIZADO EN LA PIPORÉ

“LA YERBA TIENE SECRETO, ESTÁ EN EL CORTE ...” TAREFERO

Roque Gallardo

Dr Roberto Cittadini

Director de Tesis

Dr Frédéric Goulet.

Co-Director de Tesis 
Magister Scientiae en Procesos Locales

Innovacion y Desarrollo Rural

LA RAMA MADURA UN MODELO DE PRODUCCIÓN DE YERBA MATE UTILIZADO EN LA PIPORÉ

“LA YERBA TIENE SECRETO, ESTÁ EN EL CORTE ...” TAREFERO

Roque Gallardo

Aprobada por:

MSc. Irene Velarde

Dra Felicitas Silvetti

Dra Susana Brieva 
Índice general

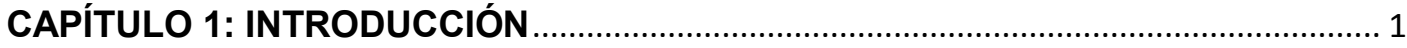

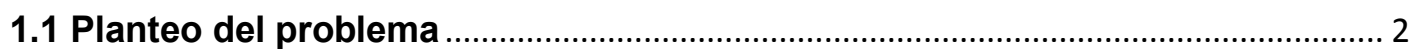

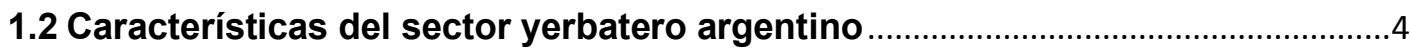

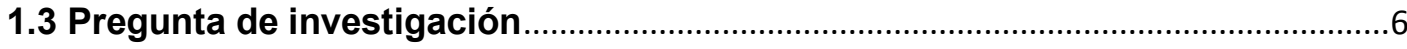

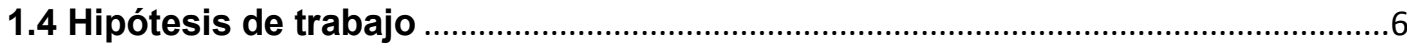

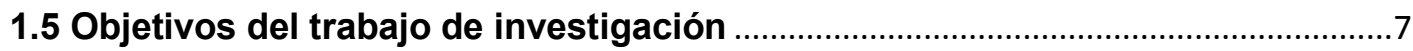

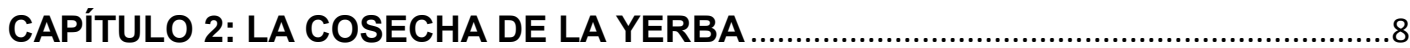

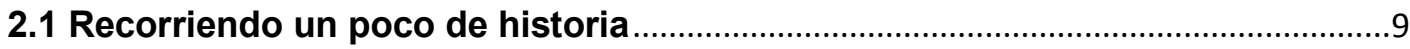

2.2 Tipos de cosechas utilizados actualmente en el sector .......................................12

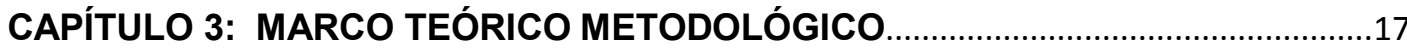

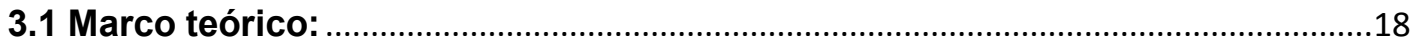

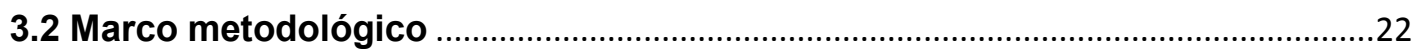

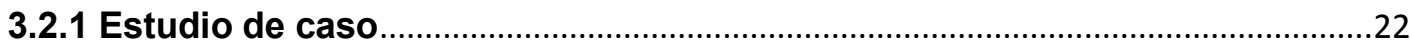

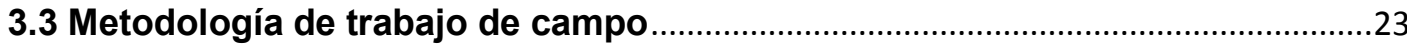

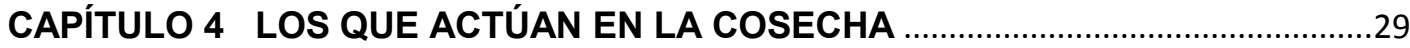

4.1 Los que actúan en la cosecha en la Cooperativa Piporé ……………..................30

CAPÍTULO 5: TODOS LOS AÑOS “LA PROBLEMÁTICA” DE LA COSECHA.........43

5.1 Todos los años "la problemática” de la cosecha …................................................4

CAPÍTULO 6: LOS PROMOTORES ENTRAN EN ACCIÓN...........................................50

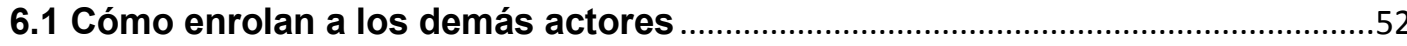

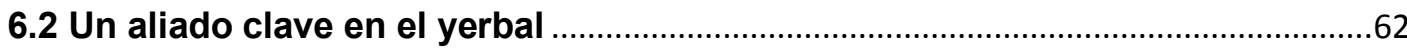

6.3 La propuesta técnica de la rama madura, el punto de paso obligado. ..............65

CAPÍTULO 7: NO TODO ESTÁ BIEN PARA LA RAMA MADURA …..............................

CAPÍTULO 8: TRANSFORMANDO DE TAREFERO A PODADOR ................................76

CAPÍTULO 9: CONCLUSIONES

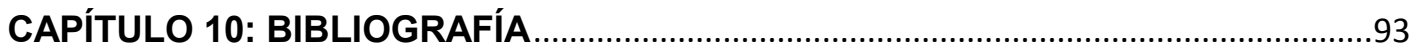

Índice de Figuras:

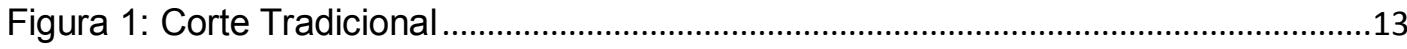

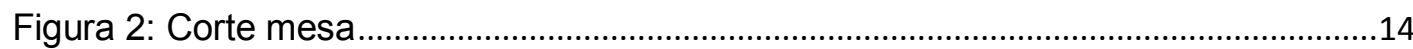

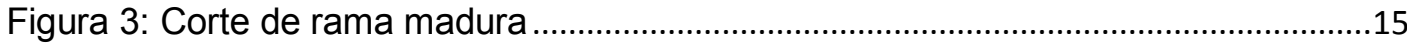

Figura 4 : Cosecha de Yerba mate, actores .................................................................30 
Figura 5: Ubicación de la Piporé . .35

Figura 6 Camino de la puesta en marcha de la rama madura.........................................45

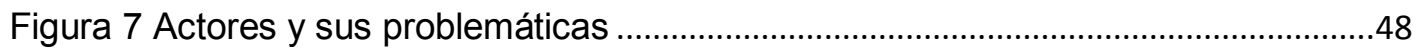

Figura 8: Cadena de mando en la cosecha de yerba mate ............................................62

\section{Índice de tablas}

Tabla 1: Distribución de yerbales en la zona productora......................................................

Tabla 2: Modelo propuesto de trabajo de poda de la rama madura ...................................79 


\section{AGRADECIMIENTOS:}

Agradezco en primer lugar a Dios nuestro Padre por darme la vida, la familia, la salud, el trabajo, el estudio y la formación.

A, Rocío el amor de mi vida, gracias, por tanto, perdón por las ausencias. A mis queridos hijos: Ignacio, Sofía y Santiago que me bancaron todo este tiempo. A Olga y Mario; a Raul y Ana que siempre estuvieron presentes. A mis padres que me enseñaron con su ejemplo.

A el INTA por la posibilidad de estudiar y seguir formándome como persona y profesional. A mis compañeros de trabajo de la agencia, que me siempre me dieron una mano en la concreción de este trabajo.

A Néstor Munaretto, Cristian Infuleski, a las personas que integran esa familia que es Piporé, gracias por el apoyo y el tiempo brindado. A los entrevistados, que me regalaron no solamente su tiempo, sino que también sus saberes.

A Roberto Cittadini y Frédéric Goulet quienes me dieron su apoyo, gracias por la paciencia y el consejo siempre tan acertado.

A mis amigos de la PLIDER, que me acompañaron en este proceso de volver a estudiar. A Guillermo Hang y en su persona, al excelente cuerpo docente de la Maestría PLIDER, que me abrieron los ojos a otro mundo que no lo veía.

A Maria Fernanda, Analía que me regalaron su tiempo en esta última etapa del trabajo final. 


\section{RESUMEN}

La Promoción y Difusión del Sistema de Cosecha de Rama Madura en Yerba Mate para el sector de pequeños productores es una de las actividades promocionadas con mayor énfasis desde los Organismos Públicos de Extensión para este sector, pero la adopción de esta técnica es muy escasa. En este contexto, el presente trabajo analiza las causas o factores que influyen en este fenómeno, tales como actores influyentes en la adopción o no de esta nueva técnica y los mecanismos de extensión que entran en juego. Para ello, se toma el enfoque teórico metodológico al Actor-red, el cual nos brinda elementos necesarios para analizar y reconstruir el proceso de innovación de la cosecha de la yerba mate. A través del estudio de caso en la Cooperativa Piporé, por medio de entrevistas a diferentes actores, participación en jornadas de capacitación, visitas a campo para analizar la utilización de la técnica de cosecha se obtuvieron los siguientes resultados: en el terreno, para la traducción del modelo de la rama madura es importante el capataz de corte, quien debe conocer en detalle el procedimiento, es un actor que controla y aplica la rama madura. Asimismo, es un método que implica inversión en tiempo de no cosechar, capacitación y seguimiento por parte de los productores a los contratistas y trabajadores que ejecutan la cosecha. En el caso de estudio, es un método exitoso, consecuencia del alto nivel de la instrucción en terreno de los actores y el acompañamiento de los extensionistas promotores de la propuesta, junto con los técnicos de los I+D. Asimismo, en la cooperativa, es importante la estabilidad laboral y la limitada rotación del personal de cosecha. En otros lugares la situación es diferente por diversas circunstancias que van desde los intereses desencontrados de los que realizan el trabajo y los dueños de los yerbales. La falta de atención a la cosecha que proporcionan los yerbateros son condicionantes en la aplicación del método. Además, aparecen en el complejo yerbatero los "tenedores" de yerba mate, que venden sus producciones de acuerdo a la necesidad o no de dinero, no viven de la actividad yerbatera. Estos en general no se comprometen con el sector. Entre las conclusiones que se llegaron con este trabajo, se pueden nombrar que la adopción de la rama madura no depende solamente del mayor o menor involucramiento que puedan tener los promotores de la rama madura, sino que también entran en tensión las empresas yerbateras que no promueven estos métodos a sus proveedores de hoja verde. Además, los intereses y el grado de estabilidad del sector trabajador son importantes a la hora de establecer nuevos métodos de cosecha. 
Palabras Claves: Estabilidad. Interés. Yerba mate. Actores.

\begin{abstract}
The Promotion and Diffusion of the Harvest System of Mature Branch in Yerba Mate for the small producers sector is one of the activities promoted with greater emphasis from the Public Extension Organizations for this sector, but the adoption of this technique is very limited. In this context, this paper analyzes the causes or factors that influence this phenomenon, such as influential actors in the adoption or not of this new technique and the extension mechanisms that come into play. For this, the theoretical methodological approach to the Actor-network is taken, which provides us with the necessary elements to analyze and reconstruct the innovation process of the yerba mate crop. Through the case study in the Cooperativa Piporé, through interviews with different actors, participation in training sessions, field visits to analyze the use of the harvest technique, the following results were obtained: in the field, for the translation of the mature branch model it is important the cutting foreman, who must know the procedure in detail, is an actor who controls and applies the mature branch. It is also a method that involves investment in time not to harvest, training and monitoring by producers to contractors and workers who execute the harvest. In the case of study, it is a successful method, consequence of the high level of instruction in the field of the actors and the accompaniment of the extension promoters of the proposal, together with $I+D$ technicians. Likewise, in the cooperative, labor stability and limited rotation of harvest staff are important. In other places, the situation is different due to various circumstances that range from the interests of those who do the work and the owners of the jobs. The lack of attention to the crop provided by the herbals are determining factors in the application of the method. In addition, the "yerba mate" holders of yerba mate appear in the yerbatero complex, who sell their productions according to the need or not for money, do not live off the grassy activity. They in general do not commit to the sector. Among the conclusions that came with this work, it can be mentioned that the adoption of the mature branch does not only depend on the greater or lesser involvement that the promoters of the mature branch may have, but also the companies that do not promote grassroots these methods to their green leaf suppliers. In addition, the interests and the degree of stability of the labor sector are important when establishing new harvest methods.
\end{abstract}


Keywords: Stability. Interest. Yerba mate. Actors. 
CAPÍTULO 1: INTRODUCCIÓN 


\subsection{Planteo del problema}

Antes de comenzar a desarrollar el problema de investigación, se realiza una breve descripción general del cultivo y la situación del mismo en la zona yerbatera de la República Argentina.

La yerba mate es un árbol cuya vida útil productiva, ronda los 30 años, dependiendo del sistema de manejo utilizado. Este cultivo, se localiza en las provincias de Misiones y Noreste de Corrientes. El sector cuenta con alrededor de 17000 productores registrados en el Instituto Nacional de la Yerba Mate (INYM), los cuales poseen $165.200,55$ hectáreas cultivadas ${ }^{1}$. El $97 \%$ de los yerbateros se ubican en Misiones y el resto en Corrientes ${ }^{2}$. En Misiones el $62 \%$ de las explotaciones agropecuarias, tiene implantado este cultivo, de los cuales, el $80 \%$ de los productores, se localiza en el estrato de los que contienen menos de 10 hectáreas, con un rendimiento promedio de aproximadamente 4600 kilogramos de hoja verde por hectárea (Gortari, 2013). Con lo cual la estructura productiva de Misiones se basa en la pequeña agricultura ( Rau, 2009; Gortari,2013)

Asimismo, un número importante, alrededor de 15 mil trabajadores, llamados comúnmente "tareferos", realizan en forma manual la cosecha de yerba mate. Esta tarea además es estacional, va desde marzo a septiembre. El $70 \%$ de estos trabajadores no está registrado en el empleo formal (trabajadores en negro), se caracterizan por tener una alta movilidad territorial recorriendo prácticamente toda la región yerbatera de la Argentina. La característica propia de la estacionalidad en la recolección, provoca vulnerabilidad laboral, por el método de contratación que es utilizado a través de la tercerización de las cosechas (Pereyra, 2013; Rau V. , 2014) Igualmente, unos 500 contratistas, participan de la zafra yerbatera, la mayoría sin registrar. Estos se desempeñan en el sector yerbatero, como agentes de servicios (Traglia et al, 2018).

Para el productor yerbatero, la cosecha es la actividad más importante del ciclo de producción, porque influye directamente en sus ingresos, genera trabajo para las familias tanto de los productores como de los "tareferos", contratistas y otros agentes

\footnotetext{
${ }^{1}$ Según Datos del INYM 2016.

${ }^{2}$ En la provincia de Corrientes, los departamentos donde se cultiva yerba mate son los de Ituzaingo y Santo Tome, ambos al Nordeste de la provincia. En cambio, en Misiones, todos los departamentos cuentan con este cultivo
} 
relacionados al cultivo. De la misma manera, el manejo correcto de sus plantaciones es lo que asegura los niveles adecuados de la producción y de la renta. La actividad de la cosecha es la de mayor valor para el productor, no solamente por el manejo de los "tareferos" que levantan la zafra, sino que también por el impacto de la misma en los costos, y la incidencia en las producciones venideras (De Coulon, 2001).

Los Institutos de Investigación y Desarrollo (I+D), vinculados a la actividad yerbatera, proponen metodologías de cosecha para el sector de pequeños productores. Desde el Instituto Nacional de la Yerba Mate (INYM), se está promocionado, en forma conjunta con el Instituto Nacional de Tecnología Agropecuaria (INTA) y los demás organismos públicos vinculados al sector yerbatero, la tecnología de "cosecha de rama madura". A pesar de los esfuerzos de las instituciones y los técnicos, la adopción de esta nueva metodología, entre los pequeños productores, ronda el $10 \%$ del total. (Munaretto, Mayol, Burtnik, com. pers, 2014). En el mismo sentido, Giancola et al (2014) destacan que en la región yerbatera se han desarrollado tecnologías de producción para los pequeños productores, pero estas, por diversas causas son de escasa adopción (Giancola et al, 2014).

De esta conclusión surgen varios interrogantes que se relacionan con la deficiente adopción de las propuestas que posee, en este caso, el INTA para el manejo de la yerba mate. Razones de tipo económicas, falta de calificación del personal, desconocimiento parcial de la metodología de cosecha por parte productores y control deficiente de las tareas, todas ellas se plasman como causas que afectan a la incorporación de las tecnologías.

En general, esta actividad de cosecha, posee un fuerte componente manual y hasta artesanal. Ya, los guaraníes, en épocas precolombinas, consumían yerba mate. Ellos han procurado de diferentes maneras extraer la yerba mate de la selva, a través de diferentes expediciones de cosechas que se hacían selva adentro. Luego, con el paso del tiempo y la instalación del cultivo a campo, los productores o colonos yerbateros, con algunos modelos de cosecha manual, fueron acomodándose a la industria y sus necesidades. A pesar de los esfuerzos de las empresas por mecanizar la cosecha, prácticamente el $80 \%$ de la recolección todavía se realiza con el trabajo de los tareferos y de manera manual. 
Desde el sector estatal relacionado a la yerba mate, coinciden en que la cosecha es la actividad de mayor relevancia para el sector primario. Asimismo, visualizan una deficitaria manera de realizarla. En ese sentido analizan otras opciones diferentes a la cosecha tradicional, de manera de consolidar al manejo en general del yerbal. Desde los I+D se considera que una "mala cosecha" es uno de los principales causales de la degradación de los yerbales implantados en la región yerbatera, que afectan al sistema productivo (Burtnik , 2006).

\subsection{Características del sector yerbatero argentino}

Debido a la importancia que posee la actividad en nuestro país, a continuación se realiza un bosquejo del sector, para lo cual se tomaron datos del Instituto Nacional de la Yerba Mate (INYM, 2016). En Argentina la distribución de los yerbales se despliega de la siguiente manera:

Tabla 1: Distribución de yerbales en la zona productora

\begin{tabular}{|l|l|l|l|}
\hline $\begin{array}{l}\text { Total Provincia de } \\
\text { Misiones: }\end{array}$ & $144.118,220$ has & $\begin{array}{l}17971 \\
\text { productores }\end{array}$ & $\begin{array}{l}8,02 \text { has/ promedio } \\
\text { por productor }\end{array}$ \\
\hline $\begin{array}{l}\text { Total Provincia de } \\
\text { Corrientes: }\end{array}$ & $21.208,591$ has & $\begin{array}{l}644 \\
\text { productores }\end{array}$ & $\begin{array}{l}32,93 \text { has/promedio } \\
\text { por productor }\end{array}$ \\
\hline Total Argentina: & $165.326,811$ has & $\begin{array}{l}18615 \\
\text { productores }\end{array}$ & $\begin{array}{l}8,88 \text { has por } \\
\text { productor }\end{array}$ \\
\hline
\end{tabular}

Fuente: Elaboración propia en base a datos de Burgos; Medina 2017

De manera de complementar la información del cuadro anterior y considerando la distribución de la superficie destinada al cultivo de la yerba mate, podemos observar que el $76 \%$ de los productores poseen menos de 10 hectáreas cultivadas, el $22 \%$ entre 10 y 50 hectáreas y el $2 \%$ más de 50 hectáreas. En ese sentido se caracteriza a la producción de yerba mate en Misiones con particularidades de pequeño productor (Montechiesi, 2008). En esta provincia, los rendimientos promedios de hoja verde están por debajo de los 3.000 kilogramos por hectárea. (CONINAGRO, 2017). La degradación de los yerbales es resultado en gran medida de falta de manejo por parte de los propietarios y disminuida asistencia técnica para su correcta conservación y producción (Traglia et al, 2018).

Otra característica del sector yerbatero, en la provincia de Misiones, es la edad de los cultivares, en general es mayor a los 30 años, sumado a esto, las densidades de plantas por hectárea son consideradas bajas (menores a mil plantas por hectárea). Estos sistemas, típicos de la provincia, se caracterizan por tener elevados estados de 
degradación tanto de los suelos como de las plantaciones. Por lo antes dicho se pueden considerar "viejos" para el sistema de producción, por lo cual los yerbales están muy lejos del potencial productivo.

Una marcada estacionalidad en la cosecha del cultivo y la baja densidad de la mayoría de los yerbales de la provincia, son dos de los argumentos empleados por los empresarios yerbateros como justificación del extendido sistema de contratación informal (trabajo en negro), que redunda en penosas condiciones laborales y de vida de los trabajadores de la yerba mate. A pesar de todas estas connotaciones la cosecha de los yerbales sigue siendo de manera manual y prácticamente artesanal. (Traglia et al., 2018)

En la actualidad, el sistema de corte tradicional manual de yerba mate, es difundido mayormente en el sector de pequeños agricultores, pero este método, posee algunos inconvenientes desde el punto de vista técnico productivo. Las plantaciones sufren podas extractivas, quedando las plantas defoliadas totalmente, lo que va en detrimento del sistema (Burtnik, 2006). Contrariamente el sistema de podas de "rama madura", que busca extraer de las plantas ramas de 2,5 centímetros de diámetro, de color grisáceo, dejando un remanente en plantas de hojas y tallos de al menos un 30 por ciento del material, simultáneamente se realiza una limpieza anual de las ramas interiores y dañadas, para mejorar los niveles de producción por planta (kilogramos de hoja verde), lo que asegura la cosecha venidera en calidad y cantidad.

Esta tecnología incrementa el volumen de hoja verde en el tiempo, es de baja utilización de insumos externos, con el manejo adecuado de las podas, los volúmenes de producción se incrementan, con lo cual, las cosechas de rama madura son las que mejoran los rendimientos totales de los yerbales. Burtnik (2003, 2006); Mayol (1997); Mayol \& Kurtz (2011); Mayol (2017), coinciden que, cuando se disminuye el remanente de material verde ${ }^{3}$, que se ha dejado en la planta, la producción de hoja verde es menos sustentable en el tiempo.

A pesar de existir estos métodos, se pueden distinguir otras opciones de corte, pero vinculados a los productores medianos a grandes, que buscan de alguna manera mecanizar o semi mecanizar sus labores de cosecha, tratando de reducir los costos de

\footnotetext{
${ }^{3}$ Se considera material remanente en planta a las banderas de color gris podadas con aumentos para brotar, banderines verdes distribuidos en toda la planta de manera uniforme. Estas partes de la planta son fundamentales para dar inicio a la brotación después de la cosecha.
} 
esa actividad. Es así que se pueden diferenciar modelos de semi mecanización, en una combinación de máquinas y hombres, o también la mecanización pura, aunque estas situaciones son muy escasas, sólo en las grandes empresas se plantean prototipos de cosecha.

\subsection{Pregunta de investigación}

Como hemos descripto anteriormente, hay diversas alternativas para la cosecha de la yerba mate, ahora bien, en el sector de productores chicos, donde predomina el sistema de cosecha manual, hay disparidad de procedimientos de la misma. Los extensionistas vinculados a los I+D, promueven a la rama madura, como uno de los métodos que mejor se adecuan al sector de yerbateros chicos.

Si la tecnología de cosecha de "rama madura" es la que asegura la producción de los yerbales en el tiempo, ¿por qué los productores no adoptan esta metodología de manera masiva? Se plantean algunos cuestionamientos que son la guía de este trabajo y a continuación se enumeran:

¿Los aspectos técnicos productivos propuestos en la cosecha de "rama madura", son relevantes para los que realizan el trabajo directo de poda de las plantas?

¿Cuáles son los aspectos sociales, que influyen en la adopción o no de la propuesta de cosecha de "rama madura" entre los pequeños productores yerbateros de la provincia de Misiones?

¿A través de qué mecanismos de difusión influyen los complejos agroindustriales en la adopción de las nuevas propuestas tecnológicas de cosecha, realizadas por los organismos de I+D vinculados al sector?

Considerando los interrogantes anteriores, se plantea la siguiente pregunta de investigación:

¿Cuáles son las condiciones socio técnicas y contextuales que influyen en el proceso de adopción de la propuesta tecnológica de cosecha de" rama madura", promocionada por los organismos del sector público para los pequeños productores yerbateros?

\subsection{Hipótesis de trabajo}

Se formula la hipótesis que guía el trabajo siguiente trabajo de investigación: 
El enfoque de innovación que predomina en los organismos públicos se basa en teorías difusionistas o de innovaciones inducidas, lo que dificulta la construcción colectiva de conocimientos, los aprendizajes en sentido amplio y finalmente contribuye a la baja adopción de las técnicas.

\subsection{Objetivos del trabajo de investigación}

De la misma manera, dentro de este trabajo de investigación se propone el siguiente objetivo general:

Conocer y Analizar la red de relaciones de los diferentes actores, las condiciones socios técnicos y contextuales que influyen en el proceso de adopción de la tecnología de la cosecha de la "rama madura" de la yerba mate.

De lo anterior se desprenden los objetivos específicos, que se proponen a continuación:

Conocer el tipo de relaciones que vinculan a los diferentes actores que integran la red de la cosecha de la yerba mate en el territorio y cómo influyen en el proceso de adopción de nueva tecnología.

Identificar los principales problemas ligados a la adopción/no adopción de las tecnologías propuestas por los organismos públicos y privados desde las diferentes perspectivas de los actores que componen la red.

Analizar los diferentes significados y sentidos que poseen los diálogos, que se generan entre los diferentes actores que componen la red, que permita ampliar la comprensión del fenómeno en estudio.

El trabajo se ordena en siete capítulos que irán llevando al lector a comprender el mecanismo de funcionamiento de la cosecha de rama madura de la yerba mate en el sector de productores pequeños de la Cooperativa Piporé, para ello y a continuación, se presentan los actores intervinientes en la cosecha de la yerba mate. 
CAPÍTULO 2: LA COSECHA DE LA YERBA 


\subsection{Recorriendo un poco de historia}

La yerba mate, es un producto originario de la selva Paranaense, hábitat natural de los aborígenes guaraníes. Ellos, la consumían habitualmente como infusión. Con el arribo de los españoles a esta región, luego de conocer las propiedades de estas plantas (estimulante para evitar la fatiga, el sueño, entre otras) adoptaron esta costumbre del mate como parte de sus hábitos. Con la llegada de los jesuitas a esta región de la Argentina, se comenzaron a instalar las primeras plantaciones de yerba alrededor de las misiones. En ese momento el comercio de la yerba mate empezó a tener auge, enviándose parte de los cargamentos al Reino español, utilizándola a la yerba mate como moneda de cambio. (Burgos; Medina, 2017; Navajas, 2013).

El negocio yerbatero fue en aumento, así también las extracciones de los yerbales naturales y en algunos lugares se realizaron plantaciones alrededor de las viviendas, para facilitar sobre todo la cosecha de las plantas. Pero cuando los jesuitas, fueron expulsados de las misiones, se abandonaron las plantaciones y los yerbales implantados se fueron perdiendo.

Recién a finales del siglo XIX, se vuelve a fomentar el cultivo en la provincia de Misiones, como parte de una política pública de colonización de esa provincia. En ese sentido también comenzaron a escribirse algunos artículos que buscaban informar a los productores sobre los diferentes manejos que se deberían realizar en el cultivo de la yerba mate. Así aparecen autores como Roger (1906) que explica cuestiones generales relacionadas al cultivo y habla de que la cosecha debería tener una frecuencia trienal, o bianual como en el Paraguay. Comenta que el trabajo se realizaba con machetes, donde se cortaban todas las "ramillas" del árbol, se dejaban solamente las más gruesas con una copa en su extremo superior. El mismo autor plantea la necesidad de realizar trabajos con tijeras en donde se puedan cortar ramas maduras con una porción de hojas distribuidas por todo el árbol, de manera que la savia circule y genere puntos de crecimientos (Roger, 1906).

En el mismo sentido, Uzal (1910) expresa que en la poda de los yerbales naturales se debe hacer lo siguiente:

"Sabido es que la explotación de la yerba se hace podando los árboles, para beneficiar las hojas. Estos árboles después de haber sido aprovechados tienen que dejarse por tres años hasta que se vuelvan a cubrir de follaje” (Uzal, 1910,19) 
En cambio, en las plantaciones implantadas se deben manejar de otra manera:

"Cuando las plantas tengan un metro y medio de altura se cortarán a unos 60 centímetros del suelo para obligarlas a ramificarse abundantemente, porque cuando mayor sea la ramazón mayor será la producción de hojas de yerba y el interés del cultivador está precisamente en formar árboles bajos y coposos que faciliten la cosecha”. (Uzal, 1910, 18)

El trabajo de cosecha lo realizan los "tariferos", que son aquellos operarios que suben a los arboles con un machete y cortan ramas dejando solamente una rama principal que la llaman " banderola" una vez cortada siguen con sus trabajos de quiebre en el suelo, siendo esta forma peligrosa para el trabajador, el mismo autor considera que deberían buscarse sistemas que sean más racionales, como ser la utilización de tijeras de corte para realizar el trabajo (Uzal, 1910).

En este sentido, coincide con Rogers (1906), en que se debe manejar frecuencia de cosecha trienales, en los periodos de abril a mayo de manera de cuidar a las plantas (Uzal, 1910). Otro autor, Galarza (1914), también se plantea realizar cosechas cada tres años. El mecanismo es a través de intervenciones manuales entre los meses de abril a septiembre, asimismo se bosqueja la necesidad de implementar tijeras de podar para la extracción de los materiales (Galarza, 1914).

Estos primeros autores diferencian las metodologías de cosecha de yerba, en función de que sean yerbales naturales o implantados. En los primeros la forma de extracción es a través de una persona o grupo de persona que se conocen con el nombre de "descubertero". Estos eligen el lugar donde se iban a instalar los meses de cosecha y se hacia la extracción con machetes en donde los "tariferos" quitan ramas y hojas subidos a los árboles. En los yerbales implantados no se necesitaba del individuo que descubra los montes de yerba, sino que lo tenían identificado e iban directamente a realizar el trabajo de corte de la yerba.

Asimismo, existieron otras alternativas para la cosecha de la yerba mate, considerando los métodos que utilizaban los jesuitas. En yerbales naturales, realizaban cortes cuadrianuales, donde dejaban gajos superiores para cubrir a las plantas de las condiciones climáticas adversas (heladas y calor). Este mecanismo, se fue modificando por la de necesidad de materia prima por parte de la industria, llegándose a realizar cortes anuales. Estos últimos, se practicaban en los yerbales implantados. A pesar de la disparidad de tiempos o turnos de cortes, se consideraba que el resultado de cosecha 
se ve favorecido por las recolecciones cada dos años con materiales remanentes en las plantas, siendo de gran importancia el hecho de no dejar a la planta sin material verde, es decir, como se conoce en la jerga "pelar" a la planta de yerba mate (Bertoni, 1926)

Asimismo, Prat Kricun (2003) hace una reseña de los diferentes sistemas de podas que se utilizaban en los años 1929. El mismo toma como base el trabajo de Palacios (1929) quien define a la cosecha o poda como:

“... todos los yerbateros han practicado una serie de cortes, arbitrarios unos, exagerados otros, moderados aquellos, pero tendientes a la finalidad loable de hallar el mejor sistema de poda para los yerbales y en el cual se condensen: conservación de la planta y aumento constante de rendimiento". (Prat Kricun, 2003)

Como parte del trabajo de Prat Kricun es el mismo autor que rescata y muestra la gran variabilidad de nombres que se le daban a las diversas formas de realizar las podas, entre las que se pueden nombrar:

“ 1) Poda de decapitación (Escuela de Agricultura de Posadas); 2) Poda de rascacielos ( la Plantadora de yerba Mate, de San Ignacio); Poda Polaca ( yerbal Ribinsky, de Corpus); 4) Poda la brosse o mesas de café ( Yerbal Santa Inés de Núñez) ; 5) Poda copa champagne( Yerbal La María Antonia, desde 1919 a 1923); 6) Poda canastita o dulcera ( Yerbal Sol de Mayo, de Gramajo); 7) Podas montañas rusas ( Yerbal Los Manantiales de Robert Blosset); 8) Podas guampitas ( Yerbal El Triunfo, de Palacios Hnos.) y 9) Poda sacrificio o cruce de cementerio (ex yerbal de Lumiere, Villa Lanus)." (Prat Kricun, 2003)

Las diferencias, entre cada una de ellas, no son muy claras, pero sí se describe que son defoliadas a mano, a través de la utilización de tijeras o serruchos y que las plantas llegaban hasta los cuatro metros de altura. (Prat Kricun, 2003).

Existen algunas pautas básicas para el tratamiento del vegetal con relación a las podas, como tipos de material a cortar, épocas y frecuencias de cosechas. Asimismo, se busca mantener a la planta con una buena cobertura de material verde después de realizada la zafra, buscando extraer entre un 70 a $80 \%$ de material verde como máximo (Furnus, 1926). 
Otro autor, Mutinelli (1933) señalado por Prat Kricun (2003) hace referencia a que en las podas de las plantas de yerba mate, se deben conservar ramas terminales y una adecuada cantidad de hojas (Prat Kricun, 2003)

También, Tarabanoff (1936), mencionado por Prat Kricun (2003) expone que los cortes en las ramas deben realizarse sobre los brotes nuevos y a la planta debe conducirla de manera tal que se evite el exceso de crecimiento de los brotes (Prat Kricun, 2003)

Prácticamente todos estos autores citados, coinciden en que se debe evitar realizar podas extractivas al vegetal, con algunas diferencias en las frecuencias de cosecha. Con la aparición de los organismos públicos, sus técnicos investigadores, comenzaron a dedicar tiempo a investigar cuestiones relacionadas al manejo del cultivo. En ese camino se abordaron diferentes metodologías de cosecha, siendo primeramente manuales y luego se buscó mecanizar la zafra yerbatera. Es importante destacar que, a pesar de los intentos por llegar a la incorporación de la máquina, es necesario una intervención manual en las plantaciones. Un porcentaje muy alto de yerbateros realizan la tarea en forma manual, en muchos casos esta actividad es considerada como un cuello de botella para los productores que deben salir a contratar el personal para lograr levantar a tiempo la materia prima de los yerbales.

\subsection{Tipos de cosechas utilizados actualmente en el sector}

En el apartado anterior se mencionaron algunos sistemas que eran utilizados, a pesar de las diferentes denominaciones de los nombres y los métodos de recolección. Se puede aseverar que se han desarrollado desde un comienzo diferentes sistemas para recolectar, algunos han logrado más aceptación que otros en el sector productivo.

En la actualidad, hay otros métodos que se observan en los yerbales. Tal es el caso de la llamada "cosecha tradicional" que pregona realizar la poda del árbol en dos operaciones para lograr recolectar la materia prima del yerbal. Ellas son: la conocida MELENA en la cual se extraen las virutas fina y virutones ${ }^{4}$; la limpieza de plantas a

\footnotetext{
${ }^{4}$ Viruta: Material verde que se desarrolla en el interior de la copa. Con alto valor industrial, se extrae con la mano.

Viruton: material verde de mayor diámetro. Se extrae con tijera de mano y se puede desarrollar en el interior de la copa del árbol. (solamente existe el viruton en el sistema de cosecha tradicional)
} 
través del deshorquetado ${ }^{5}$, levantado de laterales y eliminación de ramas cruzadas, afectadas y "San Antonio". La otra operación es la Bajada de BANDERA, que consiste en cortar ramas verdes a los 10 centímetros de su inserción, esto se conoce con el nombre de aumento, además se debe dejar banderines verdes ${ }^{7}$ y realizar un pequeño despunte de los mismos. Estas operaciones la realizan los operarios, con la mano y una tijera común de poda, el material recolectado se deposita en un lienzo conocido como "ponchada", que luego es pesado para conocer el rendimiento individual del operario y, por supuesto, el rendimiento general de cada lote.

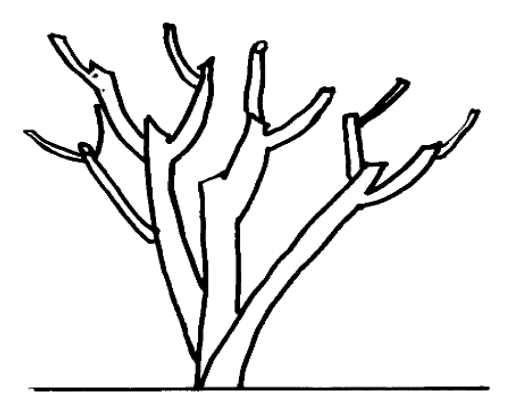

\section{Figura 1: Corte Tradicional}

Fuente: (Burtnik, 2006)

Es un mecanismo muy adaptado a grandes empresas que buscan simplificar el trabajo que realizan los trabajadores cuando ejecutan la cosecha de yerba. Además, esta técnica se adapta también a la posibilidad de mecanizar la recolección de la yerba mate a través del método del corte en forma de mesa. Consiste en realizar limpieza y melena con operarios y a mano. En la bajada de bandera se puede optar por realizar un corte formando una especie de mesa (todas las ramas a la misma altura). En donde cada año de cosecha, la altura de corte se incrementa en aproximadamente unos 10 centímetros de altura. Esto último se ejecuta con máquinas o en forma manual. Es un modelo que utilizado por las empresas de mayor envergadura.

\footnotetext{
${ }^{5}$ Se eliminan las bifurcaciones de las ramas de yerba mate, para facilitar la brotación de las mismas.

${ }^{6}$ Se denomina San Antonio o maceta a la porción de tallo que en el extremo posee una corona de yemas y heridas provocadas por el viruteo. Esta formación dificulta el desarrollo de las yemas en los tallos.

${ }^{7}$ Son ramas intermedias, generalmente subdominadas, de crecimiento vertical o lateral y con diámetro basal menor a 1 centímetro.
} 


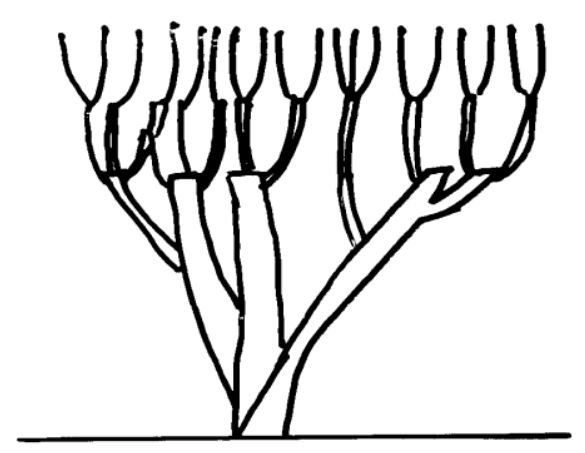

Figura 2: Corte mesa

Fuente: (Burtnik , 2006)

A pesar de ser un sistema de cosecha, que es fácilmente realizable, ya que con dos intervenciones se realiza la poda completa de la planta, este procedimiento presenta algunas dificultades. Desde los I+D, se considera que, en el corte tradicional, las plantaciones quedan prácticamente defoliadas en la copa, lo cual provoca algunos inconvenientes desde el punto de vista técnico productivo. Uno de los más importantes es el daño realizados por las quemaduras producidas por el sol en las ramas primarias, dejando a las plantas dañadas en su estructura de sostén y producción. Asimismo, un detalle que no es menor es que las podas extractivas, dejan a las plantas defoliadas casi totalmente, lo que va en detrimento del sistema (Burtnik , 2006). A pesar de esto es uno de los sistemas que más se utilizan dentro del sistema productivo yerbatero.

Desde la óptica de los I+D, es el sistema tradicional, trae consecuencias negativas a los yerbales, en primer lugar por el limitado cuidado de las plantaciones, por los modelos de cosechas de tipo extractivas, sumado a la no reposición de los nutrientes que el vegetal necesita para seguir produciendo, al mal uso de técnicas de control de malezas y la utilización inadecuada de los implementos agrícolas, básicamente rastras, provocando que los rendimientos de los yerbales en el sector de productores pequeños y medianos comenzaran a disminuir de manera notable. Esta situación fue detectada por los $I+D$, quienes buscaron diferentes alternativas a la cosecha tradicional y esa mezcla explosiva de manejos resultó en un sistema deficitario. Es allí donde comienzan a aparecer otras metodologías de trabajo, tanto para la recolección como así también para el manejo general del cultivo. Así surge la cosecha de rama madura, que plantea 
un método de trabajo diferente al que el productor y el trabajador estaban acostumbrados a realizar en los yerbales.

El sistema de cosecha de rama madura, básicamente propone realizar el corte de ramas de entre 18 a 24 meses, con un diámetro de 2,5 centímetros, de color grisáceo, en donde el corte de las mismas se realiza con un pequeño aumento de entre 15 a 25 centímetros de longitud. Esto se logra con la incorporación de serruchos de corte y tijeras eléctricas o electrónicas. Con lo cual se incorporan al trabajo de corte nuevas herramientas. Este patrón propuesto trabaja con cinco actividades que pueden coincidir o no en el tiempo, ellas son: el viruteo, la limpieza, corte de la rama madura, raleo de verdes y el despunte o mborevi caru. ${ }^{8}$.Con este tipo de cosecha, la planta debería quedar con un porcentaje de cobertura de aproximadamente un $30 \%$, ese valor es suficiente para iniciar el crecimiento en los meses estivales de manera vigorosa, asegurando la cosecha del año siguiente. Las plantas podadas de esta manera además quedan saneadas, porque todos los años se eliminan materiales (ramas) que han sufrido daños por el sol, las heladas o algún evento sanitario que pueda aparecer.
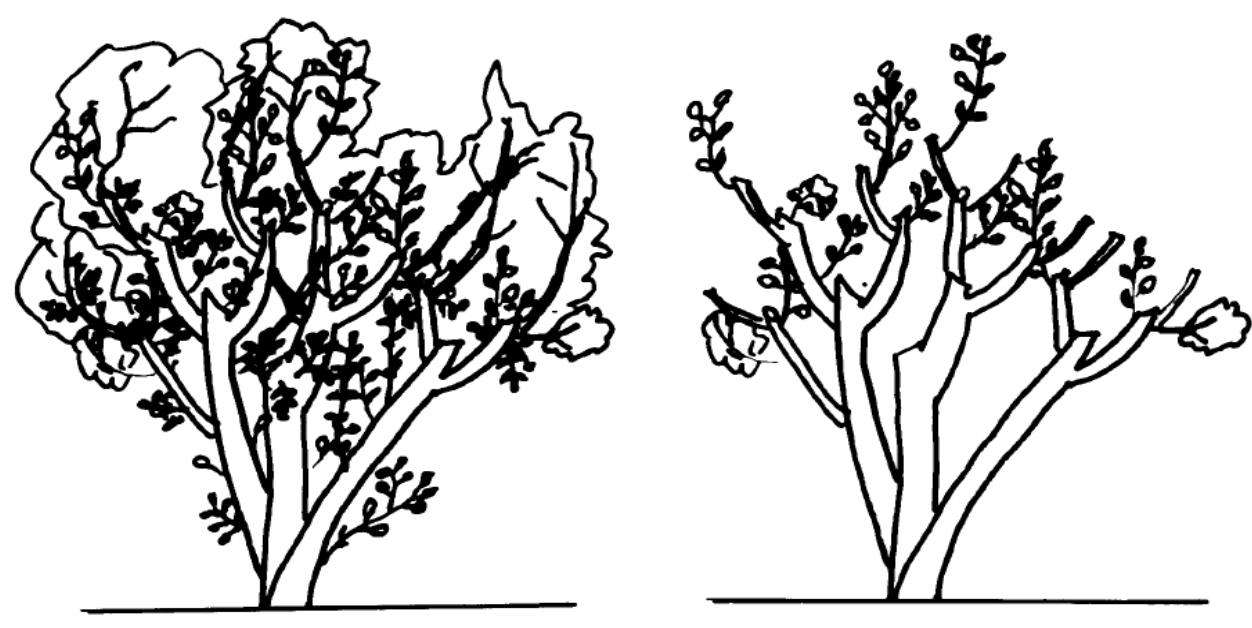

Figura 3: Corte de rama madura

Fuente: (Burtnik , 2006)

\footnotetext{
${ }^{8}$ Viruteo: eliminación de ramas finas en forma manual durante los meses de marzo a mayo. Limpieza: eliminación de ramas dañadas con serrucho o motosierras entre mayo a junio. Corte de ramas maduras: corte por medio de serrucho y o tijeras eléctricas de ramas con aumentos de ramas de color gris con diámetros de más de 2,5 centímetros de diámetro con aumento de hasta 25 centímetros. Entre los meses de mayo a agosto. Raleo de verdes: se realiza el corte con tijeras de mano a ramas verdes de un año durante los meses de mayo a agosto. Despunte o mborevi caru: eliminación del tercio superior entre agosto y septiembre de manera manual o con tijera.
} 
Otro sistema de cosecha manual es el rotativo que promueve el ingreso a la parcela de corte en diferentes etapas, iniciando la limpieza de las virutas en el primer año, al año siguiente corte de rama madura en verano y en el tercer año de cosecha realizar la extracción de la viruta y corte de rama madura en invierno. Es un modelo de transición entre el tradicional y el de rama madura, en donde cada ciclo es trianual.

Para lograr analizar el sistema de cosecha de la rama madura como una innovación socio técnica dentro de un proceso de trabajo en la cosecha de la yerba mate, se aplica el marco teórico de la sociología de la tecnología, utilizando la teoría Actor Red (ANT en sus siglas del inglés) para su análisis.

La descripción de esta Teoría será el marco teórico propuesto en el presente trabajo de investigación. El mismo se desarrolla a continuación. 
CAPÍTULO 3: MARCO TEÓRICO METODOLÓGICO 


\subsection{Marco teórico:}

El análisis de la Red relacionada a la adopción de innovaciones en la cosecha de la yerba mate, fue realizado por medio de la Teoría del actor red (ANT en sus siglas en inglés).

La misma, se origina entre los años setenta y ochenta del pasado siglo XX como un desarrollo en el dinámico panorama de los estudios sociales sobre ciencia y tecnología (Aibar, 1996; Echeverría Ezponda, 2009).

Esta teoría se enmarca dentro de lo que se conoce como sociología de la tecnología, entre los autores que son referentes en esta temática, se encuentran Bruno Latour, Michael Callón, John Law.

El ANT, es un proceso que abarca y describe las alianzas e interacciones, los movimientos de fuerzas que modifican o alteran la dinámica y la configuración de las asociaciones heterogéneas. En ella se estudian actores humanos y no humanos, intermediarios, portavoces, asociaciones, situaciones problemáticas, estrategias, enrolamientos, dinámicas, traducciones y configuraciones de las diferentes redes de relaciones que se forman.

Para poder entender el marco conceptual propuesto para este análisis de caso, se proponen diferentes conceptos teóricos, como los intermediarios. Estos se definen como cualquier cosa que pasa de un actor a otro, lo que constituye la forma y la sustancia de la relación establecida entre ellos (Callon, 2013). Estos intermediarios pueden ser de cuatro tipos:

- textos que pueden ser: informes, libros, patentes artículos científicos, publicaciones etc.

- artefactos técnicos (entidades no humanas) dentro de estos están los instrumentos que se pueden utilizar para realizar diversas tareas,

- $\quad$ seres humanos con sus conocimientos, capacidades y habilidades

- Dinero en cualquiera de sus formas.

Se denomina actor a cualquier entidad capaz de asociar a diversos elementos, intermediarios, que definen y construyen un mundo poblado de entidades lo que le otorga una historia e identidad (Callon, 2001; Thomas \& Buch, 2013). Asimismo, se 
puede hablar de actor como aquel elemento que tiene la capacidad y el poder de actuar en cualquier momento sobre otros (Echeverría Ezponda, 2009).

Por lo tanto estos actores deben tener capacidad de agencia, es decir, provocar algún efecto (Latour B. , 2008). Con lo cual, estos no son estáticos si no que están en movimiento constante, siempre buscando a través de diferentes mecanismos actuar sobre los demás actores. Estos actores pueden ser Humanos $(\mathrm{H})$ y no Humanos $(\mathrm{NH})$, hasta inclusive actantes, que son aquellos que pueden actuar en función de sus competencias (Latour, 1998).

La traducción, es el mecanismo por el cual se genera el lenguaje común, este circula a través de la red tratando de estabilizar el discurso (Akrich, 1988; Callon , 1995; 2001; 2006; Law, 1987;1998; 2006). Es el resultado de negociaciones e interacciones entre actores; donde se ajustan las visiones de los mismos. En la traducción, un actor traduce a muchos y entre ellos se establecen relaciones por medio de interacciones, negociaciones, donde buscan ajustarse las diversas miradas de los actores.

La traducción puede ser descripta en cuatro momentos: la problematización, el interesamiento, el enrolamiento y la movilización.

La problematización es el interrogante que permite relacionar a un conjunto de actores, precisar sus identidades y las uniones entre ellos, con lo cual indica los movimientos y desvíos que es preciso aceptar y las alianzas que hay que establecer (Callon , 1995).

El interesamiento son las diversas actividades, mediante las cuales una entidad intenta imponer y estabilizar la identidad de otros actores que define a través de la problematización. Cada entidad definida en la problematización puede optar o no integrarse en el plan formulado al inicio, o también negarse hacer concesiones y definir su identidad, sus metas, sus orientaciones, proyectos, motivaciones o intereses de otra forma. Si se logra el interesamiento se confirma la validez de la problematización y la alianza (Callon, 1995).

Con el enrolamiento se define y asigna un conjunto de roles interrelacionados a actores que los aceptan. A través de este mecanismo, se describe el conjunto de negociaciones multilaterales y de relaciones de fuerza que acompañan al interesamiento y le permiten obtener el éxito. Los actores se por medio la negociación se puede enrolar sin oponerse o por medio de la fuerza, mediante la seducción, a través de concesiones o logrando el consenso sin discusión (Callon, 1995). 
La movilización de los aliados define la representatividad de los portavoces. Si esta se logra, la simetría es perfecta. La secuencia de intermediarios reduce el número de interlocutores representativos y una serie de intermediarios y equivalencias conducen a la designación de un portavoz. La elección de cada nuevo intermediario hace que cada desplazamiento sea más fácil. Si se logra el consenso, los márgenes de maniobra de cada entidad quedaran reducidamente delimitados (Callon, 1995).

La problematización inicial define una serie de hipótesis negociables sobre la identidad, relaciones y metas de diferentes actores; al final de los cuatro momentos, se logra construir una apretada red de relaciones (Callon, 1995).

Los portavoces, son aquellos que hablan por otros que no hablan, se puede decir que son representantes de otros. Estos, portavoces tratan de enrolar y traducir a los demás actores. Ellos sufren cambios en el tiempo, consecuencia de las negociaciones. Hay entidades que pueden controlar a otras en el sentido del lenguaje modificándolas.

En este marco teórico, los actores buscan enrolar a través de diferentes mecanismos a los demás integrantes de manera que todos lleguen a tener o utilizar el mismo discurso o tener intereses comunes sobre determinado tema. Es un proceso donde la negociación entre actores determina la convergencia o no de la red e influye en la estabilización de las mismas a través del alineamiento y la coordinación de la red.

Un concepto que es aplicado durante el proceso de traducción, es el de la convergencia. En la problematización los actores si estos están aislados y la red no tiene convergencia; en la medida que avanza la traducción, va en aumento el grado de convergencia. Cuando se produce la movilización de los actores la red es convergente. Esta se a la capacidad de crear un espacio común, donde se produce la traducción "alineamiento" y la existencia de reglas o "formas de coordinación".

El alineamiento es el espacio compartido, definido en la problematización y validado en los diferentes momentos de la traducción, es el punto de pasaje obligado por donde pasan todas las entidades de la red.

Según este enfoque, tanto los desarrollos científicos como los tecnológicos pueden ser analizados en términos de luchas entre diferentes actores para imponer su definición del problema a resolver (Callon , 1987; Latour, 1987)

Es de destacar que "la teoría del actor-red es una colección diversa de herramientas semiótico-materiales, sensibilidades y métodos de análisis que tratan todos los elementos de los mundos naturales y sociales como un efecto, generado 
permanentemente, de las redes de relaciones dentro de las que están ubicados" (Echeverría Ezponda, 2009)

Delante de la sociología tradicional, que Latour (2008) llama "sociología de lo social", la ANT es una "sociología de las asociaciones" (Latour, 2008), que cuenta historias sobre cómo se originan, evolucionan y terminan las relaciones entre actores. De hecho, cuando los investigadores científicos agregan el adjetivo "social" a algún fenómeno, están designando un estado de cosas estabilizado. Las explicaciones en términos de "factores sociales" de, por ejemplo, una teoría científica o un sistema tecno científico, no explican realmente nada, y más bien ocultan los procesos a través de los cuales los diferentes actores y sus asociaciones han logrado la estabilización de una red. La ANT afronta esta tarea sin pretender que sea posible identificar factores explicativos y productos explicados. Su estrategia metodológica es la descripción de la dinámica de formación y estabilización de redes formadas por actores heterogéneos (Echeverría Ezponda, 2009)

Frente a las teorizaciones habituales en ciencias sociales, la ANT se determina por una radical indeterminación de los actores (Callon, 1998). Un actor puede ser individual o colectivo, humano o no humano, puede enrolar o dejarse enrolar y si algo no está previamente definido, son sus intenciones y sus intereses. La teoría del actor-red narra de qué modo los diferentes actores (humanos y no humanos) van conformándose mutuamente, definiendo y redefiniendo sus intereses en la interacción a través de procesos de traducción, "enrolamiento" y movilización, y obteniendo como producto la estabilización, siempre precaria, de una red. De esta manera, ni siquiera los actores están predeterminados antes de que la red comience a funcionar (Callon, 1986; Echeverría Ezponda, 2009).

De acuerdo con Latour (2008), un análisis podrá considerarse ANT si su objetivo no es la deconstrucción, sino la recomposición de lo social, porque busca comprobar cuáles son las nuevas instituciones, procedimientos y conceptos capaces de reconectar lo social. Asimismo, y coincidiendo con Echeverría Ezponda (2009) que la teoría del actorred está más interesada en los "cómos" que en los "porqués", su fuerza no radica tanto en las exposiciones teóricas que pretenden resumirla o mostrarla, sino más bien en la puesta en práctica a través de casos de estudio. Es que se toma a la ANT como marco teórico para analizar a la metodología de cosecha de la rama madura. 


\subsection{Marco metodológico}

\subsubsection{Estudio de caso}

Para poder realizar el trabajo de investigación, se propuso analizarlo desde los estudios de casos, considerando al caso de "la Cooperativa de Productores de Santo Pipó", de la provincia de Misiones; para lo cual debemos definir qué se entiende por un Estudio de caso y en particular qué es un "caso".

Tal como lo describen, Neiman y Quaranta (2006): "El caso es definido como un sistema delimitado en tiempo y espacio de actores, relaciones e instituciones sociales" (Neiman, 2006, pág. 220).

Asimismo, Stake (1994) dice al respecto: "el estudio de un caso no es la elección de un método sino más bien la elección de un objeto a ser estudiado. Nosotros elegimos estudiar un caso. En tanto enfoque de investigación, un estudio de caso es definido por el interés en casos individuales antes que por los métodos de investigación utilizados" (1994: 236; traducción de Neiman y Quaranta, 2006).

Por lo tanto, siguiendo a Stake y para tratar de entender el funcionamiento del sistema de poda de la rama madura, instalado en los productores yerbateros que pertenecen a la Cooperativa de Santo Pipó, se toma, a esta última, como un fenómeno complejo para el desarrollo del análisis de este trabajo de investigación.

Yin (1994) afirma que el motor para realizar estudios de casos proviene del deseo de entender fenómenos sociales complejos. Plantea tres criterios que hacen recomendable la utilización de estos estudios como estrategia de investigación: el primero es el interés por responder a preguntas del tipo ¿cómo? y ¿por qué?; el segundo criterio consiste en el grado de control que el investigador tiene sobre los fenómenos o conductas a estudiar (los estudios de casos son recomendables cuando se tiene escasa o nula capacidad para manipular experimentalmente los fenómenos a estudiar); el tercer criterio indica que los estudios de caso son recomendables cuando se desea estudiar fenómenos contemporáneos. Señala que estos utilizan muchas de las técnicas de los estudios históricos, pero que a diferencia de estos tiene la posibilidad de realizar una observación directa de los eventos y una entrevista sistemática a los participantes. Yin (1994) distingue cuatro tipos de diseño para los estudios de casos, considerando cuántos casos se decide estudiar y si se distinguen o no en el interior de estas unidades de análisis: Tipo 1: caso único, diseño holístico (una unidad de análisis); Tipo 2: caso único, diseño 
"incrustado" (embedded); Tipo 3: múltiples casos, diseño holístico; Tipo 4: múltiples casos, diseño "incrustado" (embedded).

Con lo cual, para este trabajo de investigación, se toma el caso de la Cooperativa Piporé, como una situación particular donde el desarrollo de un método de trabajo de cosecha de yerba mate, que se está implementando en esta institución que nuclea a yerbateros, ha buscado generalizarse en el sector yerbatero de la Argentina a través de los I+D. En ese sentido se busca dilucidar cuáles son las condiciones que permitan llegar a conocer y comprender el método de cosecha de la rama madura en el contexto productivo.

\subsection{Metodología de trabajo de campo}

Este trabajo de tesis se plantea como un estudio dirigido a comprender y analizar las relaciones entre los diferentes actores que influyen en la adopción de la cosecha de la rama madura en la yerba mate en la Cooperativa de productores de Santo Pipó, en la provincia de Misiones.

Para la realización de la presente investigación, se han planteado diferentes actividades, que servirán de base para poder trabajar y analizar en esta tesis. Se consideró un periodo de tiempo que van entre los meses de septiembre 2017 a mismo mes del año 2018, contemplando un ciclo de cosecha de yerba mate. Se programaron visitas a diferentes lugares cercanos a la Cooperativa Piporé: San Ignacio, Gobernador Roca, Santo Pipó, Jardín América. Además, se planificaron y concretaron visitas a Oberá, Campo Ramón, Guaraní, Apóstoles, Posadas y Capiovi, todos en la provincia de Misiones.

En los lugares nombrados se utilizaron diversas estrategias. Que se nombran a continuación:

Las observaciones no participantes para las jornadas de campo organizadas desde el INTA y el INYM, para productores agropecuarios, profesionales, técnicos y alumnos de escuelas. Se participó en:

$\checkmark \quad$ tres jornadas de podas de cosecha,

$\checkmark$ cuatro instancias de podas de formación de plantas de yerba mate,

$\checkmark$ una actividad de capacitación en nuevas tecnologías en la localidad de Apóstoles, 
$\checkmark \quad$ una jornada con jóvenes de las Escuelas de la Familia Agrícola en la localidad de Capiovi.

En estas instancias de capacitación realizadas por los I+D, desde la observación no participante, se elaboró y completó una guía de observación, buscando determinar puntos importantes, entre los que se nombran:

$\checkmark$ Quiénes participan de las capacitaciones (refiriéndose al público que asiste a estos eventos),

$\checkmark$ Qué tipo de actores son los que participan y cómo llegan a ellos estas invitaciones, a través de qué medios (las radios, mensaje de textos o whast upp o la transmisión oral). De esta manera se tiene una visión de cómo se realiza la convocatoria y cuáles son los medios que utilizan los organizadores para convocar a los asistentes.

$\checkmark$ Durante el desarrollo de la jornada, se buscó registrar "quién tiene la palabra" y cómo es la participación de los asistentes.

$\checkmark$ Qué duración lleva el desarrollo de los contenidos propuestos.

$\checkmark$ Quién plantea los temas a desarrollar: los técnicos o profesionales o productores.

$\checkmark$ Qué métodos utilizan los capacitadores durante el desarrollo de su trabajo sean estos: extensionistas o investigadores.

$\checkmark$ Se plantean espacio para el intercambio de opiniones entre los que están y los ingenieros o no.

Todas estas observaciones se fueron registrando en el cuaderno de campo.

Se utilizó el método de la entrevista, definiéndola como una técnica de investigación para recabar datos, con la idea de obtener información que permita resolver la pregunta de investigación. Existen varios tipos de entrevistas para este caso se han usado dos tipos:

- Las semiestructuradas: Las primeras preguntas más flexibles y adaptables de manera de explorar el campo de trabajo (Díaz-Bravo, 2013).

- Las entrevistas en profundidad: Las preguntas tienen estructura de guión, destacando temas importantes al realizar la misma (Robles, 2011).

Con estas técnicas de investigación utilizadas, se recabó información referida a diferentes actores, trabajadores, productores yerbateros, técnicos o extensionistas que se relacionan directamente con la cosecha de la yerba mate. 
En estas primeras intervenciones a través del contacto directo con los entrevistados, se trató de trazar una línea de búsqueda en relación al tema de investigación, como una estrategia para realizar una exploración previa. Una vez obtenidas esas bases de datos, se avanzó con las entrevistas en profundidad. A través de la técnica conocida como la "bola de nieve ", se fueron buscando a aquellos potenciales entrevistados, utilizando las redes personales de algunos contactos. Se continuó hasta obtener el "criterio de saturación", es decir cuando los nuevos contactos no aportan nuevos elementos al estudio (Marradi, 2007).

Las entrevistas semiestructuradas se realizaron a:

$\checkmark$ tres trabajadores cosecheros de yerba mate en actividad,

$\checkmark$ tres a técnicos extensionistas (relacionados con el INTA y la Cooperativa Piporé).

$\checkmark \quad$ cuatro a productores yerbateros.

Se afianzo el trabajo realizando entrevistas en profundidad a:

$\checkmark \quad$ nueve trabajadores rurales dedicados a la cosecha de la yerba mate,

$\checkmark$ tres integrantes del Sindicato de Trabajadores de Jardín América,

$\checkmark$ cuatro a capataces de corte de cosecha y contratistas;

$\checkmark$ cuatro funcionarios públicos de los I+D,

$\checkmark$ diez entrevistas a productores yerbateros,

$\checkmark$ nueve técnicos profesionales relacionados a empresas, cooperativas e institutos de I+D.

Considerando a los trabajadores rurales y contratistas. Se organizó las conversaciones de la siguiente manera: en una primera parte temas relacionados con la vida de los trabajadores, buscando información con respecto a cuestiones generales y haciendo hincapié en temas que tengan que ver con sus formas de vida. En un segundo momento, se indagó en temas concernientes a sus actividades laborales, al aprendizaje de la metodología de cosecha que utilizan y otras metodologías conocidas, pero no empeladas. Con lo respecto a las capacitaciones, si es que son beneficiarios de estas instancias, consultándoles, si conoce a quién las organiza, qué temas se desarrollan y dónde se realizan. Además, se solicitó la opinión que tienen estos actores de los diferentes cortes que se realizan en la cosecha. 
Asimismo, se buscó averiguar, la antigüedad de estos actores en el sistema productivo, de forma de conocer desde qué momento están vinculados a la cosecha de la yerba mate a través de su trabajo, como así también si han realizado incursiones en otros yerbales de la región y en qué lugar frecuentemente trabajan. Conocer qué actividades realizan una vez finalizada la zafra yerbatera. De esa manera se puede tener una visión del sector trabajador/ contratista relacionado a la yerba mate.

De la misma manera, en la localidad de Posadas, se concretó una reunión con dos profesionales del Área técnica del INYM. Estos están encargados de hacer la promoción, difusión y seguimiento de los programas financiados por el instituto. En el mismo sentido también, se realizaron dos entrevistas a referentes del sector público, vinculados al Ministerio del Agro de la provincia de Misiones. De manera tal de conocer las actividades que realizan dichos organismos públicos en relación con el cultivo de la yerba mate y especialmente en la temática de la cosecha; como así también poder visualizar las relaciones con los diferentes actores públicos, que forman parte del complejo yerbatero, desde el sector de los trabajadores hasta los empresarios molineros.

Se realizaron también, diez entrevistas a productores yerbateros entre las localidades de Santo Pipó, Jardín América, Oberá, Guaraní. En las mismas, se plasmaron diferentes cuestiones relacionadas a la actividad productiva, en las que se buscó analizar el tipo de trabajo que realizan en sus yerbales, desde el comienzo de la temporada de cosecha hasta la finalización de la misma. Se indagó, cómo realizan dichas actividades, quiénes son los que intervienen en cada una de las tareas; si contratan los servicios de trabajo o lo realizan de manera familiar. Así también se analizó de qué manera los mismos dueños o productores considera si un trabajo está realizado de la mejor manera o no.

También se incluyeron preguntas relacionadas a las capacitaciones que se realizan en relación al trabajo de la yerba mate, temas a saber: el nivel de participación que tienen estos grupos de productores en las diversas jornadas de instrucción y cómo se llevan a cabo estas últimas; quienes son los que convocan a las mismas; asuntos afines a los tipos de cosechas que realizan en sus lotes de yerba mate y cómo han aprendido el trabajo de manejo de los yerbales.

Se realizaron entrevistas con nueve técnicos de campo que se desempeñan profesionalmente en diferentes localidades, entre ingenieros agrónomos y técnicos, de acuerdo a la siguiente relación: tres profesionales de INTA, dos técnicos del Ministerio 
del Agro de Misiones, que desarrollan actividades de extensión rural con productores yerbateros. Estos técnicos, generalmente se vinculan a través de Grupos de Cambio Rural o proyectos como PROFEDER ${ }^{9}$. También a cuatro profesionales de la actividad privada que se desempeñan como asesores de Cooperativas o empresas privadas que tienen alguna relación con la Cooperativa Piporé.

En las entrevistas con los profesionales, se trató de analizar temas relacionados a la extensión y las metodologías de trabajo que utilizan en las reuniones de campo. Asimismo, se buscó información relacionada al tipo de material que se distribuye en las instancias de formación, cómo se realiza la convocatoria a las diversas reuniones de campo además de saber qué opinan de los métodos de cosecha que existen en el sector yerbatero, especialmente la cosecha de rama madura.

De la misma forma para el caso de las instituciones públicas, se relevó información relacionada al vínculo que poseen estos organismos entre sí, de manera de poder determinar qué características tienen, cómo se desarrollan las relaciones y conocer cuáles son los nexos que se demuestran en práctica en terreno. Así también conocer desde el discurso que promueven estas instituciones relacionadas al sector yerbatero. Con toda esa información se realizó el análisis de lo recabado, donde se fueron buscando los puntos más resonantes en relación a la cosecha de la yerba mate.

Dentro del marco del trabajo de investigación se realizó la consulta de fuentes bibliográficas, publicaciones en libros, diarios, folletos, revistas o en formato digital, revisión de antecedentes históricos relacionados a la temática de la recolección de la yerba mate. Estos documentos escritos, se remontan a comienzos del año 1900, hasta las más recientes publicaciones de congresos, jornadas técnicas o reuniones científicas que tuvieran alguna relación con la cosecha de la yerba mate y sus diversas metodologías de trabajo.

Dentro de la consulta de material escrito, también se encontraron publicaciones realizadas por el INYN e INTA, que incluyen temáticas relacionadas a las podas de las plantas de yerba mate, entre las que se pueden nombrar: las revistas "Bien Nuestro" publicación realizada por el INYM, con carácter general y con frecuencia bimestral.

\footnotetext{
${ }^{9}$ El Programa Federal de Apoyo al Desarrollo Rural Sustentable (PROFEDER) tiene la finalidad de promover la innovación tecnológica y organizacional de los actores del medio rural, el desarrollo de sus capacidades y el fortalecimiento de la competitividad regional y nacional, para generar un ámbito de equidad social y sustentabilidad en apoyo al desarrollo territorial (.https://inta.gob.ar/documentos/profeder-programa-federal)
} 
Publicaciones en diarios o en internet vinculadas a la cosecha de la yerba. Asimismo, promociones de jornadas de capacitaciones realizadas por los diferentes organismos de $I+D$, programas de eventos vinculados a la actividad yerbatera, por ejemplo: Fiesta del Agricultor, Fiesta de la yerba mate, entre otras. Todas fuentes que tienen relación con la temática de la cosecha de la yerba mate. 
CAPÍTULO 4 LOS QUE ACTÚAN EN LA COSECHA 


\subsection{Los que actúan en la cosecha en la Cooperativa Piporé}

Como se viene comentando, la cosecha de yerba mate, es una actividad que se realiza de manera manual, esporádicamente mecánica y estacional (de febrero a septiembre).

Durante el trabajo de campo realizado en la Cooperativa Piporé, se fueron identificando diversos actores relacionados a la cosecha manual de yerba mate, muchos de los cuales fueron visualizados a medida que se desarrollaron las visitas a campo. Algunos de estos están contenidos en el grafico que se observa a continuación:

Cosecha de Yerba Mate: Influencia de actores en las podas

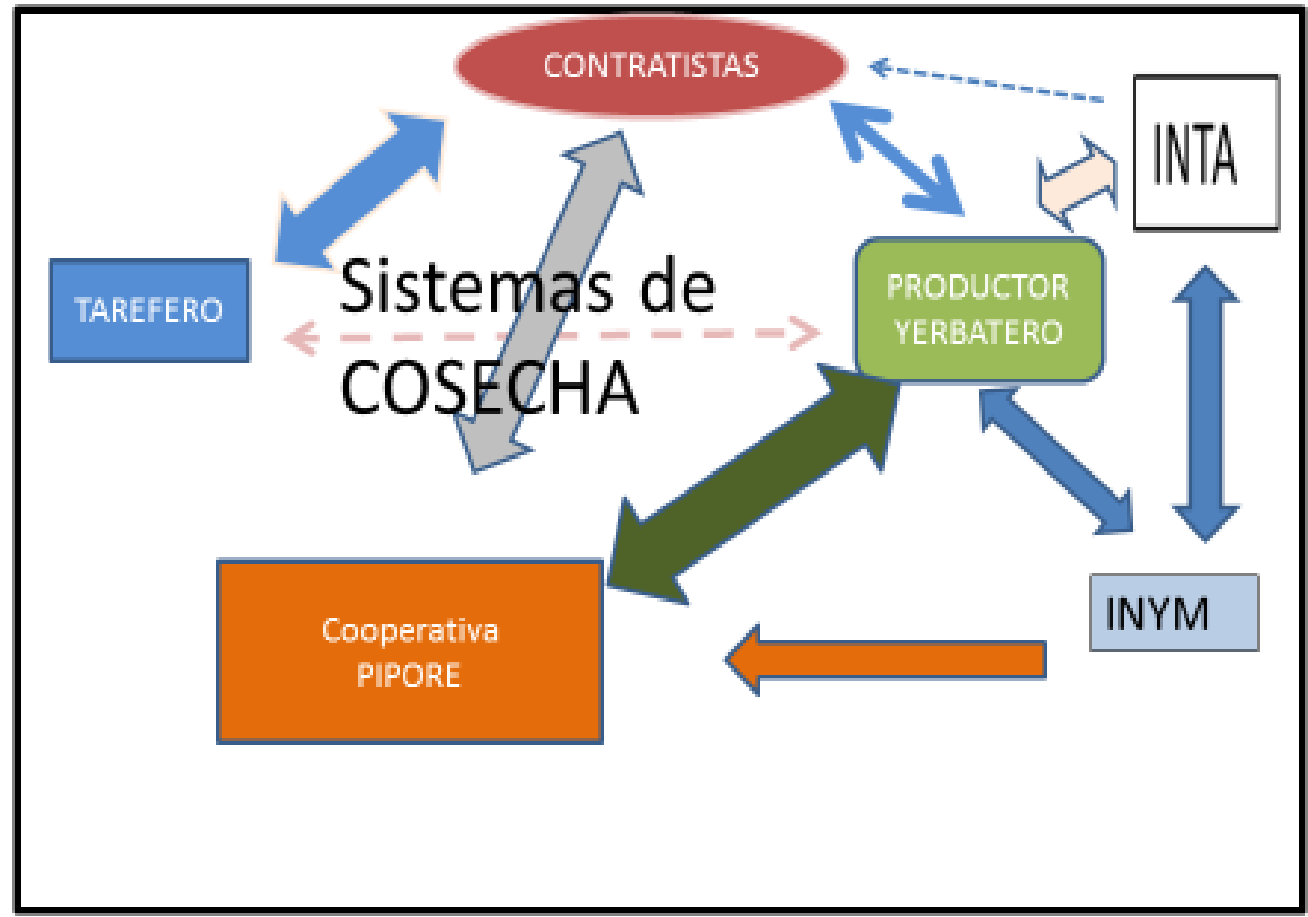

Fuente: Elaboración propia en Base a entrevistas

Figura 4 : Cosecha de Yerba mate, actores

En base al diagrama se pueden definir algunos actores. El trabajador conocido en la jerga como tarefero: es quien realiza la cosecha de manera manual, cortando las ramas con tijeras de mano y a veces, dependiendo del tipo de cosecha, con serruchos y quebrando con la mano estos materiales cortados para que luego se lleve a la industria. 
No se conoce a ciencia cierta, cuántos trabajadores están involucrados con la actividad yerbatera. Hay fuentes como el Sindicato de Tareferos de Jardín América que dicen que existen en toda la región yerbatera unos 17 mil trabajadores relacionados a la cosecha de la yerba mate.

En cambio según datos publicados en el trabajo sobre "Proyecciones del Relevamiento de Tareferos (cosechadores de la yerba mate) en Misiones" (Figueredo, 2010) estiman, que son 3 mil inscriptos en el RENATRE ${ }^{10}$ en el año 2011. En cambio, los guarismos del INYM estiman valores cercanos a los 15 mil trabajadores. Lo cual nos demuestra la gran disparidad en estas cifras según la fuente que se analice.

Rau (2016), haciendo un estudio sobre el trabajo asalariado en yerba mate, asevera que son 21.856 los trabajadores agrarios relacionados a la yerba en toda la región yerbatera. Asimismo, el movimiento del sector trabajador es muy importante. Se detectan en las cosechas trabajadores que vienen de otros lugares de la región yerbatera a cosechar, el autor los llama "exportadores" de mano de obra transitoria, (Rau, 2016).

Hay un importante movimiento migratorio dentro del sector yerbatero. Un ejemplo es el caso de migraciones de trabajadores que se realiza desde la zona centro, Oberá (Mnes) a otros lugares, como el norte de la provincia de Misiones, por ejemplo, Comandante Andresito o hasta al norte de la provincia de Corrientes, en Gobernador Virasoro, recorriendo de esa manera, toda la franja productiva de yerba mate. Estos fenómenos se han detectados en las entrevistas realizadas en la cooperativa, donde varios trabajadores han manifestados conocer otros lugares adonde fueron a cosechar con cuadrillas de la zona de Oberá principalmente.

Una de las particularidades, es el nivel de informalidad que todavía existe en el sector yerbatero, los tareferos, dan un primer indicio. No se identifica realmente, cuántos trabajadores están involucrados en la cosecha yerbatera. Al mismo tiempo, se da la particularidad de que la tarefa ${ }^{11}$ de yerba, al ser manual y estacional (aproximadamente entre 6 a 9 meses de trabajo) no les asegura a todos los involucrados una estabilidad laboral, lo cual les juega en contra. Debido a esta situación, los trabajadores, buscan otras alternativas laborales que les generen un sustento continuo y estable durante todo

\footnotetext{
10 Registro Nacional de Trabajadores Rurales y Empleadores.

11 Tarefa: vocablo portugués que hace referencia al trabajo de la cosecha de la yerba mate
} 
el año, ejemplo de ello son los trabajos de albañilería, ayudante de albañil, o se mueven a otras actividades productivas, trabajos en forestaciones, por ejemplo.

Cabe destacar que la tarefa es considerada un trabajo que se da en condiciones de precariedad, desde la contratación del personal (que muchas veces es en negro o informal) hasta en las condiciones laborales que se dan en los yerbales. En muchos casos los mismos obreros consideran que es un trabajo que implica mucho sacrificio. Trabajar cosechando la yerba con las manos en días de heladas, con temperaturas muy bajas, con mucho frio y elevada humedad en el ambiente, llegando a mojarse por el rocío hasta la última prenda. En estas condiciones laborales, se pone de manifiesto que ese esfuerzo sea considerado inhumano para estas personas. Al margen de la situación en que desarrollan sus actividades de cosechas en los yerbales, muchos dicen, que "no les queda otra" que ir al yerbal a realizar estas labores de recolección.

Para que los trabajadores yerbateros o también llamados tareferos, puedan percibir sus honorarios, se utiliza la siguiente metodología, que es una manera de controlar lo producido por cada uno de los tareferos. Se realizan pesajes de las cosechas diarias de cada trabajador, en el caso de ser individual o del equipo, para los grupos de trabajo. Estos pesajes en general se realizan a media mañana, cercanos al medio día y a la media tarde. Estos valores se registran en unas planillas, que cada fin de semana o último día de la semana se hace la liquidación de lo recolectado por los trabajadores. Sus honorarios lo perciben de acuerdo a los kilogramos de materia prima cosechados semanal o quincenalmente de acuerdo al arreglo que hayan logrado con los patrones o contratistas.

La actividad yerbatera, por el tipo de cosecha que se realiza, se caracteriza por ser estacional, por lo cual el trabajo del cosechero es de tipo temporario. Los trabajadores son un elemento relevante a la hora de realizar la cosecha, por lo tanto, no se puede prescindir de estos individuos. Incluso en aquellos sistemas que se han buscado mecanizar completamente la "tarefa" no se logra resultados satisfactorios, ya que la mano del hombre es necesaria para realizar trabajos de selección de ramas que la máquina no puede hacer.

Al ser una actividad poco estable, se da también el fenómeno de que los trabajadores que no están blanqueados o no son parte del staff de la empresa de manera permanente, van rotando sus actividades laborales anualmente. Con lo cual, no siempre son los mismos cosecheros que hacen el trabajo, se dan situaciones de ingreso y 
egresos de personal al sistema de contratación del sector, generando alta rotación del personal de cosecha de la yerba mate.

Si se considera el Departamento de San Ignacio, donde se encuentra la Cooperativa Piporé, existen unos 1.836 trabajadores agropecuarios. Este valor surge de un trabajo realizado por Rau (2016), pero hay que destacar que el mismo no llega a discriminar entre los tipos de trabajadores, pero sí supone que una gran mayoría corresponden a los tareferos (Rau, 2016). La yerba mate es una de las principales actividades agropecuarias y por ende la cosecha es una acción que absorbe mano de obra, muchas veces de manera transitoria.

Las formas de contratación de los trabajadores varían. Pueden relacionarse directamente con el productor o bien a través de un intermediario, el contratista de cosecha. En el primer caso, es el mismo productor yerbatero quien busca a sus trabajadores en lugares cercanos a las explotaciones o en áreas sub urbanas. Allí en una reunión informal "cierran las negociaciones del trabajo a realizar". Estas situaciones, se dan en particular con aquellos productores que poseen poca superficie a cosechar y con características de agricultores familiares. Donde parte de la mano de obra para el trabajo de la yerba se realiza con la familia y para el caso de la cosecha específicamente, se puede sumar alguno que otro trabajador circunstancial.

Cuando los yerbateros poseen superficies mayores, en general buscan contratar servicios de cosechas por medio de contratistas. Esta modalidad de servicio para el sector yerbatero, comenzó a aparecer en la década del 90, cuando se desreguló la actividad yerbatera. Estos surgieron como intermediarios de recolección de yerba mate, ofreciendo mano de obra a los grandes complejos agroindustriales del sector yerbatero (Rau, 2016). Luego fueron buscando otras escalas de productores hasta que en la actualidad se encuentran diseminados por toda la región. La aparición de la figura del contratista, se vio acompañada por el desarrollo de otras actividades productivas como por ejemplo la instalación de grandes empresas forestales en el NEA, que requerían de servicios de mantenimientos (en la actividad forestal, por ejemplo, para realizar las podas o los raleos) para los trabajos en sus explotaciones. De esta manera, la yerba mate, comenzó a tercerizar sus actividades de cosecha o mantenimientos en los yerbales.

Una característica de estos intermediarios, es que algunos eran empleados de las empresas yerbateras o secaderos que, con el afán de crecer, dejaban sus trabajos en 
relación de dependencia y se subían al barco de la independencia laboral, ayudados en sus inicios por las mismas yerbateras. Facilitándole trabajos a sus ex empleados ahora contratistas, para de alguna manera "ayudarlos" a dar los primeros pasos. Al ser ex empleados de empresas, conocían a los trabajadores que cosechaban la yerba mate y sabían dónde ubicarlos. Entonces al tener ese conocimiento de dónde está la fuente de trabajo, buscaban en los barrios la mano de obra que estaba por ser subcontratada para la realizar la cosecha. Formando conjuntos de entre 10 y 30 personas, estos prestadores de servicios, tienen a su cargo uno o varios equipos de trabajos. Estos empresarios de servicios, poseen una estructura que se conforma de la siguiente manera: el capataz de corte, el pesador, el transportista y el tarefero. Disponen de transporte de personal (colectivos, camionetas acondicionadas), de materia prima, carga y envío del material al secadero, esto último se realiza generalmente con camiones.

Los contratistas, son los que negocian los valores y las formas en que se va a realizar el trabajo con el productor. En este caso acuerdan los mecanismos para realizar la cosecha; a veces estos contratistas, están muy relacionados con el secadero y/o molino lo cual, en algunas circunstancias, facilita la entrega de la materia prima a estos últimos. Al ser un servicio que se brinda, estos actores tienen varios "patrones" a quienes le realizan el trabajo de la recolección de materia prima. En general trabajan prácticamente todo el año, haciendo otras actividades dentro de los yerbales o en otras explotaciones como la forestación, por ejemplo. En épocas de plena cosechas, llegan inclusive a movilizarse dentro de la zona productora, cosechando en diferentes lugares de Misiones e inclusive Corrientes.

Estos contratistas, tienen la particularidad de darle la continuidad laboral a un número mínimo de trabajadores, una vez finalizada la zafra. Lo que implica que una parte del grupo queda sin relación laboral, pudiendo, quedar desocupados o por lo general buscar otra actividad. Al disminuir el trabajo en los yerbales durante el periodo de no cosecha, para el contratista le resulta oneroso mantener la estructura de personal, con lo cual los contratos de sus trabajadores son a términos. Dejando un sin números de personas sin la posibilidad de seguir en el mercado laboral de manera estable. Estos tareferos en búsqueda de mejores horizontes, pueden relacionarse con otros contratistas "conocidos" que les ofrezcan mejores condiciones laborales, generándose de esta manera, rotación de personal no solamente para el productor, sino que también entre los mismos contratistas. 
Para el caso de estudio, tanto los contratistas como los trabajadores son de lugares cercanos a la localidad de Santo Pipó, incluso muchos de los obreros viven en barrios periféricos de esta localidad. Se movilizan a los yerbales de los asociados de la Piporé para realizar sus actividades laborales. Existen algunas empresas importantes socias de la cooperativa, ejemplo de ello son Mayerga, Madanto, El Rocío, De Coulon, que requieren de servicios de localidades cercanas como Jardín América, por ejemplo. Allí es donde se desplazan diariamente los contratistas con sus trabajadores.

Estos socios de la Cooperativa, productores, dueños de los yerbales, tienen la particularidad de ser descendientes de inmigrantes venidos de Alemania y Suiza, durante la década del 30 . Han colonizado de manera privada esta región de la provincia, comprando tierras y cultivando la yerba mate como principal medio de producción. Las superficies de las chacras que adquirieron fueron superiores a las normales para la época de las primeras colonizaciones públicas. Estas fueron diagramadas en lotes de cien hectáreas (Gallero, 2011).

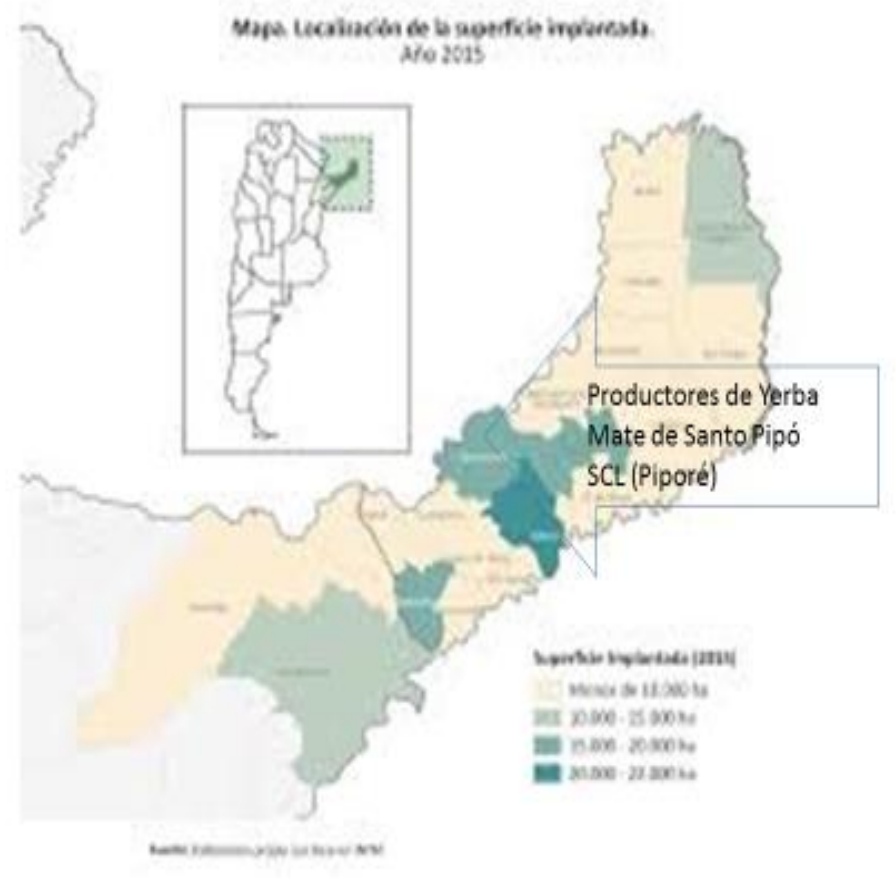

Figura 5: Ubicación de la Cooperativa Piporé

Fuente: (Anino, 2017) 
En la medida que se incrementaron las cosechas, los productores tuvieron que asociarse para lograr comercializar sus producciones, asimismo iniciaron la industrialización de sus materias primas. Así nace la Cooperativa Piporé en el año 1933. Estos productores que se asociaron, tenían algunas particularidades: profesionales de diversos rubros, universitarios, doctores, ingenieros agrónomos, ingenieros civiles, electromecánicos, comerciantes, agricultores. Varios de venidos del otro lado del mundo, llegaban a estas tierras con buen sustento económico, hasta algunos poseían financistas para costear las primeras plantaciones de yerba mate., aprovechando de esta manera el auge que poseía la yerba mate.

Ellos, fueron de diferentes maneras, cosechando las plantaciones de yerba mate, pero en su mayoría coincidían en realizar un corte de tipo tradicional característico. Algunos inclusive por influencia de empresas yerbateras, llegaban a ejecutar un modelo de cosecha "tipo mesa". Estas empresas, interesadas en la materia prima, a través de sus "compradores de yerba" se acercaban hasta los mismos productores prestando un servicio tanto de cosecha como asesoramiento promocionando "sus sistemas de manejo". Un ejemplo de ellos son las vastas incursiones realizadas por "Las Marías" en algunas empresas relacionadas a la Piporé por medio de sus negociantes, que buscaban imponer su metodología de cosecha (corte tradicional y corte mesa) de manera tal de que el material recolectado sea el que la industria necesitaba. Así que estos productores que vendían sus hojas verdes, copiaban en sus yerbales estos métodos de trabajos para poder comercializar su materia prima a las grandes corporaciones.

Hoy en día 60 socios están vinculados directamente a la Cooperativa Piporé, la cual es considerada una de las más importantes en la provincia de Misiones. La misma posee dos secaderos en Santo Pipó, con salas de estacionamiento, más un molino de fraccionamiento y envasado, en la misma ciudad. Además, es una de las principales exportadoras al mercado sirio y, por supuesto, el mercado interno con algunas marcas comerciales de renombre nacional. Los socios de la Piporé, no fueron ajenos a los vaivenes de la actividad yerbatera, para lo cual debieron embarcarse en otras actividades productivas de manera de diversificar sus producciones. Así comenzaron a aparecer las forestaciones, los sistemas ganaderos y alguna que otra actividad que el productor fue incursionando, todas ellas como complementos de actividad yerbatera.

Para caracterizar el modelo de producción yerbatera de esta cooperativa, se puede aclarar, que, cuentan con diferentes tipos de yerbales: los de baja densidad de plantas, 
con hasta 1100 plantas por hectáreas, estas son plantaciones antiguas (mayores de 50 años de edad), o también situaciones de yerbales de altas densidades, de entre 3000 a 4000 plantas por hectárea, estas últimas muchas más nuevas, con menos de una década de edad y con un potencial genético de rendimiento importante.

En esta región yerbatera, la cosecha se realiza de manera manual, con disparidad de modelos, algunos realizan las cosechas tradicionales, otros productores han ido modificando sus sistemas a la cosecha de rama madura. También están los que apuestan más allá, practican la cosecha semi mecanizada donde intervienen máquinas manuales, que realizan el trabajo de reducir el tamaño del material para él envió al secadero. Estos elementos, se vienen promocionando desde la década del 90, con relativa repercusión, muy asociado a la metodología propuesta por la rama madura y a las tijeras electrónicas o eléctricas.

En esta cooperativa, interactuarán productores, profesionales del sector público y privado, contratistas, trabajadores de la localidad de Santo Pipó como también de otras localidades muy cercanas como Helvecia, Gral. Urquiza y hasta Jardín América, todas ellas son proveedoras de mano de obra para la cosecha de la yerba. Otras instituciones también son parte del entramado que se forman en torno a la cosecha de la yerba, como, por ejemplo, empresas privadas que promocionan herramientas de corte, agrupaciones sindicales de trabajadores, que defienden sus derechos. Con lo cual el colectivo humano que se forma en esta región y el nivel de interacciones entre los diversos actores es muy variado, ya que no sólo están los productores o socios, sino que además hay agentes que vienen de otros lugares que poseen influencia en el territorio analizado, como, por ejemplo, técnicos de campo que asesoran a productores en Santo Pipó, pero viven en Puerto Rico o San Ignacio, o trabajadores que se mueven con sus contratistas desde localidades cercanas para realizar sus actividades laborales, o algunos productores asociados que viven en otras localidades. En fin, se generan una diversidad de interacciones en base a la actividad yerbatera.

Con el transcurrir del tiempo, en la localidad de Santo Pipó se abrió la agencia de extensión del INTA. A través de un contrato se pudo gestionar un técnico para esa región. Es allí donde el INTA, comenzó a tener presencia continua en esta parte de la provincia y los vínculos directos con la Piporé se fueron amalgamando cada vez más.

Pero volviendo al INTA de Santo Pipó, como actor en este complejo se puede decir que la finalidad que posee es la siguiente: 
"asesora y capacita a productores. Asimismo, realiza trabajos en experimentación adaptativa en el cultivo de Yerba mate, pro-Alimentos Programa Pro-Huerta y mandioca para consumo fresco. Trabaja en conjunto con la Cooperativa de productores yerbateros de Jardín América." (INTA, 2018).

En esta agencia de extensión rural, trabajan seis personas de los cuales solamente un técnico es el que se encarga de atender cuestiones relacionadas al cultivo de la yerba mate. Cabe destacar que esta agencia tiene delimitado su territorio de trabajo entre las siguientes localidades San Ignacio, Gobernador Roca, Corpus, Santo Pipó, Jardín América y sus respectivos parajes aledaños o colonias.

A pesar de tener injerencia en el territorio y en varias localidades, el mayor flujo de intercambio de trabajo se dio con la Piporé, por una cuestión de necesidad de parte de sus integrantes y la cercanía a la agencia. Se comenzaron a realizar experiencias en yerbales de productores, así empezaron a aparecer también trabajos de campo que propone entre otras cosas, a las diferentes formas de cosechar como parte de sus estudios. Los mismos fueron llevados a cabo por los ingenieros del INTA, no solamente de la Agencia, sino también de las Estaciones Experimentales de Montecarlo y Cerro Azul, estos en forma conjunta con sus pares de la cooperativa.

Con la aparición del INYM, Instituto Nacional de la Yerba Mate, en el año 2002, como participante del sistema yerbatero, comenzaron a generar vínculos con el INTA, a través de sus programas de intervención. Por medio del equipo técnico, se entablaron acciones en temáticas relacionadas a la producción yerbatera, manejo del suelo, de la planta y la cosecha de la yerba mate entre otras. En ese sentido el INYM a través de sus técnicos y en forma conjunta con los expertos de INTA, se fueron percatando de que la cosecha se tornaba un problema cada vez más frecuente para el sector de productores más pequeños. Con lo cual emprendieron diferentes estrategias para salvaguardar esas cuestiones relevantes para la producción primaria.

Describiendo al INYM y sus actividades dentro del complejo yerbatero, se puede decir que es un organismo que fue creado como consecuencia de la grave crisis que estaba sufriendo el sector yerbatero en su conjunto después de la eliminación de la Comisión Reguladora de la Yerba Mate (CRYM) y la consiguiente desregulación sufrida durante la década de los 90. La crisis de precio de la materia prima que provocó la disolución de este organismo, hizo que tanto productores como trabajadores y secaderos, salgan a levantar la voz de protesta. Consecuencias de estos movimientos sociales conocido 
como el "tractorazo" que se fueron suscitando con mayor avidez a finales del 2001, es que desde el Gobierno Nacional buscan una solución a este problema, con lo cual se logra por medio de la ley 25564/2002 la creación del INYM y por el decreto 1240/2002 se pone en vigencia este organismo (INYM, 2018)

Esta entidad nuevamente volvería a cumplir funciones semejantes a la antigua CRYM. Actualmente se lo conoce públicamente al INYM por la fijación de precios mínimos de ventas de la materia prima, tanto la hoja verde que vende el productor como así también la yerba mate que sale del secadero y va al molino. Además, posee la función, entre otras cuestiones, de controlar el negocio yerbatero.

Los valores de precios se fijan dos veces al año a través del voto de un directorio conformado por referentes de toda la cadena yerbatera, en esa mesa además del precio se tratan otras cuestiones de interés para dicho organismo y el sector yerbatero argentino.

El INYM, dentro de su formato de institución vinculada al sector yerbatero, convocó a la realización de un Plan Estratégico para el Sector Yerbatero Argentino 2013-2028 ${ }^{12}$. En este plan estuvieron involucrados, representantes del sector primario, de los gobiernos provinciales y nacional, de las universidades, viveristas, industriales, técnicos especialistas. A través de diferentes foros entre lo que están los siguientes:

$\checkmark \quad$ producción de plantines,

$\checkmark \quad$ producción primaria,

$\checkmark \quad$ molinería,

$\checkmark \quad$ comercialización.

Como fruto del trabajo de estas reuniones, por medio de debate e intercambio de opiniones y posturas, salió un documento consensuado entre los diversos grupos. Cabe dejar en claro que raramente, en la discusión del documento y la posterior elaboración participó el Registro Nacional de Trabajadores y empleadores Agrícolas (RENATEA). No se deja en claro en el documento la importancia de generar y fortalecer capacidades para el trabajador rural que debe realizar la cosecha y mantenimiento de los yerbales, con lo cual parece que este sector no pertenece a la cadena productiva.

Al margen del comentario surgieron diferentes propuestas para los sectores intervinientes. En el caso del eslabón primario de la producción algunos puntos relacionados a la cosecha y a los productores. A continuación, se mencionan algunas propuestas vinculadas al trabajo de investigación:

\footnotetext{
12 https://www.inym.org.ar/operador/plan-estrategico/
} 
$\checkmark$ El aumento de productividad de los yerbales de pequeños y medianos productores por medio de la implementación de pautas de manejo, tecnologías, con asistencia técnica, financiera y capacitación.

$\checkmark$ Implementar sistemas de cosechas que se adecuen a las condiciones del productor, como así también mejorar las condiciones de trabajo y la eficiencia de las cosechas a través del uso de tecnologías y capacitaciones (INYM, 2018).

Asimismo, el Instituto posee algunos programas de intervención que están relacionados a diferentes temáticas, como es el plan de mejoramiento de la cosecha. Programa que está en vigencia para aquellos operarios (productores, secaderos o contratistas) que busquen mejorar las condiciones laborales de sus empleados. Con lo cual el objetivo que se persigue con este beneficio, tanto para el contratista, pero más para el trabajador, es mejorar las condiciones de trabajo de estos últimos, buscando una disminución del esfuerzo físico que deben realizar los operarios, tanto para extraer las ponchadas o lienzos cargados con yerba mate, como así también las cargas de estas en los transportes.

Por medio de este plan y a través del financiamiento del INYM se pueden adquirir guinches, para cargar la materia prima (hoja verde en las ponchadas o raídos) a los camiones de transporte, carritos de arrastre para los obreros, estos últimos son utilizados para el transporte de las bolsas con yerba desde los lineos (interior del yerbal) hasta los extremos donde posteriormente se pesan y son cargados a los camiones de transporte. De esta manera se disminuye el esfuerzo físico que debe realizar el trabajador rural, estando en el yerbal mientras dura la cosecha. Hay que recordar que es el mismo tarefero, el encargado de sacar sus "raídos" con sus propias fuerzas, desde los entre líneos de cosecha hacia los extremos para su posterior pesaje. También una de las tareas asignadas, es que debe ayudar a cargar en el campo los raídos en el medio de transporte y descargar el mismo en los secaderos con las ponchadas llenas de hoja verde.

Para poder acceder a este beneficio que se promueve desde el INYM, hay que cumplir una serie de requisitos. En primer lugar, debe ser prestador de servicio de cosecha, contratista, productor o bien secadero. Para el caso de los prestadores de servicios de cosecha y flete, estos deben entregar más de 300.000 kilogramos por zafra yerbatera. Asimismo, se debe realizar un pedido a través de una solicitud formal de inclusión, en la cual se detallan las cantidades de guinches y carritos de arrastre que se 
solicitan. Según datos del INYM durante el periodo 2010-2015 se entregaron 200 guinches y 500 carritos de arrastre.

Otra de las propuestas que posee el Instituto, es el programa de compra de tijeras automáticas, con el cual, según cita la finalidad del mismo, busca mejorar las condiciones laborales de los cosecheros y hacer más productiva la cosecha de la yerba $^{13}$ a través del financiamiento de la compra de estas herramientas. Es un programa adaptado al sistema de corte de rama madura. En los sistemas tradicionales, estas innovaciones quedan descartadas, porque el trabajador necesita solamente una tijera de mano y eventualmente algún serrucho, con lo cual este mecanismo de financiamiento y ayuda al sector, está orientado a aquellos productores medianos a grandes, o contratistas que buscan agregar innovaciones a la cosecha.

En este programa en particular, esta explicitado que los beneficiarios de las compras de las tijeras, es decir productores, contratistas o asociaciones de productores, deben asistir a un curso de capacitación certificado de manejo de las herramientas como condición sine qua non para acceder al beneficio.

Otra línea de trabajo, es el plan de apoyo a los trabajadores de la cosecha de la yerba mate. En el mismo se brinda indumentaria de trabajo a los cosecheros que se encuentren en blanco. Este proyecto es discontinuo en el tiempo, esta acción busca dignificar al trabajador y mejorar la cosecha.

En el INYM, se encuentra el Programa de Asistencia al Sector Yerbatero (PRASY), quien tiene a su cargo las instancias de formación, capacitación y seguimientos de programas vinculados al sector productivo yerbatero. El Programa de Renovación de Yerbales Degradados ${ }^{14}$ conocidos como los " $3 \times 1$ ", promueve la sustentabilidad del sistema yerbatero primario. Está orientado para productores muy pequeños, dentro de la propuesta, se plantea a la cosecha rama madura como un medio para lograr ese objetivo.

Asimismo, existe un reconocimiento por parte de este organismo, a aquellos productores que apliquen prácticas de manejo innovadoras y sostenibles con el medio ambiente. Entre ellas se encuentra el sistema de manejo de rama madura. El premio

\footnotetext{
${ }^{13} \mathrm{ttp} / / / w w w . i n y m . o r g . a r / 2017 / 12 / 07 / e l-i n y m-p o n e-e n-m a r c h a-e l-p r o g r a m a-d e-t i j e r a s-$ automaticas/

${ }^{14}$ Este programa plantea la renovación de yerbales degradados, en el cual el INYM propone realizar una hectárea de plantación nueva a cambio el productor deberá dejar de utilizar tres hectáreas. De allí su nombre vulgar (3x1) el paquete tecnológico lo propone INYM y el productor debe aplicarlo con el seguimiento en forma conjunta de técnicos del INYM y de INTA.
} 
estímulo se denomina el "Buen Productor Yerbatero" ${ }^{15}$ y está vigente desde el año 2013. Los productores distinguidos son propuestos por el Área Técnica del INYM y evaluados por el Directorio de la institución, que año tras año promueve este tipo de incentivos.

El área técnica del INYM se vincula estratégicamente con el INTA y sus agentes de extensión, en algunos casos con técnicos del Ministerio del Agro de Misiones (técnicos contratados por el Departamento de Yerba y Te pertenecientes al Área de Desarrollo y Producción Vegetal), para todos aquellos trabajos que tengan relación con la extensión, difusión, capacitación y promoción de estrategias de manejo sustentable del sistema productivo primario.

\footnotetext{
15 iniciativa que establece reconocer a productores que se destaquen por aplicar prácticas de manejo de planta y suelo que contengan principios innovadores basados en condiciones de sustentabilidad. La iniciativa, denominada "Buen Productor Yerbatero", se orienta a distinguir aquellas chacras con plantaciones de yerba mate que puedan servir de modelos productivos, independientemente de la superficie, ubicación y nivel tecnológico o mecanización aplicada.
} 
CAPÍTULO 5: TODOS LOS AÑOS “LA PROBLEMÁTICA” DE LA COSECHA 


\subsection{Todos los años "la problemática" de la cosecha}

La cosecha de la yerba es la etapa en la cual se puede ver el resultado del trabajo del año. Los yerbales, pueden reaccionar de diversas maneras, ya sea por los eventos climáticos o por el manejo realizado por el dueño. En esto último tiene importancia el momento de la cosecha, la forma en que se realiza, malas intervenciones provocan efectos negativos en el crecimiento de las plantaciones. Además de las otras tareas culturales que influyen en el sistema productivo, como ser: el manejo de las plagas, enfermedades y las plantas competidoras de la yerba mate, la reposición adecuada de los nutrientes en los lotes de cosecha. Con lo cual no es menor el hecho de tener que, necesariamente, cuidar a las plantas de yerba mate de manera de sostenerlas productivas en el tiempo.

Cada yerbal es un mundo diferente. En el sector los productores yerbateros, aun cuando se desarrollan semejantes sistemas de cosechas, cada uno tiene pequeños matices que lo hacen particular. Cada dueño le pone una característica que lo hace diferenciar de sus vecinos productores. Hasta los mismos trabajadores perciben que en cada chacra, los dueños ponen su impronta o aplican su "librito" de poda. Son ellos, los productores, que proponen el modelo de cosecha.

"ellos nos dicen que debemos hacer" Entrevista a un tarefero

"son los dueños los que nos dicen como cortar" Entrevista a contratista

O son los técnicos de campo, contratados por las empresas o extensionistas, que visitan los yerbales, antes de comenzar el trabajo, aunque siempre no se cumple este requisito. Estos son los que llegan a dar las indicaciones del trabajo a realizar al capataz o al grupo:

"antes de empezar viene el ingeniero y nos muestra cómo tiene que ser" Entrevista a trabajador

Asimismo, las diferentes incursiones de las empresas compradoras de yerba mate, fueron instalando sus modelos de cosecha en diferentes sectores de la provincia; Santo Pipó, no escapó a ese movimiento. En las entrevistas con los tareferos, estos recuerdan los distintos métodos implantados en los yerbales de la zona de estudio, tal es el caso del corte mesa. Así quedan en los recuerdos, de los entrevistados, aquellos capataces, 
que controlaban casi de manera autoritaria que el corte se realice de esa manera y no de otra.

"andaba el capataz de la empresa con una regla, con la medida, el que no cumplía le echaba directamente de la chacra" Entrevista con un trabajador

"acá se hacía el corte mesa, cuando venía Las Marías" Entrevista a un trabajador.

Con las diferencias en el manejo productivo de las chacras, tantos técnicos públicos, privados y algunos productores profesionales, comenzaron a verificar que sus lotes de yerba mate empezaron a demostrar signos de degradación, con disminución de los rendimientos. En forma conjunta técnicos del INTA como así también privados, comenzaron a verificar que los yerbales estaban en declinamiento, disminuyendo sus rendimientos, consecuencia no sólo de las actividades realizadas por el productor con relación al cuidado de sus explotaciones yerbateras, sino que también a las abusivas cosechas realizadas utilizando los métodos tradicionales.

Percatándose de esa situación de desgaste, los profesionales (técnicos investigadores) dieron el puntapié inicial en el desarrollo de propuestas técnicas para el sector. Se empieza así a caminar en el sistema de cosecha de la rama madura para la yerba mate. Esta senda se plasma a continuación en la siguiente figura:

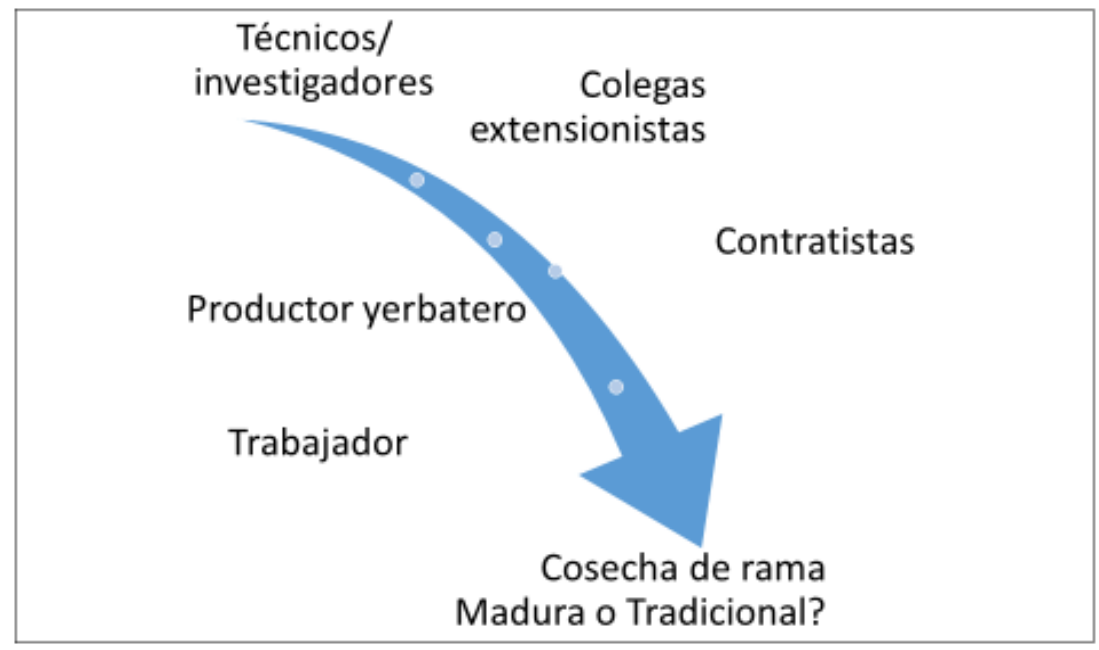

Figura 6: Camino de la puesta en marcha de la rama madura Fuente: Elaboración propia en base a entrevistas y observación en terreno 
Entonces se empieza a transitar, (con el consentimiento de algunos yerbateros profesionales) el camino de la experimentación a través de diferentes pruebas de cosecha y de manejo en general de los lotes de yerba mate. Estas se arrancaron por la década del 90 aproximadamente, fue en ese entonces donde empezaron a poner en dudas al corte tradicional y se comenzó a trabajar en otras opciones de cosecha que acompañen a la labor que debe hacer el dueño del campo. En ese momento, se daba inicio a una empresa familiar de ventas de tijeras eléctricas, iniciativa de un ingeniero agrónomo, socio de la Piporé, que proponía el uso para la cosecha de nuevas herramientas. Estas, las tijeras electrónicas, que van de la mano de la rama madura y la semi mecanización. Esto fue un punto de inflexión clave para el posterior desarrollo de investigaciones a campo realizadas en la región de la cooperativa relacionadas a la rama madura.

Es así, como casi a finales de los 90 , se proponen a la rama madura como una alternativa de cosecha manual para productores pequeños y medianos yerbateros. En ese momento no existía el INYM, entonces la iniciativa la tomo el INTA y sus técnicos, que iniciaron un proceso de trabajo no solo de investigación, sino que además de extensión hacia los productores en general. Son los que iniciaron el proceso de "interesamiento" de colegas y demás actores del sistema. Recién a comienzos del 2002, el Instituto Nacional de la Yerba Mate, se suma a la carrera de promover el uso de la metodología de cosecha como la opción para los yerbateros en general.

A través de diferentes pruebas a campo, o en las estaciones de INTA, los mismos investigadores fueron demostrando a sus colegas extensionistas, las bondades de la rama madura. Se dieron jornadas de campo en las experimentales, para buscar aliados y demostrar que la rama madura estaba siendo una alternativa para el sector. Casi de manera simultánea, algunos técnicos socios de la Cooperativa Piporé, también dieron paso hacia la puesta en campo de las metodologías de cosecha de rama maduras, con el adicional de la aparición de las tijeras eléctricas, que se fueron complementando a este modelo. Así se fueron sumando productores, que cedieron lotes para poder "probar" en los yerbales el desempeño de estas nuevas formas de cortes y empezaron a aparecer los lotes demostrativos de cosecha de yerba mate.

Estos lugares fueron tomados por los técnicos (INTA y algunos privados aliados de las tijeras), como una herramienta más para demostrar a los demás colegas y socios de la cooperativa, que el manejo de los yerbales y las formas de realizar los diferentes 
cortes de la poda de rama madura son muy relevantes para el sector primario y que esta práctica ocupa un lugar importante en este esquema.

Algunos yerbateros, se estaban poniendo en línea con las novedades en la cosecha manual de rama madura. Casi como de la mano de los productores, los servicios que proponían los contratistas, se fueron sumando a estas innovaciones de cosecha. Empezaron a ver que sus rindes de recolección se incrementaban. Esto fue un incentivo para estos actores, algunos de los cuales comenzaron a "enrolarse" en la práctica de la cosecha de rama madura.

Los trabajadores, juntos con los productores, dependen casi de manera directa de la yerba mate. En los primeros, sus ingresos semanales están ligados a los kilogramos cosechados en los yerbales, en los segundos dependen de los que produce en las plantaciones y de los volúmenes que entregan en el secadero. Con lo cual, en teoría debería existir una alianza estratégica, entre productores y trabajadores, unos. a través del cuidado de las plantaciones y otros en el cuidado de la cosecha, de manera de que ambos se alinean para aprovechar estas simbiosis que se manifiesta en la cosecha de la yerba mate. La recolección de la yerba mate, es el final de un ciclo de trabajo, independientemente del tipo de cosecha que se realice. Es aquí donde ambos ganan.

Desde los I+D promueven a la rama madura como el sistema que mejor funciona, sus argumentos se basan en pruebas realizadas en campos de productores y trabajo de más de diez años de investigación. Pero en la realidad, en el sistema productivo primario, se nota relativa aceptación de la rama madura. Con lo cual deben existir intereses contrapuestos entre los diversos actores, algo o alguien que tracciona para el sentido contrario a la rama madura. No dejando, por diversos mecanismos, que se establezcan alianzas entre actores (productores-trabajadores; productores-contratistas; Contratistas-Trabajadores; I+D-Trabajadores; entre otros).

Ahora bien, se pueden manifestar diferentes situaciones que pueden llegar a obstaculizar la instalación de la cosecha de rama madura en el sector productivo. Estas se revelan en el siguiente cuadro: 


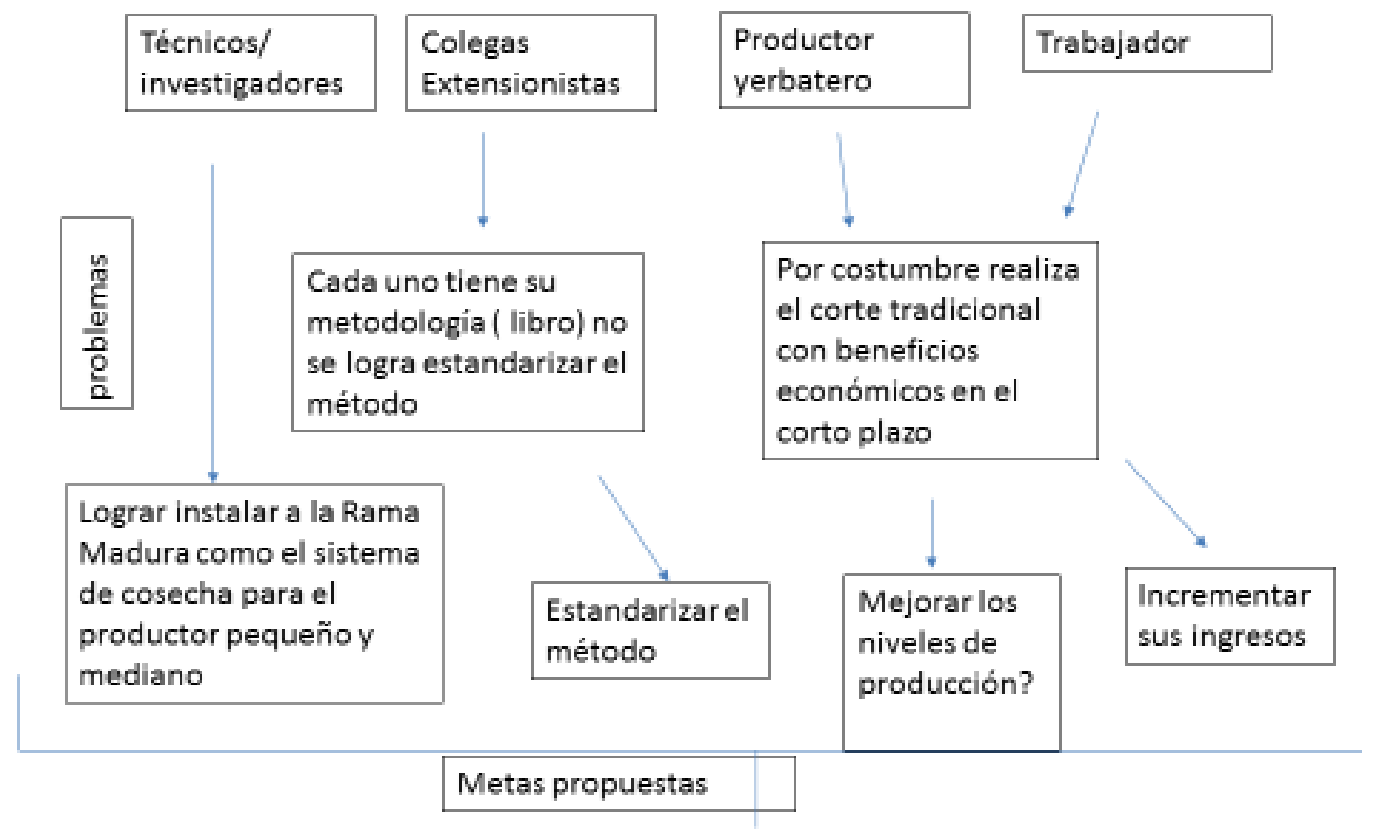

Figura 7: Actores y sus problemáticas

Fuente: Elaboración propia en base a entrevistas

Los técnicos que están convencidos del sistema, proponen este método como una "salida" para el sector de pequeños productores yerbateros. En la misma línea se encuentran los colegas extensionistas. Cada uno transmite y aplica su propio sistema de cosecha, pareciera que cada referente actuara su propio "librito" de cosecha, en donde dicen qué, cómo y cuándo, realizar las tareas de podas. Están los que siguen el libro de podas de Valentín, o de Néstor, o de Oscar o el de Marcelo. Esto provoca en cierta medida que el método no se estandarice. Incluso algunos colegas plantean diferencias en los nombres de los materiales o partes de las plantas, que se cosechan, complicando aún más el trabajo en el terreno. Sobre todo, cuando se habla en jornada de campo o reuniones técnicas entre los extensionistas y técnicos privados que se vinculan a la yerba mate.

En relación al productor y el trabajador, entran en juego escenarios que obstaculizan la instalación de la rama madura, como la costumbre de realizar de una determinada manera, la cosecha de los yerbales. Lo que se podría llamar la "herencia ${ }^{16 "}$ del tarefero,

${ }^{16}$ En el sentido del aprendizaje que tuvo el trabajador desde muy chico, yendo con sus padres a realizar los trabajos en los yerbales. 
considerando que es el operario el que está acostumbrado a realizar la cosecha tradicional, debiendo incorporar a su trabajo, la aparición de nuevas herramientas (serruchos ${ }^{17}$ o tijeras eléctricas ${ }^{18}$ ) que entran en juego en los nuevos sistemas propuestos. Sumado a esto, la cosecha tradicional proporciona ingresos anuales por el tipo de recolección que se proyecta. Este último condiciona tanto a los trabajadores como al dueño, ya que, en el inicio de la cosecha de rama madura exige no cosechar por un año en el siguiente periodo, se puedan realizar los pasos propuestos por el método, con lo cual muchos no quieren correr ese riesgo. Esto favorece sustancialmente a la cosecha tradicional, que busca todos los años levantar la yerba sin dejar de cosechar. Emergen así dificultades en el proceso de "traducción", no se logra la convergencia en la red sociotécnica.

Las metas propuestas por los que promocionan a la técnica buscan instalar el método de podas de rama madura como un sistema, estandarizar el método para su posterior aplicación, como también mejorar los niveles de producción de los yerbales y de esa manera incrementar los ingresos para el productor y los trabajadores. Entonces se deben poner en marcha una serie de mecanismos que lleven al sistema de cosecha propuesto a ponerlo en el sector como "la alternativa". Con lo cual los promotores de la misma deben realizar ese esfuerzo tanto en el ámbito de trabajo con los productores como también en los demás sectores (actores) involucrados.

\footnotetext{
${ }^{17}$ En entrevistas a trabajadores se ha detectado que estas herramientas producen fatiga a los operarios que deben estar entre 8 a 9 horas por día.

${ }^{18}$ Promocionadas por el IMYN como instrumentos para el trabajo de cosecha de rama madura
} 
CAPÍTULO 6: LOS PROMOTORES ENTRAN EN ACCIÓN. 
Con las situaciones que se manifiestan en el cuadro anterior y cotejadas en el campo, (es decir, prevalencia de sistemas tradicionales de cosecha, yerbales con degradación del sistema de producción, trabajadores cosechando de manera tradicional) los técnicos investigadores o promotores de la rama madura, deben poner a funcionar diversos mecanismos para que lleguen a despertar el interés al resto de los actores, considerando la propuesta de la rama madura como la más viable para el sector.

En ese sentido, a través de diferentes acciones los investigadores y promotores de la técnica buscan relacionarse y alinear al resto de los actores involucrados. Los abanicos de estrategias utilizadas van desde instalaciones de módulos de trabajo, a nivel Estación de Experimentos de INTA hasta también explotaciones de productores de la Cooperativa, que consideran válida la propuesta y se logran alinear en forma casi espontánea. En estos lugares de prueba, se van ajustando las diferentes prácticas en el terreno, de manera de no dejar nada librado al azar. Analizan a través de los años, el comportamiento del sistema de producción, relevan datos de cosecha año tras año e inclusive se comparan con los otros sistemas de cosecha disponibles en el sector. Se analizan la evolución de la producción de los lotes de yerba mate y también el porcentaje de aporte que realiza cada etapa de la rama madura; ejemplo: la viruta 15\%, la limpieza $5 \%$, el corte de la rama madura $50 \%$, el raleo de las ramas verdes $5 \%$ y el mborevi $25 \%$.

Los trabajos en las explotaciones de productores, se toman como base de referencia de investigación a campo para el resto del sector productivo ligado a la Cooperativa Piporé. En ese sentido, tanto estos ingenieros promotores de terreno, como también algunos investigadores, tratan de aliar a sus pares buscando convencerlos de que, la rama madura es una buena opción para el sector. De esa manera; ponen a la metodología de cosecha nueva en la agenda de los técnicos, buscando siempre dejar planteado que es un sistema que mejora sustancialmente los índices de producción. En sus trabajos de investigación, en los Institutos de ciencia y en las chacras experimentales, se promueven desde la práctica y el discurso, la mejora de la rentabilidad, junto con el cuidado del suelo para así lograr una mejor cosecha, de esa manera los yerbales incrementan sus rindes todos los años.

Los promotores, tratan de poner en evidencia que la cosecha tradicional es responsable en parte de los limitados rendimientos de los yerbales, esto sumado a otros factores que se relacionan con el cuidado de las plantaciones. Buscan, los inspiradores de la nueva modalidad, demostrar las bondades del sistema, que se fundamentan en las mejoras de las ganancias por hectárea y como consecuencia directa el incremento 
en los réditos unitarios, beneficiándose así a los productores, los contratistas y sus trabajadores. El argumento utilizado de los que buscan alinear a los actores en la metodología de la rama madura, es el mismo, es decir, mejoras sustanciales en los rindes y su resultado directo, en los ingresos.

\subsection{Cómo enrolan a los demás actores}

Los iniciadores de la técnica que la tienen estudiada y desarrollada en el campo aseguran tener éxito en las plantaciones con la rama madura, ya que el impacto en el incremento en los niveles de producción es notorio. Estos ingenieros, promotores de la metodología, están constantemente, trabajando para llegar a convencer a sus colegas investigadores y extensionistas, de los buenos resultados de la rama madura, en los trabajos en campo. Buscan trasmitir esos logros a través de presentaciones en congresos, jornadas técnicas, científicas, resultados de sus prácticas en los centros de I+D.

Se plantean técnicamente, cuestiones que tienen que ver con el sistema de podas, aseveran que se asegura la producción venidera en calidad y cantidad. Esta tecnología incrementa el volumen de hoja verde en el tiempo, es de baja utilización de insumos externos $\mathrm{y}$, con manejo adecuado de las podas, los rendimientos se incrementan ${ }^{19}$. A través de algunas reuniones en las dependencias INTA, se pone en la mesa de trabajo al modelo rama madura, con una sensibilización previa donde se visualiza el estado de las plantaciones y la relación con la metodología de manejo, pero principalmente el modelo de cosecha que se propone.

En los resultados de trabajos hechos en situaciones de campo (experimentación en yerbales de productores/ ingenieros) se plasma el método como parte de un paquete de medidas que debe ser utilizado para asegurar el éxito. Cuando se logra estabilizarlo, siguen por otros colegas, captan la atención de estos y llegan a completar el universo de ingenieros estatales que conocen a la rama madura. Esto se puede obtener, por la disposición espacial de las agencias de INTA en el territorio, que permiten llegar a prácticamente toda la región yerbatera argentina.

No solamente, van por los extensionistas del INTA, sino que los promotores, alinean a los técnicos del INYM, que en poco tiempo ya usan el vocabulario propio de la rama madura, logrando los inspiradores, de esa manera, entrar al Instituto de la Yerba Mate,

\footnotetext{
${ }^{19}$ En ese sentido coinciden, Burtnik (2006), Kurtz (2011) y Mayol (2011).
} 
promoviendo a la nueva forma de cosechar. En el organismo, se instala el sistema, con un discurso que incluye a la rama madura, como un modelo acorde al sector. Incluso, el uso de estas prácticas por parte de los productores, es premiada y pasan a ser parte de los programas de intervención del organismo.

A través sus planes de intervención técnica, es el mismo INYM el que ahora lleva la bandera de la rama madura, con el programa de renovación para viejos yerbales de pequeños productores, con un paquete transferencista ${ }^{20}$ de medidas, que incluyen asesoramiento técnico a grupos de pequeños productores, recetas claras de implantación de los yerbales nuevos, aplicación de toda una gama de insumos que asegura la correcta instalación de los nuevos modelos productivos. La práctica de la rama madura busca llegar a todos los productores minifundistas de la región, por medio de las reuniones técnicas que se organizan en los grupos de trabajo, siendo estas abiertas para los que deseen ser parte, intentando socializar a la metodología de cosecha.

Este plan, conocido como $3 \times 1^{21}$, plantea la posibilidad de armar grupos, proponer un paquete tecnológico y contratar a un técnico para asesorar el grupo. Los técnicos privados, apadrinados por los ingenieros del INTA o INYM, forman conjuntos de productores yerbateros de semejantes características sociales, económicas y productivas. Trabajando primero desde la teoría, analizan diferentes situaciones que se dan en el terreno, técnicamente proponen alternativas para estos grupos. Pero ahora son los ingenieros públicos, los que deben alinear a los privados como parte del programa del INYM. Se multiplican las reuniones de los " $3 \times 1$ ", en las que los privados y yerbateros, van a ser el objetivo de los ingenieros promotores; buscando que se alinean a esta nueva modalidad. Con este despliegue estratégico utilizado con los otros colegas, son los mismos promotores los que presentan en el campo a la rama madura con sus virtudes.

\footnotetext{
${ }^{20}$ Modelo desarrollado por Rogers (1955), de carácter rectilíneo, donde la información se genera por los que investigan y los receptores solamente deben aplicarla. Las innovaciones siempre son buenas. Las estrategias de convencimiento pasan por el aumento en la producción y la mejora en sus ingresos.

${ }^{21}$ Plan de reconversión para yerbales degradados del INYM: metodológicamente se trabaja con grupos de hasta 10 productores que tienen menos de 10 hectáreas, con rendimientos promedios por debajo de la media provincial. Con situaciones de degradación de sus yerbales, ya sean por la misma edad de las plantas, manejos inadecuados. Buscan con el plan reconvertir tres hectáreas "viejas" en una hectárea" nueva" con buena genética y manejo del sistema. Para lo cual el INTA con el INYM realizan el seguimiento de estos grupos con el apoyo técnico correspondiente.
} 
En el mismo Instituto, se alinean e investigan por diferentes caminos como establecer al sistema de cosecha. Los grupos del programa de reconversión yerbatera $(3 \times 1)$ son una alternativa, otra forma es a través de un reconocimiento público a los productores yerbateros que han trabajado de manera "correcta" en sus explotaciones. Plantean un premio estímulo al mérito como "Buen productor del año", que lo entrega el INYM a aquellos productores yerbateros que se han destacado en el manejo de sus yerbales, dentro de los cuales la rama madura, es un componente primordial.

Lentamente comienzan a aparecer los productores yerbateros, quienes ahora deben enrolarse con la nueva cosecha. Entonces los mismos ingenieros a través de jornadas técnicas a campo, en algunos casos organizadas entre el INTA y el INYM, o solamente desde el INTA, tratan de captar la atención del actor "productor yerbatero". En las jornadas de capacitación, el discurso que se utiliza para captar el interés de los productores se refiere a la mejora en los rendimientos y ser parte del manejo de las buenas prácticas de cosecha. Los mismos promotores que han analizado la cosecha en relación a los diferentes pasos que la componen, se manifiestan esta manera a través de sus discursos:

"la rama madura y mborevi produce el $75 \%$ de los kilos de la planta,...... en cambio la limpieza, raleo de verdes, virutas producen el $25 \%$ de los kilos de la planta" Entrevista a técnico promotor

De esa manera el público que participa, se lleva una mirada técnico productiva del método de poda. El objetivo de los promotores es justamente demostrar con números cómo influye cada actividad y cuál es su importancia dentro de la rama madura. En estas jornadas se utiliza el método transferencista de extensión, y además de demostrar los beneficios económicos a los dueños, los promotores no plantean casi ninguna variable de negociación con el productor

"no hay que negociar con el productor después le va mal y la culpa es tuya" Entrevista a referente técnico

Estas jornadas en general son masivas y abiertas, asisten productores en su mayoría, aunque también estudiantes e hijos de yerbateros. Es muy raro ver trabajadores, salvo algunos capataces de cosecha de mucha confianza del dueño. Desde lo Metodológico, se realiza en general una presentación con fundamentos teóricos, esto puede hacerse en algún salón o lugar acondicionado para la misma; se 
suelen utilizar dependiendo del lugar, computadoras portátiles con proyector o también láminas que muestran la poda de la planta.

Seguidamente se suele realizar una demostración a campo a través de la práctica con diferentes plantas de yerba. En estas actividades se pueden ver in situ los errores más frecuentes, que son remarcados por los técnicos que dan su visto bueno o no al corte que realizan los asistentes. Los técnicos tienen en claro que es importante hablar el "idioma" de ellos y demostrar "qué y cómo hacer". Conocer bien la técnica de trabajo para que el productor pueda entender lo que se quiere transmitir, saber bien qué ramas hay que sacar y cuales se deben dejar, reconocer en detalle a las cinco variables y sus posibles modificaciones. De manera que el asistente a la jornada o reunión sale con una aproximación muy certera de la aplicación del sistema.

Para los técnicos, es importante que el productor conozca bien el método para no mostrar flaqueza en sus conocimientos; corriendo el riesgo de que el trabajador, imponga sus metodologías de trabajo.

Los tareferos, dicen al respecto:

"cuando estamos en la yerba, enseguida nos damos cuenta cuando el patrón no sabe de lo que está hablando" Entrevista a trabajador

La Cooperativa Piporé, no escapa a esta metodología de intervención, las jornadas son convocadas por los ingenieros promotores, de forma masiva para los yerbateros. En ellas se busca "bajar línea", tratando de explicar los "por qué" de las diferentes intervenciones. A pesar de la imposición que se pretende de la metodología, expresan que se debe consensuar entre el ingeniero y los productores, unos vienen de las ciencias y los otros de la práctica, como si hubiera allí un doble discurso.

Ese pequeño equipo técnico de la rama madura en la Piporé, además de buscar capacitar a los yerbateros, atiende consultas puntuales de socios de la cooperativa. En ese sentido, las visitas a los yerbales se inician al comienzo de la cosecha o durante la zafra yerbatera. Estas pueden ser más o menos frecuentes en relación a la solicitud que requiere el productor, el nivel de aceptación y la confianza que existe. Desde lo discursivo, el rendimiento y sus formas de obtenerlo, es el aliado clave a la hora de presentar a la rama madura.

Con respecto a lo metodológico, en las intervenciones durante la cosecha se realizan de diversas maneras: el técnico promotor de INTA o su colega de la Cooperativa, 
muestra el método en el terreno cortando algunas plantas de yerba mate. Explican los motivos y porqué se realizan las diferentes intervenciones, de manera de no dejar espacio a dudas sobre los diferentes pasos o parámetros que se deben tener en cuenta desde lo técnico para realizar el trabajo de poda. Esas demostraciones prácticas pueden estar dirigidas tanto al productor como también al capataz de corte, en algunos casos también participan los trabajadores. Esta actividad, puede realizarse al inicio de la zafra, antes de ingresar al lote de yerba mate o después de iniciada la cosecha. En este último caso, tratan de ir corrigiendo el sistema de poda a los trabajadores, siempre tendiendo a la rama madura.

Cuando se realiza la demostración al grupo de trabajadores, estos observan atentamente cómo se realiza el trabajo. Se plantea una charla previa un día antes de arrancar la actividad, en el mejor de los casos, en ella se define cómo se va a trabajar, qué tipo de corte se pretende realizar. Para ello el capataz de corte de cosecha es quien debe atender y entender lo que se plantea. Esta charla previa generalmente teórico/ práctica, la da el técnico asesor de la empresa, que toma el mando de la cosecha y explica asuntos administrativos, cuestiones relacionadas al trabajo de campo, en qué lote se va a iniciar el trabajo, cómo van a ser los horarios, cuestiones que tienen que ver con el mantenimiento y el orden del lugar de trabajo. A veces se trabaja solamente con el prestador de servicio, después en terreno con el resto del personal de campo.

Una vez que se ha realizado la mencionada demostración e inclusive elegido el lugar de inicio de cosecha se comienza con los trabajos. Es el técnico promotor, quien muestra las diferentes tareas a realizar. Es una actividad que no lleva más de dos horas y luego el equipo se marcha a otro lugar, quedando el productor y el mismo capataz al mando del desarrollo de la técnica, en su explotación.

Cuando se trabaja con productores más chicos, la situación es un poco diferente: pueden ir los asesores de INTA a demostrar cómo hacer el trabajo o bien es el mismo productor, junto con el capataz o jefe de la cuadrilla, muestra el tipo de trabajo que se quiere hacer. En general el dueño ya tiene "su" planta que la usa de modelo, donde el patrón realiza el corte que quiere que hagan en sus lotes de yerba. Esto pasa en general al inicio de la cosecha en donde se reúnen, patrón y trabajadores. El dueño pone las condiciones en la que quiere que se realice el trabajo de cosecha y demuestra en una planta de yerba como debe quedar la labor. Luego de esto, los trabajadores comienzan con la tarea, quedando a cargo del capataz de cuadrilla o del contratista la ejecución de 
la tarea, es este último quien debe rendir cuenta al dueño de las actividades que se realizan en los diferentes lotes.

En el terreno con la intervención de los promotores ingenieros, donde se plasman los fundamentos de la metodología de cosecha de la rama madura, el lenguaje común utilizado, busca conciliar el tipo de trabajo con los trabajadores o capataces de corte quienes se manifiestan con frases de este tipo:

"muchachos, ustedes saben un poco, nosotros otro poco y entre los dos si nos juntamos, sabemos mucho" Entrevista a técnico

Con esa frase "se busca romper el hielo" y dar inicio a la charla con los trabajadores. Se nota la distancia que separa a cada uno de los actores que intervienen en estas jornadas, quienes buscan defender su posición, el técnico "es el que sabe". Se va dando la siguiente interacción: El técnico del INTA habla, muestra y demuestra en el terreno qué cosas deben hacer los operarios, en las plantaciones de yerba que van a ser recolectadas, mientras que el trabajador escucha. Al final de la charla, queda girando en el aire la frase "... cualquier cosa nos comunicamos..." como un gran signo de pregunta.

Algunas veces es el mismo dueño que hace de instructor de cosecha, manifestando a los trabajadores qué labor se va a realizar. El método es el mismo, a través de una planta modelo demuestra el tipo de trabajo a realizar cuando se poda la yerba. Tratando de enseñar y establecer un modelo de cosecha en sus trabajadores.

“yo aprendí con mi patrón a corta yerba" Entrevista a trabajador

"El Sr Fulano me enseñó a tarefear en sus yerbales..." Entrevista a trabajador.

“después que aprendimos a cosechar aparecieron los ingenieros". Entrevista a trabajador

El mismo promotor del INTA, junto con otros colegas, en las diversas oportunidades que se le presentan, ponen de manifiesto la comodidad de trabajar en este sistema, donde el operario va a tener que hacer menos cortes con las herramientas propuestas por la técnica, pero con más kilogramos de hoja cosechada. Se vuelve, desde lo discursivo, sobre la relevancia del rendimiento o producción y su relación con el sistema de corte en la planta de yerba, además del trabajo en sí mismo que debe hacer el tarefero. De ese modo, se pretende demostrar el menor esfuerzo o la disminución en la intervención que debe hacer el operario en la planta. Cuando se exponen las bondades 
al sector trabajador se hace referencia, no solamente al incremento en sus ingresos, porque se acrecientan los kilos cosechados, sino la posibilidad de jerarquizar sus trabajos, incluso hasta de cambiar el nombre al trabajador, dejar de ser tarefero para pasar a ser podador.

Otros productores que están dentro de la Cooperativa, pero que miran con recelo a la rama madura, son captados por el equipo promotor para lo cual se realiza un verdadero despliegue de jornadas técnicas con muestras de las bondades de la rama madura. Allí se pueden observar sus principales virtudes y explican por qué debe ser el método a utilizar por parte de los productores. Van adicionando estrategias, demostrando a través de los resultados económicos y productivos de las explotaciones de los socios (chacras demostrativas de la rama madura) que se convencieron del método. Tratando siempre de aclarar que la poda de la yerba mate, es importante.

"la cosecha, es el punto culminante del trabajo que hace el productor, es ese momento donde se evalúa el trabajo de todo el año, hay que debe darle la importancia que se merece" Entrevista con referente técnico

Además, llevan a la discusión y puesta en escena al problema que se genera con la cosecha tradicional, tomando a la disminución de los rindes, como el principal inconveniente. Hacen hincapié en las diferentes maneras que tiene la rama madura de contrarrestar ese problema; la poda de la rama madura deja en planta un $30 \%$ de material verde y la utilización de herramientas adecuadas para el corte, mejora en el cuidado del yerbal. Relacionan a la poda de ramas con el sistema productivo haciendo uso de estrategias para el manejo de las "malezas, plagas y enfermedades" de manera de promover en su conjunto una buena práctica de cosecha; buscan de diversas maneras formar aliados (yerbateros), convencidos de que la cosecha "nueva" es mejor que la anterior.

Tal como sucede con los yerbateros, son los mismos técnicos promotores que buscan otras asociaciones, para lograr que se establezca de una vez a la rama madura. En ese sentido realizan una serie de eventos destinados a "capacitar al resto de los colegas públicos y privados" de manera tal de que, a través de esas instancias, los argumentos técnicos de la rama madura busquen convencer al "grupo de técnicos yerbateros", mostrando a través de los ensayos y las experiencias a campo que es una metodología que funciona. Muchos de esos colegas pertenecen al programa del $3 \times 1$, a cooperativas de otras partes de la región yerbatera, algunos son asesores de empresas 
privadas de tamaño mediano, otros son integrantes de secaderos, son parte del universo a capacitar.

La metodología se repite, los expositores cuentan las experiencias positivas que desarrollan con el método de poda de la rama madura, las virtudes del trabajo y la importancia técnica que posee el modelo para los yerbales de la provincia. Así se desarrolla un cronograma de eventos en la región, donde son las mismas agencias de extensión rural de INTA, que trabajando con el equipo del INYM, convocan a los profesionales que asesoran a productores.

"Desde el Instituto El 80 \% de las jornadas de capacitación se habló sobre el tema de cosecha. Estas siempre parten del interés de las personas. Hemos trabajado con las municipalidades, los secaderos, los productores secaderos, ellos nos solicitan las jornadas. Se trabajan siempre en las temáticas que ellos tienen interés y así hay interés de participar, porque sin interés no vas a ningún lado" Entrevista a referente de sector público

En la misma línea de formación, se gestionan jornadas para hijos de productores que asisten a los colegios agrarios o con orientación agrícola, en estas también se habla del manejo del sistema productivo y por supuesto de la rama madura.

"es importante el trabajo con los colegios secundarios de orientación agrícola o agropecuaria, donde, en general van los hijos de los productores...", Entrevista a referente de sector público

"la capacitación es importante para el instituto, se designa un presupuesto anual para capacitaciones de secaderos y productores de yerba mate. También capacitaciones a las escuelas, EFA, IEA...." Entrevista a referente de sector público

Con lo cual el reducido conjunto de ingenieros de la rama madura del INTA y el equipo de técnicos del INYM, consideran que la acción conjunta de ambas instituciones que trabajan en pos del sector es muy importante a la hora de desarrollar acciones concretas que manifiesten beneficios para la región yerbatera, para lo cual:

"Se trabaja con articulación en distintas instituciones, se trabaja en diferentes fiestas o jornadas técnicas" Entrevista a referente técnico del sector público

Se van gestando acciones en diversos puntos de la provincia aprovechando los diferentes eventos, la Fiesta Nacional e Internacional de la yerba mate, que se realiza en Apóstoles, donde cada año se reúnen todos los actores que están relacionados al 
cultivo. Dentro de la misma fiesta está previsto un día exclusivo para "las jornadas tecnológicas" 22 , a través de la cual se muestran los diferentes avances en el sector yerbatero, en donde la poda de cosecha no queda ajena a ello y es parte de casi todas las ediciones.

Con distintos mecanismos, buscan realizar el "intercambio" de conocimientos entre los diferentes actores. Es un lugar donde se convocan a cientos de personas, entre productores, industriales, estudiantes, técnicos, representantes del sector, figuras políticas entre otras. Pasa lo mismo con la Fiesta del Agricultor en Andresito ${ }^{23}$, donde también la yerba mate juega un rol importante en la economía del lugar y las nuevas tendencias son parte de estos eventos. Se aprovechan el calendario de festividades relacionadas al sector agropecuario en Misiones, como medio para mostrar a la metodología de la rama madura a los productores yerbateros que asisten a estos eventos.

Se van conformando alianzas entre diferentes actores. El Ministerio del Agro de Misiones, con sus técnicos, también forman parte de ese grupo de colegas que se unen a la rama madura. De la misma manera que con los colegas de INTA e INYM, son los mismos promotores, los que empiezan a poner en agenda del gobierno a la cosecha de rama madura, de manera de que sean "los del ministerio" que se sumen a estos nuevos vientos de cosecha. Las estrategias de análisis siempre pasan por los mismos indicadores, rendimientos de materia prima de los lotes, mejora en los ingresos, seguridad en las cosechas, presentación de datos técnicos con evolución de las plantaciones, entre otros argumentos. No se logra un consenso generalizado en la cúpula gubernamental, los funcionarios, manifiestan:

"es el INYM el que está trabajando en cosecha, pero que "la rama madura" está muy lejos de la realidad, debemos trabajar juntos para el sector, hoy no hay coordinación de actividades, cada uno actúa independientemente" Entrevista a referente técnico del sector público.

\footnotetext{
22 Todos los años se realiza un encuentro de intercambio de conocimientos entre los organismos nacionales y provinciales, establecimientos yerbateros de la provincia y la región, empresas dedicadas al suministro de insumos y maquinarias, servicios etc. en las Jornadas Tecnológicas donde discuten temas de la producción, innovaciones tecnológicas, modo de mantener la rentabilidad, como también soluciones de problemas y cuidados de nuestros recursos naturales. ( https://www.fiestadelayerbamate.com.ar/la-fiesta/jornadas-tecnologicas)

${ }^{23}$ http://www.primeraedicion.com.ar/nota/100159718/andresito-se-prepara-para-recibir-la-fiestaprovincial-del-agricultor/
} 
Un reducido número de técnicos distribuidos en la provincia, que se desarrollan laboralmente en el ámbito yerbatero, es el que participan, los promotores buscan convencer del método aprovechando la afinidad que hay entre ellos. Cuándo logran persuadir y alinear a los colegas de otras instituciones se oyen voces que expresan lo siguiente:

“. Vos siempre vas manejando, en el sistema tradicional tenes que renovar cada tanto, por quemaduras de sol, plantas altas, hacer un rebaje selectivo o varios problemas que posee la estructura. Pero con rama madura la planta siempre está sana" Entrevista a referente técnico del sector

"Se aplican parámetros bien determinados, con criterios bien explícitos" Entrevista con un referente técnico del sector.

"En cuanto a productores chicos, hay que generarles producción e ingresos estables, con este sistema se logra eso. Porque vos siempre renovas la planta" Entrevista a referente técnico del sector.

Ahora bien, los contratistas parecen estar fuera de las acciones, pero no es así. Son el técnico de INTA de la agencia de Santo Pipó junto con el colega de la Cooperativa Piporé, los que en poco tiempo alinean a los dueños de cuadrillas, juntos con sus capataces. Los creadores de la rama madura, son conscientes de que los capataces de corte y los trabajadores son piezas fundamentales en la cosecha, para lo cual buscan que sean los jefes de los grupos de tareferos, juntos con el productor quienes asisten a los eventos de capacitación. Esto no siempre se da, pero en la cooperativa, se logra debido a que, al tener pocas cuadrillas, que realizan el trabajo de poda, es relativamente más sencillo demostrar a todos, el método de poda. Además, hay que tener en cuenta, que algunos productores de la Cooperativa Piporé, realizan su propio servicio de cosecha, contratando algunos trabajadores de manera estacional y en épocas de levantamiento de la zafra.

De esta manera se conforma el siguiente esquema: 


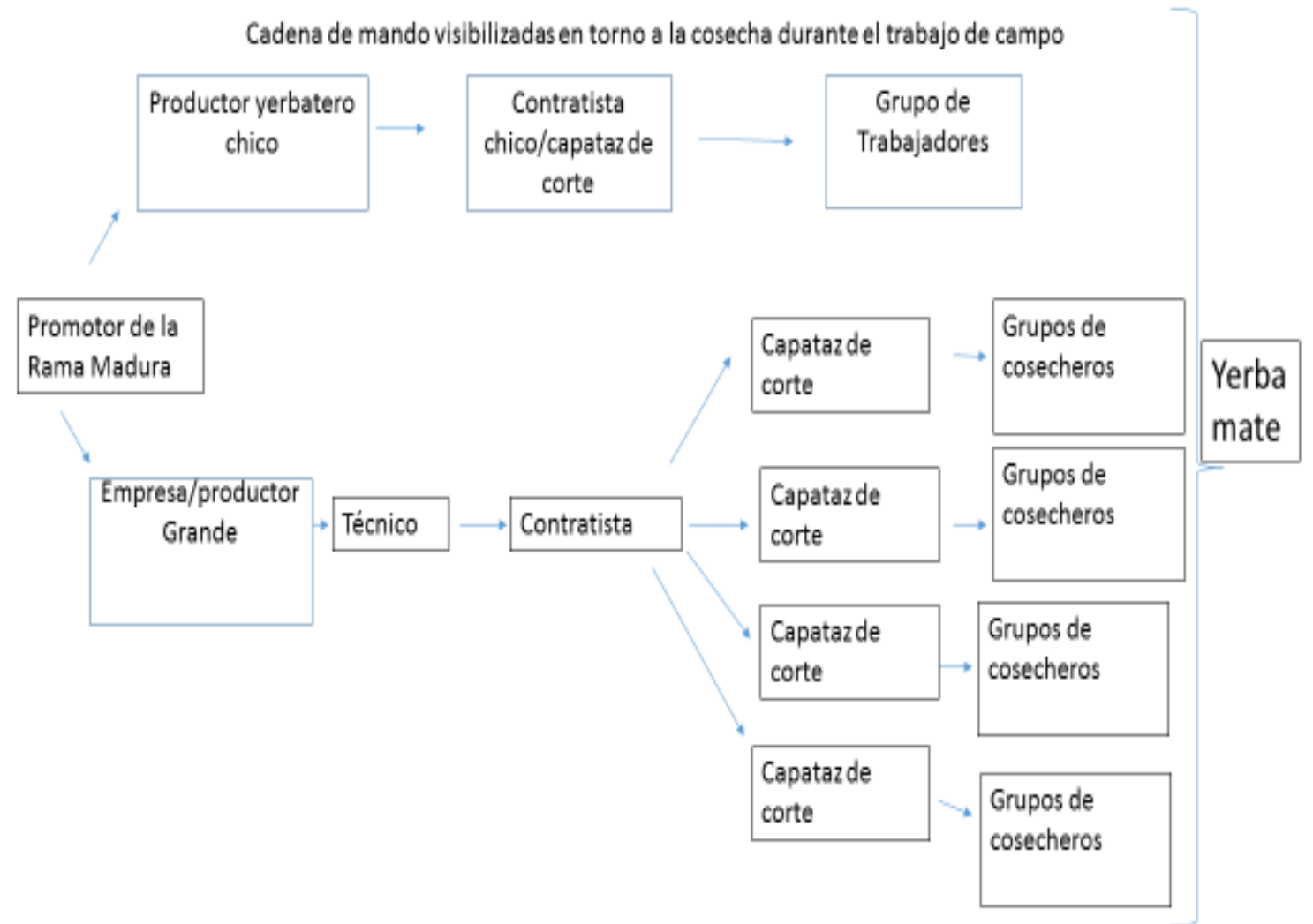

Figura 8: Cadena de mando en la cosecha de yerba mate

Fuente: Elaboración propia en base a entrevistas

Los nuevos aliados prestan especial atención a la evolución de la poda de rama madura y cómo se van comportando los yerbales en las diferentes situaciones. Los autores del método no desaprovechan esos logros y a cada lugar donde van a capacitar utilizan esas virtudes para implantar la bandera de la poda de cosecha de rama madura. Las estrategias se repiten en diferentes oportunidades, siempre buscando aliados nuevos.

\subsection{Un aliado clave en el yerbal}

Aparecen en el escenario dentro del grupo de trabajadores, los capataces de corte, quien es un peón con trayectoria en la cosecha, que conoce los diferentes métodos de corte y que muchas veces por su capacidad de manejo de personal, lleva adelante el control del trabajo realizado por los tareferos en los lotes de yerba mate:

"el capataz siempre se da una vuelta" Entrevista a trabajador 
A veces con responsabilidades de enseñar lo que deben hacer sus operarios en los diferentes lotes. Es, muchas veces, quien muestra el sistema de corte y la quebranza, además, es el mecanismo de control que tienen los contratistas, técnicos o productores.

“...siempre le pido alguna ayuda al capataz... que venga a fijarse donde puede estar mal..." Entrevista a trabajador

"tenés que estar el día entero explicando a la gente y recorriendo los lotes" Entrevista a capataz de cosecha

Es el que participa de la charla previa de inicio antes de la cosecha de la yerba. Este actor, es considerado una pieza fundamental en la cosecha para los asesores y contratistas. Los gestores de la rama madura, buscan que sea el mismo, el capataz de corte. El que debe transferir a los trabajadores, lo que se quiere realizar en los diferentes lotes de yerba. Se rescatan frases como la siguiente que hacen alusión a la importancia del capataz:

"es él, el que tiene que entender, porque es el quien va a trasmitir", Entrevista a un técnico de campo

"en el campo, siempre pasa por hablar con el capataz en primera instancia, luego él manifiesta al resto de los trabajadores la forma de trabajo que queremos hacer" Entrevista a técnico de campo.

Para cuadrillas grandes que trabajan con empresas, esta figura, es una persona de confianza para el técnico, en el cual recae la responsabilidad del trabajo en la chacra. Es, como se dice comúnmente "la mano derecha" del asesor o del dueño. Asimismo, en el caso de grupos chicos de trabajo, es el capataz de corte el que mantiene una relación más fluida con el dueño del establecimiento, es quién aplica lo que el dueño le solicita.

El capataz de cuadrilla es por lo general quién participa de las reuniones previas que se realizan al inicio del ingreso de las cuadrillas al lugar donde se va a cosechar. En ellas, se ponen de manifiesto "las reglas" que se deben seguir por parte del grupo trabajador a la hora de realizar la cosecha. Además, lleva la responsabilidad de controlar que el sistema de cosecha que se realice. En general, es la persona que hace la "recorrida previa" del yerbal antes de iniciar la recolección de la materia prima en los yerbales y es el que tiene una relación fluida con el dueño o asesor.

"ellos, los dueños, vienen y hablan directamente con Toti y Toti nos dice a nosotros que tenemos que hacer "Entrevista un trabajador 
Además, el capataz es quien realiza las tareas de control de los rendimientos que tienen cada trabajador, a través del uso de sus cuadernos o planillas controlan lo que cada cosechero hace durante el día y la semana. También llevan el control de las planillas de asistencias de los tareferos.

"el controla el corte y los kilos,.... hace las planillas" Entrevista a contratista en relación a la función de la actividad del capataz de corte.

Controla también que se cumplan los parámetros con los que debe salir de los yerbales, la materia prima que se envían al secadero. Porque si no se cumplen con los requisitos planteados por la industria que recibe el material, se aplican sanciones a los contratistas o los productores, muchas veces rechazando la carga que envían desde los yerbales de estos últimos. Entonces, son los contratista o dueños de los yerbales, presionan a los capataces de cosecha. El nivel de presión que imponen los capataces es elevado, a tal punto que, si los trabajadores no cumplen con las exigencias de lo que se entrega en el secadero, se sancionan a los tareferos por incumplimiento en sus trabajos.

"muchachos traten de no mandar mucho palo porque van a tener que requebrar." Entrevista a Capataz de corte.

"ayer no nos rindió mucho el día porque tuvimos que ir al secadero a requebrar" Entrevista a Capataz de corte.

En esa última frase hacen alusión a repasar el trabajo que no está bien hecho. En ese tiempo que están rehaciendo su labor, no reciben ningún tipo de incentivo; muchas veces dependiendo de los encargados, se les aplica descuentos en sus jornales, considerándolo como un trabajo mal hecho. Cabe destacar que una de las responsabilidades del capataz de la cuadrilla es justamente dar cumplimento de las normas dispuestas por los establecimientos industriales.

En ese sentido son los mismos industriales los que no quieren modificar sus sistemas de recepción de materia prima y ejercen presión hacia abajo, donde son los productores, contratistas y por último los trabajadores los que deben sufrir sanciones por incumplimiento en la calidad de la materia prima:

"En las grandes empresas, ya tienen acondicionado el secadero para ese material traído del campo, es más cuando compran material de terceros, son más exigentes." Entrevista a referente técnico 
"pero si en el secadero donde entregas deben hacer muchas modificaciones para recibir tu material no lo reciben" Entrevista a referente técnico.

"Los molinos controlan la planchada de los secaderos para que no vaya material no deseable para el molino" Entrevista a referente técnico

En el terreno, son los mismos capataces de corte los que buscan imponer sus criterios de cómo realizar el trabajo, de acuerdo a cosechar mucho o poco, al tener el trato directo con el dueño (en aquellas situaciones de productores familiares) comentan de las diversas formas que han probado en otras chacras y tratan de aplicarlo nuevamente:

"en la chacra de fulano, hicimos así y le anduvo bien" Entrevista a capataz de cosecha

Así como lo describe (Rau, 2014), este actor, es quien posee trayectoria en el sector trabajador, además experiencia de trabajo con personal a cargo y conoce del manejo del cultivo. El mismo, recibe una retribución monetaria de acuerdo a su función en la cadena de mando que se forma cuando se está cosechando la yerba mate. Además, es quien tiene la posibilidad de formarse en temáticas de manejo de plantas, cuando existen instancias de capacitación para trabajadores. En general cuando se realizan algunas jornadas de capacitación para los productores y estos invitan a sus trabajadores, son ellos los elegidos y cuando se dan las condiciones ${ }^{24}$, son elegidos para las instancias de instrucción que realizan los organismos de extensión.

\subsection{La propuesta técnica de la rama madura, el punto de paso obligado.}

Hasta ahora hablamos de los promotores de INTA e INYM, y de las diversas formas proclaman a la poda de rama madura como salvadora para los pequeños y medianos productores; pero ¿en qué consiste ese sistema? Se sustenta, básicamente en respetar cinco parámetros fundamentales que están relacionados entre sí y hasta encadenados

\footnotetext{
${ }^{24}$ Generalmente en las instancias de formación de técnicos públicos se convocan a los productores para que asistan, es difícil ver en estas convocatorias a trabajadores. Salvo excepcionales casos, son llamados los cortadores y/o capataces de corte.
} 
de una manera secuencial. Estos son el viruteo, la limpieza, el corte de las ramas maduras, el raleo de las ramas verdes y el mborevi caru.

Todos los actores vistos y analizados se relacionan de alguna u otra manera con la cosecha de la rama madura. Los productores, contratistas, trabajadores, las plantas de yerba mate y las industrias, dependen de que la cosecha de la yerba mate (en este caso la rama madura) se desarrolle de la mejor manera, sin inconvenientes. Son los mismos técnicos extensionistas e investigadores públicos en su mayoría y algunos privados, que se interesan en establecer de una vez y para siempre a la rama madura en el sector productivo. Sus intereses son parte también de este juego. Así es que la cooperativa, como una de las principales exportadoras de yerba mate, no deja pasar la oportunidad de fortalecer sus sistemas de producción primaria, para lo cual este método de poda le sienta muy bien. Pasan a ser una vidriera de la rama madura para otras instituciones que se quieran sumar; reconocen que se deben dar estas alianzas con beneficios para todos los involucrados en la cosecha, pero no siempre se da esta situación ideal. 
CAPÍTULO 7: NO TODO ESTÁ BIEN PARA LA RAMA MADURA 
A pesar de los esfuerzos de los I+D, de los creadores de la técnica de la rama madura, que se han esforzado de diferentes formas en el terreno para mostrar los beneficios que tiene para el productor, el trabajador y el sistema productivo con este método, se comienzan a dar diferentes controversias que dificultan la estabilización del sistema en la zona productora de yerba mate de Misiones y Corrientes.

Sucede que muchos yerbateros viven de otras actividades, son prácticamente denominados como "tenedores de yerbales". Estos en general ingresan al mercado yerbatero cuando el negocio es rentable y atractivo; cuando se produce una sobre oferta de materia prima, salen del mercado yerbatero. Estos tenedores de yerba, dejan que sus yerbales sean atendidos por contratistas, empresas o alguna persona de su confianza, que se encargan de todas las labores culturales, los cuidados de sus plantaciones y por consiguiente la poda de cosecha. Estas situaciones son aprovechadas por empresas grandes, ejemplo Las Marías, que buscan de alguna manera asegurarse de materia prima para los secaderos. Le realizan el servicio de mantenimiento de los yerbales al tenedor de yerba y le reintegran una parte de las ganancias, que muchas veces es ínfima, descontando por supuesto lo gastado para la realización del mantenimiento y cosecha de sus plantaciones.

También se da el caso de aquellos yerbateros que optan por recibir beneficios en corto plazo, cuando los precios de la materia prima son apreciables, para lo cual eligen seguir con la cosecha tradicional. Ya que la rama madura propone disminuir un año el volumen cosechado para poder recuperar al segundo año los ingresos de hoja verde y por consiguiente los ingresos monetarios.

Muchos productores no están abiertos a los cambios de sistemas de cosecha, conservan su tradición de trabajo, que viene de los abuelos, padres, con lo cual, para que se modifique el sistema de tarea en la yerba mate,

"Mayormente en la cosecha tradicional se deja un 5 por \% contra un $20 \%$ en la planta. Vos temes un periodo de adaptación que la gente no quiere, por querer cosechar y llegar a los kilos no se adopta bien" Entrevista a productor 
El propietario debe estar convencido del trabajo que debe hacer en sus plantaciones. Son los capataces de cosecha que ven en primer lugar deben estar convencidos los patrones, dueños de los yerbales, porque son los ellos los que dicen que tipo de trabajo deben realizar sus empleados, con lo cual allí comienza todo, para la rama madura y su estabilidad en el sector.

"el dueño debe estar convencido de ahí en adelante" Entrevista a capataz de corte.

Los mismos yerbateros se cuestionan sobre la cantidad de madera que queda en la planta y hasta inclusive en el mismo yerbal, se deja mucho material tirado en el suelo, como residuo lo que se llama en la jerga el "cambito ${ }^{25 "}$. Es más, dicen:

"vos fertilizas, cuidas la planta, le pones fertilizante para que crezca y dejas plata tirada en la chacra" Entrevista a productor

Otro cuestionamiento que surge en el yerbal está enfocado en lo siguiente: ¿Es el sistema de rama madura un método de trabajo que produce madera? Esto suena como un tema de debate no solamente para el productor, sino que además son los mismos trabajadores que ven en el método lo siguiente:

"produce mucho gajerio26, la gente cuando va a quebrar ahí está el problema y es el secadero que no recibe mucho palo" Entrevista a trabajador

"mborevi sobre mborevi queda con mucho palo la planta, para el año que viene se va a tener que meter serruchos" Entrevista a un trabajador

Con lo cual, al ser un sistema que maneja a la planta de yerba mate con ramas más bien gruesas de 2,5 centímetros como mínimo, la planta cambia su forma, pasando a tener mucho material más viejo, obligándole a las plantaciones a desarrollar más madera en relación a los materiales verdes. En ese sentido corre con ventaja la cosecha tradicional que produce siempre ramas verdes.

Como contrapartida, en el sistema tradicional, lo que se cosecha va a la ponchada y de la misma al secadero, prácticamente queda muy poco material restante en las plantaciones, casi nada de "cambito", se cosecha todo lo verde (ramas y ramitas) que va a la industria. En este mismo sistema se extraen ramas verdes que van a la

\footnotetext{
${ }^{25}$ Remanente de ramas maduras o no que quedan en los yerbales después de la cosecha, en general son materiales de diámetros superiores a los que recibe el secadero

${ }^{26}$ Referencia a los tallos de yerba mate
} 
ponchada, en cambio en la rama madura se cortan materiales de mayor diámetro (banderas de color gris), se fracciona, una parte va a la industria (secadero) y la otra queda en el campo, como residuo. Es importante destacar, que en el sistema tradicional se utilizan las manos para extracción de material liviano y para el corte de las ramas verdes, la tijera de mano o también conocidas como comunes. En cambio, en el sistema de rama madura hay que empezar a trabajar con el serrucho de corte y en el mejor de los casos con las tijeras eléctricas, como nuevas herramientas para el trabajador yerbatero.

Los trabajadores que realizan la tarea de cosecha, coinciden que es un sistema, el de la rama madura, que no les rinde mucho, porque deben cortar tallos con serrucho de mano, en algunos casos más tecnificados con tijeras eléctricas. Necesitan algún tiempo extra para hacer la operación de quebrado del material. En el caso que trabajen solos, el mismo tarefero hace el trabajo de corte y quiebre de las ramas cosechadas y las coloca en la ponchada. Las cosas cambian cuando se trabaja en equipo, aunque el ritmo de la jornada, lo impone el que corta, si este último es lento el trabajo es limitado.

Entre los operarios que usan los serruchos de mano, la fatiga también es una limitante a la hora de evaluar el rendimiento de la cosecha de rama madura; es una herramienta que los agota (serrucho de mano), en cambio las tijeras son más eficientes. Aseveran que:

"antes el corte con tijera manual, era más rápido y nos rendía, se extraían mucho material, viruta, que se llevaba directamente a secadero" Entrevista a trabajador.

Considerando que la cosecha incluye materiales de menor diámetro en las metodologías tradicionales, con los nuevos diámetros de corte y la incursión de serruchos de corte y tijeras eléctricas, el trabajo en el campo puede fatigar un poco más que en otros sistemas.

"yo cortaba, corté varios años, pero es un trabajo muy cansador, tenés que estar al mismo ritmo todos los días" Entrevista a trabajador

"el corte tradicional cuesta menos" Entrevista a trabajador

“el corte cambió, antes era mas gajos nuevos, hoy solo serrucho" Entrevista a trabajador

Ahora bien, tanto técnicos, como trabajadores que están convencidos del sistema, dicen que "la planta te enseña donde cortar". Consideran, desde su perspectiva, que 
están bien definidos las diferentes partes del vegetal, es un sistema muy práctico para explicar y entender desde la teoría. La complejidad se pone de manifiesto, a veces, al querer aplicar en los yerbales, donde cada productor en general tiene su modelo de trabajo. A su vez cada trabajador viene con una carga de conocimiento que no siempre es el de la rama madura. Además de esto y viendo que el sistema propone cinco momentos importantes para la realización de la cosecha, el mayor inconveniente se da cuando se tienen que hacer el raleo de material de las ramas verdes por parte de los empleados, este es un punto crítico, porque no quieren perder tiempo y buscan hacer lo más rápido posible de manera de aprovechar bien su período de trabajo.

También se debe poner en relieve que los mismos trabajadores plasman situaciones de Microplanteos, circunstancias en que los obreros "paran" el trabajo, para renegociar las condiciones de la labor. Estas circunstancias, también se dan en otras actividades como la citrícola. Este tipo de estrategias de resistencia lo plantean autores como Alfaro (2014).

Son de corta duración en el tiempo, pero relevante en el lugar de trabajo a la hora de iniciar los trabajos de cosecha, a pesar de estas resistencias locales, después de renegociar los parámetros de trabajos estos momentos de crisis o de tensión, se resuelven luego de algunas horas. (Alfaro, 2014).

En la actividad yerbatera, se presentan estas situaciones de reclamos de paritarias, que se pueden dar por los limitados rendimientos que se obtienen en lotes que no son productivos o en aquellos casos, en que se aplican solamente algunos de los parámetros de la rama madura, ejemplo el despunte o el llamado mborevi" en donde al tarefero no le significa cosechar los kilos necesarios para ganarse el jornal diario.

Se pueden plantear estas situaciones, también con la introducción de herramientas de corte en los yerbales. Durante el trabajo de campo se puso de manifiesto esta postura, por parte de un grupo trabajador, después de haber sido visitado por el ingeniero en un lugar donde estaban por empezar a cosechar. El mismo técnico defensor de la rama madura, determinó que tipo de corte deberían hacer los trabajadores y como consecuencia de ello se dio la siguiente realidad de paro laboral comentada por el propietario:

"nosotros ese corte no vamos a hacer, el mborevi con raleo no nos rinde para nada, los ingenieros no saben nada, vamos a estar toda la mañana para sacar nada de kilos. Así que o nos paga el doble de precio o nos vamos" Entrevista a productor 
"Un apriete, que, con la yerba lista para cosechar, con las condiciones climáticas que no estaban favoreciendo, tuvo que ceder y "agachar la cabeza", mejorar el precio para que se pueda hacer el trabajo, acomodar un poco el corte de la yerba siguiendo a medias las indicaciones de manera de poder cosechar algo" Entrevista a un productor.

Como corolario de la situación, es el mismo dueño que expresa que en realidad "la gente viene a sacar kilos", en eso coinciden con los asesores que trabajan con el método de rama madura que "el tarefero va al yerbal a sacar kilos", quiere que su trabajo le rinda, no quiere perder tiempo tratando de elegir ramas que deben cortar; a pesar de, como dicen los tareferos que son convencidos del método, la planta te enseña a cortar. La realidad es que, así como el productor quiere que sus yerbales les produzcan muchos kilos de hoja verde, el trabajador también quiere cosechar esos kilos, para así ganarse unos pesos.

Asimismo, al momento de la cosecha existe una problemática que hacen sentir, es la alta rotación de personal, esta situación se manifiesta en el sector de los productores, sobre todo en los más pequeños y en los contratistas de cosecha. A pesar de los incentivos que las empresas o productores les entregan a los trabajadores que son temporarios, para que vuelvan al año siguiente a trabajar con sus mismos patrones, esta situación, no se da.

Es una constante en la mayoría de los lugares visitados. Muchos trabajadores entran y salen de la actividad, en función de que, si tienen otra opción laboral para elegir lo hacen, dejando a la tarefa como una última elección. El cambio de personal en las cuadrillas, implica algunos problemas para los que están encargados de las cosechas, en primer lugar, relacionados con las capacitaciones no formales, es decir, las que se dan en el campo antes de dar inicio al trabajo de poda en los yerbales. Al existir alta rotación, se deben capacitar cada periodo a los nuevos.

Todos los años aparecen caras nuevas. Eso implica que muchas veces se dificulte el trabajo en el terreno, lo que lleva un tiempo prudencial para las personas que puedan acostumbrarse al sistema planteado de la rama madura, ya que muchos de ellos vienen de realizar cosechas de tipo tradicional. Son los mismos capataces de corte que plantean que los cambios de personal, como consecuencia de la rotación, producen en el trabajo de cosecha cambios de sistemas en la labor, afectando al sistema de recolección de rama madura de manera sustancial y, por consiguiente, su estabilización. 
Pero son los mismos trabajadores que a veces buscan nuevos lugares para ir a cosechar yerba:

"yo estuve en San Jose, en San Carlos, con Sergio en los Helechos, también hacíamos la yerba de Ramon en Oberá" Entrevista a un trabajador.

Esa misma movilidad dentro del complejo yerbatero que tienen los trabajadores, implica no solamente problemas para los productores y contratistas como ellos mismos lo expresan. sino que además el hecho de alejarse por unos cuantos días de sus familias, en busca del sustento familiar, perjudica la convivencia en sus hogares. Se pueden ver cuadrillas enteras moviéndose, o bien trabajadores golondrinas que van de un lado para otro hasta encontrar la estabilidad laboral.

Otra cuestión que surge como problema, no relacionado directamente con la rama madura, pero si con la cosecha, es el limitado número de personas para la cosechar. Los productores consideran que hasta inclusive cada año hay menos personal o es más difícil que los trabajadores vuelvan a los yerbales. Estas campanas de falta de personal para la cosecha vienen sonando desde hace varios años, se ha utilizado como estrategia para implantar en su momento a la temática de la mecanización de la yerba mate, sin lograr una relevancia en el sector, salvo las empresas de mayor envergadura. En la actualidad nuevamente, se está buscando instalar a la mecanización en la agenda productiva. Los productores son los principales precursores de esta idea, consideran que los tareferos no quieren trabajar, es más, muchos jóvenes llegan hacen los kilos diarios que necesitan y se van. Aseveran que actualmente los tareferos son personas muy jóvenes, sin experiencia inclusive en el manejo de las plantaciones con lo cual:

"los muchachos llegan hacen sus kilos y se van, antes las personas vivian en el yerbal". Entrevista a un productor

Estas complejidades del recambio generacional también condicionan el trabajo en los yerbales, donde se suman otras cuestiones, como es el caso de productores con edad avanzada que tienen yerbales sin manejo de suelos, nutrición de las plantas, podas. Ellos no les quieren "poner plata" a su explotación, solamente les interesa el rendimiento y no manejar su yerbal, con lo cual es la gente mayor que no quiere cambiar o no le convence la propuesta, sabiendo que en la cosecha tradicional puede cosechar hasta dos veces al año y todo va al secadero. 
Un actor que tiene una importancia especial es la industria, principalmente el secadero. Estos (a pesar de que en los I+D aseveran que no son importantes decisores en el material a cosechar), son los que definen qué tipo de materia prima van a recibir en relación al largo y al diámetro de lo cosechado; aplicando descuentos severos a los contratistas, por consiguientes a los trabajadores y dueños de los yerbales si es que no cumplen con las normas establecidas.

¿En qué se relaciona esto con la cosecha de rama madura? en que este sistema de poda, tienden a producir ramas más gruesas y esto lleva a un esfuerzo mayor por parte del trabajador cuando las tienen que separar y evitar así estos descuentos. Con lo cual lleva la delantera el sistema tradicional que realiza corte de materiales más bien verdes de diámetros chicos. Esta normativa por parte de la industria se vuelve más severa mientras exista una oferta abundante de yerba mate cosechada sin elaborar. Cuando se incrementa la oferta, los secaderos se ponen más exquisitos. En cambio, cuando hay escases de materia prima, los parámetros se vuelven más lábiles.

Un detalle que no es menor, es la cantidad de técnicos que se relacionan directamente al cultivo, a pesar de la gran presencia territorial del INTA, son escasos los profesionales que trabajan exclusivamente con la yerba mate. Con la alianza estratégica con el INYM, no se llega al universo de productores yerbateros. Esto condiciona de gran manera las aplicaciones de nuevas metodologías de trabajo.

Los trabajadores, son otro eslabón importante en la cadena yerbatera, poco atendidos desde el INYN, quien en sus discursos resaltan el trabajo del operario, la lucha contra el trabajo infantil y el trabajo en negro. Pero se hace relativamente poco desde la práctica concreta, solo algunas intervenciones con programas de apoyo. Pasa lo mismo con el gobierno provincial, su accionar se plantea desde el apoyo en el período de la no cosecha a través del subsidio de inter zafra. Los que si velan por sus colegas son las asociaciones de tareferos que buscan de diversas maneras luchar para lograr las mejorar en las condiciones de trabajo de sus compañeros.

Hay que considerar también que la propuesta de la rama madura es una forma de trabajo que lleva mucho de capacitación y seguimiento por parte de los técnicos. La capacitación es una inversión que muchos productores no quieren asumir, para transformar al tarefero en podador. Se dan algunas intervenciones realizadas desde los organismos públicos para capacitar al sector trabajador, con resultados poco favorables. 
Los ingenieros, se valen de diferentes estrategias a través de las cuales buscan de implantar la cosecha de rama madura en la agenda. Folletos, publicaciones en las redes sociales, instructivos, jornadas técnicas, entrevistas a referentes, demostraciones a campo, son parte de ese bagaje de herramientas que se utilizan. A pesar de la variedad y diversidad de estrategias, no llegan a cumplir plenamente con sus planes, los mismos trabajadores manifiestan que:

"los folletos en las charlas no sirven para nada, se tiene que ver como se hace". Entrevista a un trabajador.

Los trabajadores, hacen hincapié que las jornadas de capacitación tienen que realizarse en el campo, donde se pueden ver in situ el trabajo de cosecha. Plantean la necesidad de palpar de primera mano cómo se hace la rama madura y qué tiene de diferente con los demás sistemas de cosechas.

Un tema no menor y que se pone en agenda de la rama madura, es la formación de equipos de trabajo, muy ligado este modelo a la semi mecanización de los yerbales, que se puede adaptar sin problemas al modelo de rama madura. 
CAPÍTULO 8: TRANSFORMANDO DE TAREFERO A PODADOR 
En el sistema de cosecha de rama madura, tal como se plantea, implica varias cuestiones: en primer lugar, se necesita conocer qué ramas cortar o podar, cuáles son las secuencias de trabajo a realizar, qué tipo de material se debe dejar en planta. Los tareferos distinguen las ramas o los diferentes materiales a extraer en función del tipo de corte que se realice. Ese conocimiento viene de la herencia recibida por parte de sus antepasados. Hay que recordar, que la mayoría de los tareferos son trabajadores "por herencia", su saber hacer viene desde que han sido pequeños yendo a los yerbales con sus padres y abuelos, a realizar esas tareas, esto se manifiesta en las conversaciones con los trabajadores, por ejemplo:

"siempre tarefee desde chiquito" Entrevista a trabajador de 42 años

"yo con mi viejo en los yerbales, de 10 u 11 años por ahí, siempre corté yerba" Entrevista a trabajador

“de tarefa tengo como 40 años .... aprendí con mi papa" Entrevista a trabajador “desde los 12 años por ahí estoy tarefeando," Entrevista a trabajador de 47 años

Antes se observaba en el yerbal a las familias trabajando, cada uno con una tarea específica, papá, mamá, adolescentes y niños colaboraban en el yerbal con las diferentes tareas; en la mayoría de los casos en condiciones inhumanas para trabajar, muchas veces en situaciones de total indigencia, tal como mencionan varios autores que han estudiado los escenarios en que se desempañaban los cosecheros (Rau , 2009; 2014; Traglia ,2016).

Las familias enteras que se movilizaban en los yerbales para levantar la cosecha, trasmitían el saber hacer del oficio del tarefero. Los chicos y chicas aprendían trabajando con sus padres, de esta manera esa "herencia del tarefero" se fue pasando a través del trabajo en los yerbales y cuando los padres se retiraban de la actividad por que por sus condiciones físicas ya no daban más, quedaban los "herederos" que continuaban con la ocupación.

Así aparece también el "guayno", aquel niño o joven que acompaña en dupla al trabajo de un mayor, siempre bajo la orden del adulto. Esta figura, aparece, en su gran mayoría en aquellas familias que vienen de tradición cosecheros. El adolescente, está bajo la subordinación del mayor, quien percibe la retribución por el trabajo de ambos. Esta relación perdura hasta el momento en que el muchacho adquiere las habilidades suficientes para desempeñarse solo en el campo laboral de la cosecha; la situación 
contractual del joven, en general estaba en negro, sin gozar de los beneficios sociales, no así el mayor, quien si poseía el trabajo en blanco (Re, 2015).

Hoy con las nuevas tendencias y las políticas públicas aplicadas desde el INYM, que buscan jerarquizar el trabajo, las condiciones laborales, se han modificado sustancialmente. En los yerbales no se ven familias completas, o por lo menos no las se ha visto mientras se realizaba el trabajo de campo. En muchos casos se observa casillas móviles con abastecimiento de agua potable para el consumo, con un lugar para descansar. Pero la forma de trabajo que plantean los tareferos se repite. El trabajo individual del cosechero, ya que es la misma persona que hace el corte del material y quiebra para completar su "ponchada".

Casi no se ven en terreno equipos de trabajo salvo algunas excepciones, grupos de dos o tres personas trabajando en sus respectivos líneos de cosecha. Esos módulos son formados por afinidad de trabajo o relación familiar o amistad, pero no están tan popularizado el grupo de trabajo en líneas. Sí se manifiesta estos modelos de equipos, en aquellos lugares donde se han hechos pruebas con tijeras eléctricas.

Con lo cual desde el equipo promotor (INTA e INYM), consideran que es necesario la formación de podadores/cortadores, personas capacitadas en la poda de la yerba mate dentro del sistema de rama madura. Ellos, son los deben conocer las diferentes etapas o pasos que se realizan para concretar una poda acorde al método. Cumplen la función solamente de realizar el trabajo de cortes o podas, no realizan la quebranza del material verde cosechado. Para esta última actividad están los quebradores.

Es allí donde entran temas tan relevantes como la división del trabajo, la formación de equipos de cosecha, el incremento en los rendimientos por grupos, la utilización de los serruchos y de vez en cuando la aparición de tijeras electrónicas de la mano de la rama madura.

"Dentro de este sistema, la división de trabajo es fundamental, esto conlleva a que vos tengas, cortadores capacitados que se dedican solamente esto. Por que lo fundamental es que se haga una buena poda, la eficiencia que vas a tener es mucha más alta" Entrevista a referente técnico

Estos equipos de podadores y quebradores, ya no más llamados tareferos, se forman de la siguiente manera, en función del tipo de herramienta de cosecha que utilicen para realizar la labor en los yerbales: 
Tabla 2: Modelo propuesto de trabajo de poda de la rama madura

\begin{tabular}{|c|c|}
\hline \multicolumn{1}{|c|}{ Equipo propuesto: } & \multicolumn{1}{|c|}{ Tipos de tareas } \\
\hline $\begin{array}{c}1 \text { Cortador ( con tijera electrónica } \\
\text { o serrucho) }\end{array}$ & $\begin{array}{c}\text { Específica: conocen que tipos de ramas se } \\
\text { deben cortar, qué material deben dejar en la } \\
\text { planta, cómo se debe realizar el trabajo de poda. }\end{array}$ \\
$\begin{array}{c}2 \text { a } 3 \text { quebradores de ramas ( a } \\
\text { mano o con máquina) }\end{array}$ & $\begin{array}{l}\text { Actividad sin especificidades, solamente } \\
\text { debe afinar el material y colocarse en la bolsa } \\
\text { acondicionada ( ponchada ) para su posterior } \\
\text { pesaje }\end{array}$ \\
\hline
\end{tabular}

Fuente: Elaboración propia en base a entrevistas

Estas innovaciones, vienen de la mano de la cosecha, no solamente incluyen al método en sí mismo y sus diferentes etapas, si no que van más allá: buscan modificar el sistema de trabajo de los tareferos. Esto impulsado por uno de los socios de la Cooperativa Piporé, que, además es uno de los promotores del sistema de rama madura, muy vinculado también a la empresa que provee las tijeras eléctricas.

El mismo promotor, ha estudiado detenidamente el método de trabajo en la cosecha, analizando su eficiencia productiva y económica en las diferentes etapas que se desarrollan en el terreno. Se ha encargado de buscar la tecnificación del trabajo, donde aparecen las nuevas herramientas que se acoplan a la rama madura, las tijeras electrónicas.

En diversas entrevistas, salieron cuestiones relacionadas a la división del trabajo estas se expresan a continuación:

"Una vez que tenes armado el equipo, el rendimiento por persona aumenta, en vez de hacer muchos cortes chicos, haces pocos cortes grandes con mucha yerba, el operario que antes en esa yerba te hacían 400/500 kg, hoy se puede llegar a los 800 o 900 kg". Entrevista a referente técnico.

“.... Lo fundamental es que se haga una buena poda, la eficiencia que vas a tener es mucho más alta. ..." Entrevista a referente técnico 
"Dentro de este sistema, la división de trabajo es fundamental, esto conlleva a que vos tengas, cortadores capacitados que se dedican solamente esto y quebradores que no necesariamente sean capacitados por que su trabajo es más simple solo deben quebrar con la mano la yerba..." Entrevista a referente técnico.

"Vos necesitas tres quebradores por cada cortador entonces ahí vos necesitas mínimo 1200 kilos por día de quebranza para ganar un jornal. Como si vos estuviera solo tarefeando corte y quiebre, es ahí donde entra la discusión de la gestión del proceso de cosecha ..." Entrevista a referente técnico.

"Lo que hay que buscar resolver es el tema de la quebranza, el vago que solo quiebra le rinde bien hasta el miércoles, después flaquea, entonces el rendimiento general no va". Entrevista a referente técnico.

Es muy evidente las diferentes manifestaciones que se dan en relación al sistema de cosechas de la rama madura y el modelo propuesto de equipo, para realizar el corte y quiebre. Se ha llegado a trabajar a nivel de UATRE, con resoluciones ${ }^{27}$ que diferencian el pago que percibe el trabajador en función del tipo de cosecha que realice.

${ }^{27}$ https://www.uatre.org.ar/attach/resol/2019 104.pdf 


\section{CAPÍTULO 9: CONCLUSIONES}


La cosecha de la yerba mate, es una de las actividades más relevantes para el sector yerbatero, no solamente por los volúmenes que se cosechan, sino también por los diversos actores que están incluidos en esta cadena productiva. En este sistema de producción, se plantean diferentes formas de cosechar a las plantas, algunas de ellas con más aceptación que otras. En el sector existen diversas metodologías que han sido difundidas, no solamente por los I+D, sino que también por las empresas privadas, entre ellas están el corte tradicional, la cosecha de rama madura, los sistemas rotativos, los modelos mecanizados de cosechas entre los más relevantes.

Dentro de los nombrados, el sistema de cosecha tradicional, es considerado como uno de los métodos más antiguos, con lo cual prácticamente tanto los trabajadores, contratistas y productores, lo han practicado o utilizado en algún momento. Sin embargo, el método tradicional presenta algunos inconvenientes, entre los que se pueden citar: deja a los yerbales en situaciones de degradación por la excesiva extracción de materia prima, consecuencia de esto las plantas de yerba mate empiezan a sufrir problemas en sus niveles de producción que tienden a disminuir, sufren ataques de patógenos y el sistema comienza con un deterioro progresivo.

Desde los I+D han analizado esa situación que se estaba generalizado, en el sector primario, para lo cual, buscaron otras alternativas de cosecha de la yerba mate, que puedan subsanar estos inconvenientes detectados, es allí donde aparece la rama madura.

Sin embargo, actualmente se puede visualizar en la práctica, que esta forma de cosecha parece no estar siendo adoptada por el sector de pequeños yerbateros. Para lo cual, se pone en relieve la problemática de la adopción o no de la metodología "rama madura", como una forma de cosecha para los yerbateros.

Abordamos este caso a través del marco teórico de la teoría Actor red (ANT) que brinda los elementos necesarios para realizar el análisis de esta red socio técnica particular.

Este trabajo de investigación, se guió por los siguientes objetivos específicos:

- Conocer el tipo de relaciones que vinculan a los diferentes actores que integran la red de la cosecha de la yerba mate en el territorio y cómo influyen en el proceso de adopción de la nueva tecnología. 
- Identificar los principales problemas ligados a la adopción/no adopción de las tecnologías propuestas por los organismos públicos y privados desde las diferentes perspectivas de los actores que componen la red.

- Analizar los diferentes significados y sentidos que poseen los diálogos, que se generan entre los diferentes actores que componen la red, que permita ampliar la comprensión del fenómeno en estudio.

En la medida en que se fue desarrollando el trabajo de campo, realizado en la Cooperativa Piporé (a través de las visitas y entrevistas a referentes del sector, productores, trabajadores, contratistas y técnicos; participación en la cosecha en diferentes momentos del año, incluso en eventos de capacitación organizadas en varias localidades por técnicos de INTA e INYM, en donde la temática principal era el de la cosecha), se puedo observar con claridad situaciones que nos dieron indicios sobre los diferentes actores, que intervienen en la aplicación socio técnica del método de la rama madura.

Es la Cooperativa Piporé, con sus técnicos de campo se transforma en una de las promotoras y defensoras del mecanismo. En sus discursos ponen en relieve la importancia del método, no solamente para los mismos socios, sino también para el sector en general.

Las estrategias de convencimiento: discursos, reuniones técnicas, muestras de prácticas a campo, instalaciones de ensayos, son parte de las diversas operaciones de traducción que se utilizan para construir y reforzar las asociaciones de la red socio técnica de la rama madura. Son los mismos técnicos promotores, los que consideran a este método, como uno de los que les aseguran a los actores que intervienen, ingresos crecientes en la cosecha, por el incremento en los volúmenes de producción. Se postula que, con un manejo adecuado de las podas el sistema productivo, se estabiliza en el tiempo con buenos niveles de producción de hoja verde.

En el mismo sentido, a nivel general, se pudo comprobar parcialmente la hipótesis del trabajo que menciona lo siguiente: "el enfoque de innovación que predomina en los organismos públicos se basa en teorías difusionistas o de innovaciones inducidas, lo que dificulta la construcción colectiva de conocimientos, los aprendizajes en sentido amplio y finalmente contribuye a la baja adopción de las técnicas". Esto es así porque en la mayoría de las intervenciones que realizan en la Provincia los $1+D$, utilizan estrategias muy relacionadas al enfoque de las innovaciones inducidas, en donde ponen 
de manifiesto la importancia de las ganancias unitarias, como estandarte del sistema de cosecha de la rama madura. Se pudo observar que el nivel de adopción es muy escaso. Evidentemente no alcanza con la difusión de información, sino que hay otros factores que dificultan la adopción.

Sin embargo, en la Cooperativa Piporé la adopción de la técnica de la rama madura es generalizada, pero allí se supera el enfoque difusionista, desarrollándose una estrategia activa para hacer converger los intereses de los distintos actores que intervienen en la red socio técnica.

La adopción o no de la técnica en este caso, no depende solamente del enfoque metodológico que apliquen los extensionistas de los I+D, sino que también de diferentes condiciones estructurales que se presentan, que van más allá de la metodología en sí mismo. Estrategias, intereses entre los diversos actores, estabilidad de los trabajadores, alianzas, son condicionantes encontrados en esta investigación que inciden en la aceptación de la rama madura.

Es importante aclarar que solamente con el estudio de caso de la Cooperativa Piporé, es difícil corroborar la hipótesis, porque en la misma, se utiliza una estrategia activa, con condiciones y estrategias planteadas que favorecen la adopción de la rama madura en Piporé. Asimismo, intervienen una serie de factores y de alianzas que, en el caso de la cooperativa, se manifiestan en el interés común que poseen los propietarios, el capataz de la cosecha, los contratistas, los obreros que tienen estabilidad plurianual, la misma cooperativa con su industria; esta situación favorece a la metodología de la rama madura y su aplicación.

En el resto de la provincia, al no lograr consolidar a la rama madura utilizando estrategias que se relacionan con el difusionismo o la innovación inducida, se demuestra que no alcanza solamente con la difusión del conocimiento y la intervención de los I+D con sus extensionistas. Hay factores o condicionantes que hacen reflexionar que, la convergencia da cuenta de un montón de elementos que posibilitan que, en algunos lugares, funcione el método y en otros no se logra.

Solamente con el difusionismo y el trabajo del extensionista no se llega a instalar el método, porque no se busca o no se obtiene la convergencia de actores que si se da en la cooperativa Piporé. 
Ahora bien, en el caso de estudio, de la Cooperativa Piporé, la red tiende a estabilizarse, existe un proceso de convergencia, donde se producen alineamientos de actores. Los promotores de la técnica están muy relacionados a la Cooperativa, con lo cual, el nivel de seguimiento y capacitación tanto de productores como contratistas y por consiguiente tareferos es muy elevado. Son los mismos técnicos que están full time para la rama madura, convencidos que el sistema funciona. Estos mismos actores son los que ponen en circulación a los intermediarios, buscando influir en otros para que se pueda estabilizar la red, a través del interés común entre los que forman este entramado en la Piporé.

Con lo cual se puede decir que el sistema propuesto por los I+D en la Piporé, funciona con una lógica de producción, donde a través de diferentes estrategias de manejo cultural se logra cuidar a las plantaciones de yerba mate para que produzcan materia prima de manera continua en el tiempo. Acompañamiento e instrucción constante de los contratistas, obreros, capataces y productores, logran alinearse en un espacio común, donde todos estos comparten el mismo discurso "el de la rama madura", con el interés común de mantenerse en el sector yerbatero.

En el terreno, son los ingenieros promotores, que van traduciendo y ponen en circulación, diferentes estrategias, de manera que el interés común, de la mejora en los yerbales a través del rendimiento, por el uso de las podas de rama madura, sea el modelo viable para sus explotaciones. Siendo muy importante la actuación de los técnicos de INTA, como intermediarios entre actores del sector (grupos de productores, otras cooperativas, contratistas, secaderos chicos) y promotores de la técnica de cosecha.

Un dato interesante, es que, uno de los referentes técnicos de la rama madura, pero del sector privado, promotor de las nuevas herramientas (tijeras eléctricas), socio en la Piporé, es un acérrimo defensor de la técnica. En su negocio familiar aplica y prueba nueva técnicas de trabajo, promueve la formación de equipos, la división del trabajo y la incorporación del uso de tijeras eléctricas. Considerando que, para el sistema de podas de la rama madura, estas herramientas, se adaptan muy bien. Además, no solamente se promocionan estas herramientas y nuevas formas de trabajo desde esta empresa, sino también desde el Instituto nacional de la Yerba Mate (INYM) con sus programas.

Pero en los yerbales de los socios de la Piporé, la figura del "capataz de corte", cumple un rol importante, quien alinea a los trabajadores para la realización de la 
cosecha; es el que realiza el control del trabajo, a través del contacto directo con el operario, siendo el nexo entre técnico o dueño y los cosecheros y tienen a cargo el control no solamente de la forma de podar, sino que también de la quebranza del material que va a la industria. Estos poseen un papel importante como traductores de las técnicas de recolección, al estar íntimamente ligados a quienes realizan el trabajo en los yerbales.

Es tan relevante este actor, que en aquellos casos en donde el productor casi no se involucra con la cosecha, deja en manos del capataz de corte quien define qué es mejor para cada situación, según su criterio, es quien va corrigiendo el método de cosecha en función de las necesidades, ya sean del patrón o del grupo de trabajo o propias, con lo cual es importante para el método que el mismo capataz se alinea en el mismo discurso que proponen los que promueven a la rama madura

Una cuestión que no es menor, tiene que ver con la estabilidad de los cosecheros, en el mediano y largo plazo. En la Piporé, los tareferos, tienen continuidad en sus trabajos. Todos los años cosechan, algunos con una leve rotación de sus patrones, pero en su gran mayoría son los mismos empleados prácticamente todos los años en los lotes de yerba mate, llegando incluso a que cada trabajador tenga asignado "su" lote o lineos de cosecha. Eso juega a favor en la estabilización de la rama madura, considerando que es un método que requiere de capacitación para el inicio y la estabilización de la tarea, conocimientos de los parámetros que deben aplicar. Si la rotación de personal disminuye, con una mayor estabilidad laboral, el método propuesto de cosecha de estabiliza, los trabajadores formados mantienen sus trabajos.

En la aplicación del método, los trabajadores y capataces, deben, conocer al detalle una serie de instrucciones para el buen desarrollo del sistema de cosecha. Son los conocidos "cinco puntos" que se pregonan para el sistema de rama madura, en contraposición con dos puntos bien conocidos en el sistema tradicional. Estos parámetros son el viruteo, la limpieza del material dañado en la planta (ya sea por el sol o malas cosechas anteriores), el corte con aumento de las ramas maduras mayores de 18 meses de edad y de color grisáceo y por último el "mborevi caru" o despunte de las ramas verdes. Con lo cual el conocimiento y aprendizaje por parte del que ejecuta el trabajo es relevante para la técnica de poda. 
Con lo mencionado anteriormente se puede decir que se alinean intereses comunes de los diversos actores, se logra la convergencia y, en definitiva, se logra la construcción de la red socio técnica de la rama madura en la Cooperativa Piporé.

De la misma manera se ha detectado algunas cuestiones relacionada a la rama madura que podrían afectar la implementación del sistema a nivel general, entre estas se pueden destacar lo siguiente.

En la rama madura, los trabajadores, deben modificar sus hábitos de cosecha, la aparición de nuevas herramientas (serruchos y tijeras eléctricas) que acompañan a la técnica, provoca en los trabajadores, reacciones a la hora de utilizarlas en los yerbales; los operarios están acostumbrados a la tijera común y no al serrucho. Además, los mismos promotores de la rama madura fomentan la formación de equipos para cosecha, donde los rendimientos son fruto del equipo y por consiguiente las ganancias. Pero la costumbre del trabajador es realizar solo el trabajo, aunque a veces con la ayuda de algún familiar, sin depender de otro operario para mantener o mejorar sus ganancias.

Otro escenario que afecta la convergencia de la rama madura, es la alta rotación de personal, con la consiguiente migración que se da en el sector de los trabajadores. Van como "golondrinas" recorriendo diversos sitios para trabajar; estos movimientos condicionan al proceso de capacitación y formación que deben participar los tareferos para utilizar el sistema de cosecha de rama madura. Sumado a esto, que en su gran mayoría los mismos tareferos han trabajado para contratistas de empresas grandes, que, en general no aplican la rama madura como sistema de cosecha. En esto hay que sumar no solo la rotación por falta de estabilidad laboral, sino que también la deficiente o nula capacitación que deben recibir los operarios, factores estos que también afectan a la adopción de prácticas en el sector.

Además de la falta de aceptación de la metodología de trabajo en algunos lugares, está relacionado a los "años de inversión" que necesita el productor para entrar al sistema, considerando que debe dejar de cosechar uno o dos años, dependiendo de la situación inicial; para poder realizar los diferentes pasos que implica la rama madura. Muchos productores no están en situación económica, financiera como para dejar de cosechar un par de años. Ellos tienen organizados sus gastos de manutención y hasta las posibles inversiones siempre en relación al ingreso que le produce la cosecha de la yerba mate. 
Esta inversión se tiene que dar no sólo en tiempo de no cosechar, sino que también en capacitación y seguimiento, con un mayor involucramiento del productor yerbatero, que, además de conocer la técnica, debería estar con más presencia en los yerbales, no dejar en manos de los capataces o contratistas el trabajo de control de la cosecha. Muchas veces deben decidir en el terreno que método les conviene a ellos para ganar más dinero con la cosecha.

En los lugares donde la técnica no se estabiliza, los trabajadores que no se alinean a la propuesta, ven en los yerbales con rama madura, que estas plantas producen, poca viruta, algunas ramas verdes y mucha madera, siendo, la viruta y las ramas verdes, de alto valor para las industrias. En el sistema de rama madura, el nivel de producción de virutas es muy limitado en algunos casos, llegan al 10 por ciento; en cambio en los sistemas tradicionales estas representan hasta el 50 por ciento de la cosecha. Este tipo de material es de alta calidad industrial, los productores reciben un buen pago por parte de los secaderos que reciben este material, en los primeros meses de cosecha. A pesar de esta ventaja del sistema tradicional, se debe considerar que es de corto plazo, si se analiza el deterioro que se produce en los lotes de yerba consecuencia de las sucesivas extracciones de estos componentes por medio de las podas tradicionales. Pero muchos productores prefieren aprovechar ese material vendiéndole a la industria en detrimento de ganar unos kilos más si se cosecha con 18 a 24 meses las plantaciones de yerba mate.

Otra cuestión, es que los mismos operarios, van a los yerbales a sacar kilos de yerba y esos kilos van todos al secadero, con lo cual su interés se mueve en función de lo que puedan ganar cosechando durante la jornada laboral o la semana, muchas veces no quieren perder el tiempo realizando algunos de los pasos de la rama madura, considerando que en esta técnica necesita cortar ramas gruesas, se las debe separar y luego quebrar y acondicionar en las bolsas, con lo cual para el trabajador eso significa pérdida de tiempo.

Asimismo, se generan tensiones entre los actores, productores, contratistas, técnicos, capataces de cosecha con los tareferos, por la utilización de nuevas herramientas que van de la mano de la cosecha de rama madura. Una de ellas es el serrucho, que deben utilizarlos para realizar las tareas propuestas en la rama madura, aunque no quieran hacerlos por el cansancio que implica (cortar con los serruchos ramas de diámetros considerables durante un lapso de tiempo prolongado). La situación 
es un poco diferente con el uso de las tijeras eléctricas, estas últimas no causan tanta fatiga al podador, pero son onerosas.

Pero no solamente la implementación de nuevas herramientas, afecta la práctica. La tradición en la forma de cosechar de los yerbateros que por costumbre no quieren modificar, afecta considerablemente el sistema de trabajo que realizan en sus plantaciones. Atentando esto, con las nuevas propuestas que se promocionan de los I+D como es el caso de la rama madura. Son los mismos productores que optan por no cambiar, siguen realizando las tareas culturales, entre ellas la cosecha, como la hacían sus abuelos, que implantaron y cuidaron las primeras plantaciones de yerba mate.

Asimismo, se pueden dar casos de yerbateros, que buscan copiar los modelos de producción industrial de las grandes empresas o por lo menos le prestan atención. Es evidente que el éxito de una empresa grande, hace pensar a los productores sobre cómo hacen para llegar a donde están, buscan por diversos mecanismos conocer la "fórmula del éxito", sin darse cuenta que su sistema de producción no se puede comparar con un agricultor pequeño, a pesar de ellos buscan seguir el exitoso modelo empresarial. En muchas situaciones, esta forma de producir de la gran empresa está muy lejos de la rama madura, ellos utilizan métodos de cosechas tradicionales o mecánicos.

Es de destacar que también estos yerbateros pequeños, cuando realizan sus actividades de recolección y contratan a sus cosecheros y dejan librado al azar las decisiones de las podas que debe realizar. Estos trabajadores muchas veces lo único que conocen es el sistema de cosecha de la "gran empresa", con lo que buscan aplicarlo a los yerbales.

A esta situación hay que agregar que, a comienzo de zafra, faltan trabajadores para la cosecha; el principal motivo es que el personal "capacitado", generalmente esta en forma permanente con las grandes cuadrillas, con lo cual, les queda a los demás yerbateros chicos lidiar con grupos de personas poco o nada capacitados haciendo más compleja la aplicación de sistemas de cosecha de la rama madura, considerando además de que muchos de estos tareferos o pseudo tareferos, suelen ser jóvenes que ingresan o provienen de otras actividades que nada tienen que ver con la cosecha de la yerba mate.

En el sector productivo existen muchos "tenedores de yerba mate", ellos para el registro del INYM, son considerados productores. Pero en realidad, varios de ellos son profesionales o personas que viven de otra actividad, que solamente buscan réditos 
económicos en momentos de buenos precios de materia prima. Estos dejan librado al azar sus plantaciones, sin aplicación de casi ninguna labor cultural.

Estos en general están muy ligados a las empresas que les asegura una pequeña ganancia anual por sus cosechas, muchas veces incluso dejan de cosechar si los valores de hoja verde no acompañan, pero cuando los valores son acordes para generar divisas adicionales, al ingresar al mercado yerbatero pueden generar problemas de sobreofertas de materias primas. Eso condiciona la negociación entre los actores, que utilizan esa excusa de exceso de hoja verde para financiar los pagos en cuotas de la materia prima que vende el colono, lo que también viene a dificultar la puesta en escena de nuevas metodologías de trabajo en la yerba mate, sin ingresos estables no se puede invertir en los yerbales.

Un detalle a tener en cuenta es la competencia que realizan las industrias a través de los secaderos, para captar materia prima, obstaculizan la formación de la red de la rama madura. Muchas empresas parten de sistemas de podas que tienden al tradicional, alejándose de la red de la rama madura como modelo productivo. Sus ingenieros o compradores de hoja verde, alinean a los actores (productores, contratistas) dentro de la cosecha tradicional. Estas empresas, negocian y buscan la coordinación de la red de la cosecha tradicional, entran a competir por los espacios a través de diferentes acciones o relaciones de poder.

Son los mismos secaderos, pertenecientes a estas grandes corporaciones, que logran, a través de la implementación de parámetros exigentes, que los actores (contratistas y trabajadores) se tengan que alinear a la cosecha tradicional. Prácticamente sus compradores de hoja verde, como sus capacitadores privados, proponen métodos que son más adaptables al sistema de secansa de las industrias, promoviendo la recolección de ramas más delgadas en diámetros, para facilitar el secado y el manejo dentro de la industria.

En todas estas condicionantes que se plantean en la conclusión con relación a la aplicación y adopción de la rama madura, entran en juego una serie de variables no solamente técnicas, sino también de interés por parte de los actores. En la aplicación de la nueva metodología tanto en la Cooperativa Piporé, como en los demás lugares citados, presentan la característica del constante seguimiento de parte de los I+D, a los actores intervinientes, el involucramiento e interés de estos actores en la propuesta. Con lo cual en ese sentido se deberían replantear algunas estrategias de dichos organismos. 
Es evidente que han trabajado en capacitar a los productores yerbateros, han puestos sus esfuerzos en ese sector, demostrando las bondades de la rama madura, pero descuidando no solamente a los trabajadores, sino también a los contratistas de cosecha.

Desde esa perspectiva y considerando las estrategias de convencimiento o de interés que logran la estabilización de la rama madura; estas se deberían re direccionarse hacia los que realmente hacen el trabajo en los yerbales, trabajadores, capataces de corte, contratistas de cosecha y por supuesto productores "tenedores" de yerba mate.

Una de las estrategias de política pública de apoyo a los tareferos y sus organizaciones de base; es que se deben afianzar los lazos con otros estamentos del Estado que tengan influencia directa con los trabajadores, ejemplo de ellos puede ser el Ministerio de Trabajo Nacional o Provincial, UATRE, los mismos Sindicatos de Tareferos o contratistas, las cooperativas yerbateras más chicas, que poseen dentro de sus estructuras servicios de cosechas. Se debería retomar el programa de certificaciones de competencias laborales para el sector yerbatero, de manera de fortalecer las habilidades y responsabilidades que debe cumplir dicho trabajador, buscando jerarquizar su trabajo.

De la misma manera plantear acciones de políticas públicas consensuada con el sector productivo que ayuden a la defensa de la estabilidad laboral, no solo del tarefero, sino que también de los contratistas, considerando que es un sistema de cosecha es un método que genera ganancia en el mediano y largo plazo.

Habría que aprovechar la estructura de las cooperativas yerbateras de Misiones, como intermediarios para promover en sus asociados, a través de sus técnicos de campos, el modelo de la rama madura. Además, hay que repensar también incentivos a aquellos productores que apliquen este método, como por ejemplo una desgravación en algún aporte patronal que incentive a la aplicación de la rama madura por parte de los productores.

Se debe poner en práctica, el plan estratégico para el sector yerbatero argentino que se ha confeccionado entre los actores de la cadena de la yerba mate, de manera de fortalecer, no sólo productivamente al sector, sino que también social y ambientalmente. En este plan están descriptos valores como igualdad de condiciones y oportunidades para todos los eslabones de la cadena, trabajo registrado, digno y formal para la familia yerbatera, distribución equitativa de la riqueza, entre otros. 
Queda un camino por recorrer que va más allá de la metodología de cosecha, que abarca a las diferentes partes de la cadena yerbatera, algunas olvidadas desde sus inicios. Surgen algunos interrogantes al respecto:

¿Qué puede pasar con la técnica de la rama madura y las nuevas tendencias en cosecha que se planteen tendientes a la mecanización?

¿Qué conflictos se pueden generar entre los actores, con estas nuevas modalidades de cosecha que se promocionan desde el sector privado? En ese sentido hay que examinar qué rol pueden cumplir los diferentes actores de la cosecha, considerando que, por ejemplo, el capataz de corte es un actor clave en este modelo.

Finalmente habría que analizar en un futuro, la conformación de otras redes en la cosecha, la semi mecanización del sistema o la mecanización completa. Investigar de qué manera pueden influir estos modelos productivos en el sector yerbatero, en la modificación de los métodos de cosechas, las formas de realizar el trabajo, los parámetros contractuales y los ingresos que se generen. La relación entre los trabajadores y contratistas con los yerbateros, como así también con los secaderos y los productores. También lo que puede pasar con la estabilidad de los mismos, si se llegan a instalar estos modelos en los yerbales.

Estos interrogantes quedan abiertos, dando la posibilidad a la continuidad del presente trabajo a través de nuevas investigaciones. 


\section{CAPÍTULO 10: BIBLIOGRAFÍA}

Aibar, E. (1996). La vida social de las máquinas: Orígenes, desarrollo y perspectivas actuales en la sociología de la tecnología. Revista Española de investigaciones Sociologicas, , , 141-170.

Akrich, M. (1988). Cómo describir los objetos técnicos?. Técnicas y Cultura,. En Comment décrire les objets tecniques, (págs. 49-64). Publicaciones La Casa de las Ciencias HumanasTecnique et culture

Alfaro, M. I. (2014). La conflictividad social en mercados de trabajo rurales intermediados. Nuevas formas de contratación en el trabajo agrario, 7.

Anino, P. (2017). Informe de la cadena de valor. Yerba mate. Buenos aires: Subsecretaria de planificacion economica y Planificacion Regional.

Bertoni, M. S. (1926). Problemas y puntos críticos en la plantación cultivo y elaboración de la Yerba Mate. Te del paraguay. . Ed Ex SYLVIS 34pp.

Burgos, A; Medina, R. (2017). Idas y Vueltas de la Infusion Nacional. En P. e. Capelari, Yerba Mate, Reseña historica y Estadistica (pág. 310). Cuidad Autonoma de Buenos Aires: Consejo Federal de Inversiones.

Burtnik, O. (2006). Yerba Mate: Manual de Producción. INTA AER Santo Tome Corrientes 52 pp: Ediciones INTA $3^{\circ} \mathrm{Ed}$.

Burtnik, O. J. (2003 ). Manual del pequeño yerbatero correntino. Corrientes, Argentina.: INTA, AER Santo Tomé.

Callon, M. (1986). La sociología de una red de actores: el caso del vehículo eléctrico. . En L. J. Callon M., Mapping the Dynamics of Science and Technology (págs. 19-34). Londres: Palgrave Macmillan.

Callon, M. (1987). Sociedad en formacion: el estudio de la tecnologia como herramienta para el analisis sociologico.La construccion social de los sistemas tecnologicos: nuevs direcciones en la sociologia e historia de la tecnologia.

Callon, M. (1995). Algunos elementos para una sociología de la traducción: la domesticación de las vieiras y los pescadores de la bahía de St. Brieuc. . En I. J. (Eds), In Sociología de la ciencia y la tecnología (págs. 259-282). Madrid: Consejo Superior de Investigaciones Científicas, CSIC.

Callon, M. (1998). El proceso de construccion de la sociedad. El estudio de la tecnologia como herramienta del analisis sociologico. En M. Domenech, \& F. Tirado, Sociologia Simetrica. Ensayo sobre ciencia, tecnologia y sociedad. (pág. 302). Barcelona: Gedisa.

Callon, M. (2001). Redes tecno-económicas e irreversibilidad. REDES ,VOL. VIII, NÚM., pp.83-127.

Callon, M. (2006). Luchas y negociaciones por definir qué es problemático y qué no es problemático. La socio-lógica de la traducción. Redes. Revista de estudios sociales de la ciencia, Vol. 12, N²3, Bernal, Universidad Nacional de Quilmes, 103-128.

Callon, M. (2013). La dinámica de las redes tecno-económicas. En H. B. THOMAS, En Actos, actores y artefactos. Sociología de la tecnología. (pág. 296). Buenos Aires: Universidad Nacional de Quilmes. 
CONINAGRO. ( 2017). informe tecnico N 4 Yerba Mate.

De Coulon, E. (2001). Innovación tecnológica y proceso de trabajo en la cosecha de yerba mate ,. Tesis de Maestría en Administración Estratégica de Negocios. Facultad de Ciencias Económicas, Universidad Nacional de Misiones).

Díaz-Bravo, L. T.-G.-H.-R. (2013). La entrevista, recurso flexible y dinámico. Investigación en educación médica, 162-167.

Echeverría Ezponda, J. \&. (2009). La teoría del actor-red y la tesis de la tecnociencia. Arbor: Ciencia, pensamiento y cultura.(738), 705-720.

Figueredo, E. N. (2010). Proyecciones del Relevamiento de Tareferos (cosechadores de la yerba mate) en Misiones. Políticas Económicas y Desarrollo Rural,, 48.

Furnus, A. C. (1926). Cartilla del cultivo de la yerba mate. Buenos Aires: Direccion General de Enseñanza Agricola.

Galarza, J. B. (1914). La yerba-mate. Buenos Aires: Talleres Gráficos del Ministerio de Agricultura.

Gallero, M. C. (2011). Pipore: 80 años haciendo historia en yerba mate. Misiones: Productores de Yerba Mate de Santo Pipó, S.C.L.

Giancola, S. M. (2014). Análisis cualitativo de los factores que inciden en la adopción de tecnología en pequeños y medianos productores de yerba de la provincia de Misiones. Buenos Aires: INTA.

Gortari, J. (2013). Concentración y diferenciación social en la economía regional yerbatera. voces en el fenix, 52-59. Obtenido de http://www.vocesenelfenix.com/: www.vocesenelfenix.com

Latour, B. (1987). Ciencia en acción: cómo seguir a científicos e ingenieros a través de la sociedad.

Latour, B. (1998). La tecnologia es la sociedad hecha para que dure. En M. Domenech, \& F. Tirado, Sociologia simetrica. Ensayos sobre ciencia, tecnolgia y sociedad (pág. 302). Barcelona: Gedisa.

Latour, B. (2008). Reensamblar lo social: una introducción a la teoría actor-red. Buenos Aires,: Ed Manantiales.

Law, J. (1987). "Tecnología e ingeniería heterogénea. El caso de la expansión portuguesa", Traducción en castellano de Alfonso Buch. En W. Bijker, \& T. Hughes y T. Pinch (eds.), The social construction of technical systems: new directions in the sociology and history of technology, (págs. 111-134). Cambridge: MIT Press.

Law, J. (1998). Del Poder y sus Tácticas. Un Enfoque desde la Sociología de la Ciencia. En M. y. Doménech, Sociología simétrica. Ensayos sobre ciencia, tecnología y sociedad, (págs. 63-107). Barcelona: Gedisa.

Law, J. (2006). Traducción / trahison: Notas sobre ANT. . Convergencia , 13 (42), 4772.

Marradi, A. A. (2007). Metodología de las ciencias sociales. Buenos Aires: EMECE.

Mayol, M. (2017). Podas de Formacion, limpieza y Cosecha. el cuidado fundamental para la sustentabilidad de la planta. En P. e. Capellari, Yerba mate. Reseña historica y 
estadiscica. Produccion e Industrializacion en el siglo XXI (págs. 249-266). Buenos Aires: Consejo Federal de Inversiones.

Mayol, M. (1997). La experiencia argentina en sistemas de poda de yerba mate. I Congresso sul-americano da erva-mate II Reunião Técnica Do Cone Sul Sobre A Cultura Da Erva-Mate (págs. 337-349). Curitiba: EMBRAPA.

Mayol, M., \& Kurtz V. (2011). Evaluación de sistemas de cosecha de yerba mate. $5^{\circ}$ Congreso Sudamericano de Yerba Mate. , (págs. 149-152). Posadas Mnes.

Montechiesi, R. (2008). Yerba Mate, cambios en la producción, no en la actividad. Estrategias para un plan agroyerbatero.

Navajas, P. (2013). Caá porã: el espíritu de la yerba mate: una historia del Plata. Buenos Aires: Establecimiento Las Marías.

Neiman, G. y. (2006). Los estudios de caso en la investigación sociológica. Buenos Aires,: Gedisa.

Pereyra, S. (2013). Mercado de trabajo Yerbatero: El tarefero. Un estado de la cuestión. Buenos Aires: X Jornadas de Sociología. Facultad de Ciencias Sociales, Universidad de Buenos Aires.

Prat Kricun, S. P. (2003). Cosecha tradicional de la yerba mate. Estacion Experimental Agropecuaria Cerro Azul.: INTA.

Rau, V. (2009). La yerba mate en misiones (Argentina): Estructura y significados de una producción localizada. Agroalimentaria, 28,.

Rau, V. (2009). La yerba mate en misiones (Argentina): Estructura y significados de una producción localizada. Agroalimentaria, 49-58.

Rau, V. (2014). Cosechando Yerba Mate: estructuras sociales de un mercado laboral agrario en el Nordeste Argentino. . Buenos Aires: Ediciones CICCUS.

Rau, V. (2016). El trabajo asalariado agropecuario en la región yerbatera argentina: Imágenes de situación en datos cuantitativos. Mundo agrario,, 17(36),.

Re, D. A. (2015). La "ayuda" infantil en la tarefa de yerba mate. Cultura, mercado y legislación. Conflicto Social, 8(14), , 221-242.

Robles, B. (2011). La entrevista en profundidad: una técnica útil dentro del campo antropofísico. . Cuicuilco, 18(52), 39-49.

Roger, L. (1906). Cultivo de la yerba mate. Anales de la Sociedad Rural Argentina.

Stake, R. (1994). "Case Studies". En: Denzin, N. y Lincoln, Y. et al., . California, Sage.: The Sage Handbook of Qualitative Research, .

Thomas, H., \& Buch, A. (2013). Actos, actores y artefactos: sociología de la tecnología. Bernal: Universidad Nacional de Quilmes.

Traglia, C. (2016). Nuevas conceptualizaciones del trabajo: procesos de articulación entre las políticas sociales y las políticas laborales en el mercado de trabajo yerbatero de Misiones, Argentina. . En: LaRivada, V. 2, $n^{\circ} 3$.

Traglia, C., Vidal, M., Gortari, J., Rosenfeld, V., \& Oviedo, A. (2018). Concentración económica en cadenas agroindustriales de Misiones, Argentina: yerba mate, té y mandioca. SaberEs, 10(1). 
Uzal, C. M. (1910). La yerba-mate (ilex paraguayensis). Tip. La nueva(672), 47.

\section{Fuentes electrónicas}

https://inta.gob.ar/. (21 de agosto de 2018). Obtenido de https://inta.gob.ar/paginas/historia-del-inta

INDEC. (13 de 09 de 2018). www.indec.gob.ar. Obtenido de https://www.indec.gob.ar/gis/index_sig.html?_ga=2.158012792.399794683.153686592 5-611587481.1536865925

INTA. (28 de Agosto de 2018). Obtenido de www.inta.gob.ar: https://inta.gob.ar/santopipo

INYM. (27 de junio de 2016). www.inym.org.ar. Obtenido de www.inym.org.ar

INYM.(21 de Agosto de 2018). www.inym.org.ar. Obtenido de http://www.inym.org.ar/operador/plan-estrategico/

UATRE-Resolución Comisión Nacional de Trabajo Agrario (CNTA) Nro: 104/2019 Disponible en : https://www.uatre.org.ar/attach/resol/2019 104.pdf. Última Visita 11 septiembre 2019. 